University of Louisville

ThinkIR: The University of Louisville's Institutional Repository

$5-2014$

\title{
Myocyte-specific overexpression of stromal cell-derived Factor 1 facilitates cardiac regeneration and improves myocardial function after infarction in mice.
}

Detlef Ernst-Rudolf Obal

University of Louisville

Follow this and additional works at: https://ir.library.louisville.edu/etd

Part of the Biophysics Commons, and the Physiology Commons

\section{Recommended Citation}

Obal, Detlef Ernst-Rudolf, "Myocyte-specific overexpression of stromal cell-derived Factor 1 facilitates cardiac regeneration and improves myocardial function after infarction in mice." (2014). Electronic Theses and Dissertations. Paper 1076.

https://doi.org/10.18297/etd/1076

This Doctoral Dissertation is brought to you for free and open access by ThinkIR: The University of Louisville's Institutional Repository. It has been accepted for inclusion in Electronic Theses and Dissertations by an authorized administrator of ThinkIR: The University of Louisville's Institutional Repository. This title appears here courtesy of the author, who has retained all other copyrights. For more information, please contact thinkir@louisville.edu. 
MYOCYTE-SPECIFIC OVEREXPRESSION OF STROMAL CELL-DERIVED

FACTOR 1 FACILITATES CARDIAC REGENERATION AND IMPROVES

MYOCARDIAL FUNCTION AFTER INFARCTION IN MICE

By

Detlef Ernst-Rudolf Obal, M.D., M.S., D.E.S.A.

\begin{abstract}
A Dissertation in Partial Fulfillment of the Requirements

for the Degree of

Doctor of Philosophy

Department of Physiology and Biophysics

University of Louisville

Louisville, Kentucky
\end{abstract}

Submitted to the Faculty of the School of Medicine of the University of Louisville

May 2014 
Copyright 2014 by Detlef Ernst-Rudolf Obal

All rights reserved 

MYOCYTE-SPECIFIC OVEREXPRESSION OF STROMAL CELL-DERIVED

FACTOR 1 FACILITATES CARDIAC REGENERATION AND IMPROVES

MYOCARDIAL FUNCTION AFTER INFARCTION IN MICE

By

Detlef Ernst-Rudolf Obal, M.D., M.S., D.E.S.A.

A Dissertation Approved on

April, $15^{\text {th }} 2014$

By the following Thesis Committee

Gregg D. Rokosh, Ph.D.

Dissertation Director

William B. Wead, Ph.D.

Aruni Bhatnagar, Ph.D.

Stanley D'Souza, Ph.D.

Gary L. Anderson, Ph.D. 


\section{DEDICATION}

This dissertation is dedicated to

my wife, Ruth Obal, MBA, CAPM,

my parents, Friedegard and Gunter Obal,

and my brother, Michael Obal and his family,

who have supported me during this exciting endeavor. 


\section{ACKNOWLEDGMENTS}

I would like to thank Dr. Gregg Rokosh, Ph.D. for his guidance and help making this enterprise possible for a faculty colleague challenged by the combination of significant clinical work and exciting new experimental approaches. I would also like to thank the committee members, Drs. Aruni Bhatnagar, Ph.D. and William Wead, Ph.D. and Roberto Bolli, M.D. for their comments and assistance of the past five years. I would also like to express my thanks to my wife, Ruth, for her understanding and patience during the difficult times and frustrations after long hours in the laboratory. Special thanks are directed towards my clinical Chair in the Department of Anesthesiology and Perioperative Medicine, Dr. Mark Boswell, Ph.D., MBA, who supported my research and provided the framework for my success in research. Last but not least, I would express my gratefulness to the faculty within the Department of Anesthesiology who supported my research and allowed me to be in the laboratory to finish my Ph.D. thesis. 


\begin{abstract}
MYOCYTE-SPECIFIC OVEREXPRESSION OF STROMAL CELL-DERIVED

FACTOR 1 FACILITATES CARDIAC REGENERATION AND IMPROVES

MYOCARDIAL FUNCTION AFTER MYOCARDIAL INFARCTION IN MICE

Detlef Ernst-Rudolf Obal
\end{abstract}

April 15, 2014

Background: Interruption of cardiac stromal cell-derived factor 1 (SDF1)-CXCR4 axis by chronic AMD3100 administration increased myocardial injury after permanent coronary artery ligation, demonstrating the important role of this chemokine in cardiac regeneration.

Hypothesis: Cardiomyocyte-specific conditional overexpression of SDF prevents heart failure after permanent coronary ligation and facilitates cardiac regeneration.

Methods and Results: Tetracycline-controlled, $\alpha-$ myosine heavy chain promoter directed overexpression of cardiac SDF resulted in a significant increase of SDF expression (SDF: $8.1 \mathrm{ng} / \mathrm{g}$ protein) compared with littermate WT mice (0.02 ng / g protein) four weeks after doxycycline withdrawal. SDF overexpression increased AKT and casein kinase 1 levels in the heart. Although there was no difference in cardiac function and scar 
size one week after infarction, SDF overexpression improved left ventricular (LV) ejection fraction $(47 \pm 5 \%$ vs. $29 \pm 4 \%, \mathrm{p}<0.05)$ decreased end-diastolic volume ( $78 \pm 10$ vs. $158 \pm 30$ $\mathrm{p}<0.05)$ and reduced infarct size measured by trichrome staining $(\mathrm{SDF}): 13 \pm 3 \%$ vs. WT $(\mathrm{n}=15): 23 \pm 3 \%$ of LV wall, $\mathrm{p}<0.05)$ four weeks after permanent ligation. Bromodeoxyuridine (BrdU) staining revealed increased regeneration indicated by a 5-fold increase in $\mathrm{BrdU}^{+} / \alpha$-sarcomeric actin ${ }^{+}$-cells in the border zone of the infarct $(22 \pm 3 \%$ cardiomyocyte $(\mathrm{CM})$ nuclei vs. $5 \pm 1 \% \mathrm{CM}$ nuclei, $\mathrm{p}<0.01)$. Increased proliferation in SDF mice was confirmed by a higher number of $\mathrm{Ki}^{+}$cells compared to WT mice. Cardiomyocyte cross sectional area in the border zone was significantly reduced in SDF mice $\left(375 \pm 13 \mu \mathrm{m}^{2}\right.$ vs. $\left.434 \pm 10 \mu \mathrm{m}^{2}, \mathrm{p}<0.001\right)$ while capillary density remained unchanged $\left(2348 \pm 151 / \mathrm{mm}^{2}\right.$ vs. $\left.2498 \pm 153 / \mathrm{mm}^{2}\right)$ compared to WT mice.

Conclusion: This study demonstrates that cardiac-specific overexpression of SDF increases myocardial regeneration and improves LV function after permanent coronary ligation. 


\section{TABLE OF CONTENTS}

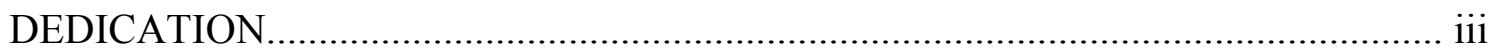

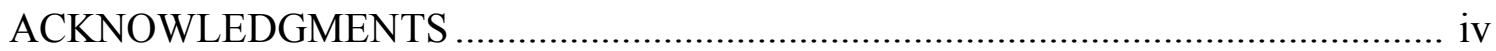

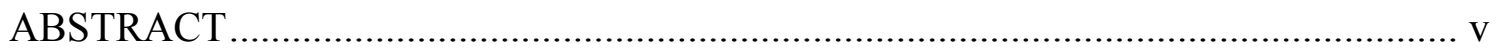

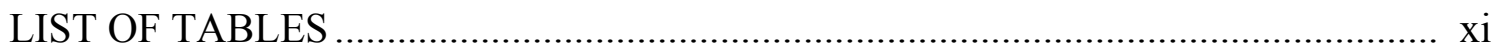

LIST OF EQUATIONS ................................................................................ xii

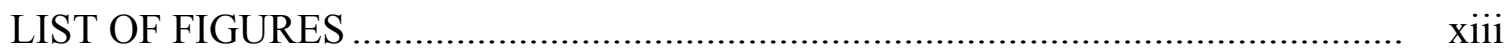

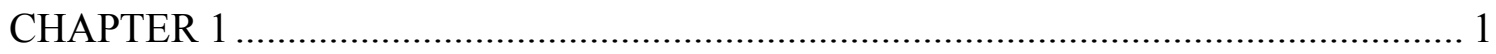

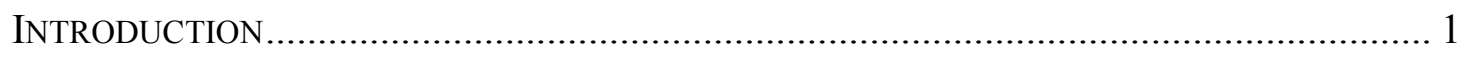

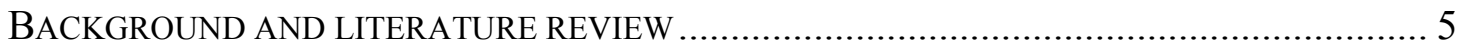

Classical role of SDF: Homing factor and regulator of bone marrow homeostasis 6

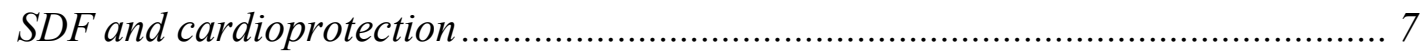

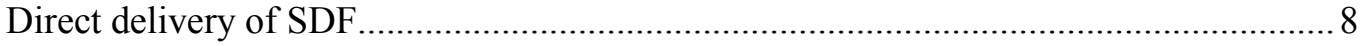

Transplantation of SDF overexpressing cells .....................................................

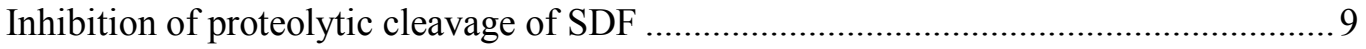

Up-regulation of CXCR 4 ......................................................................................

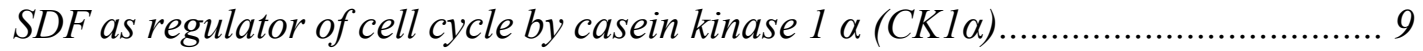

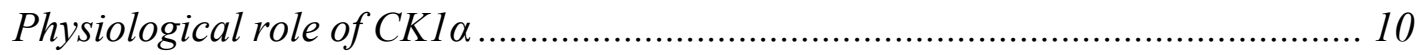

STROMAL CELL-DERIVED FACTOR 1 TRANSGENIC MICE / GENOTYPING AND BREEDING . 11

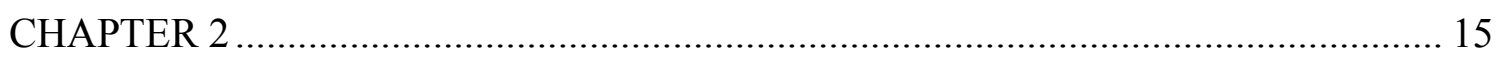

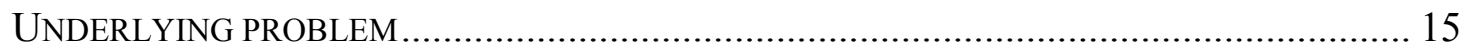

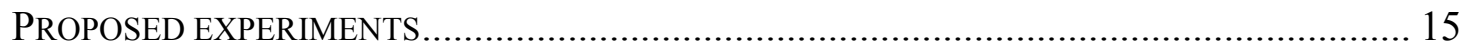

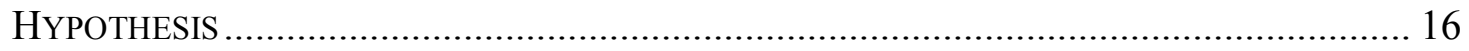

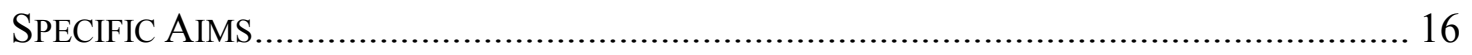

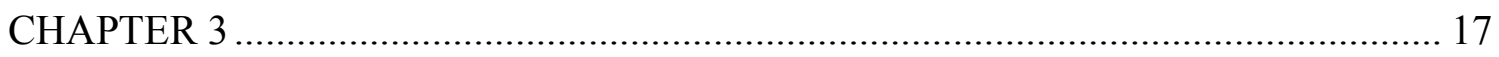


AIM I - TO DETERMINE THE EFFECT OF CHRONIC CARDIOMYOCYTE-SPECIFIC OVEREXPRESSION OF SDF ON CARDIAC AND BONE MARROW HOMEOSTASIS. ................ 17

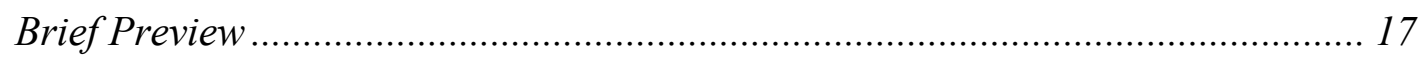

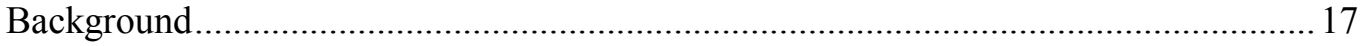

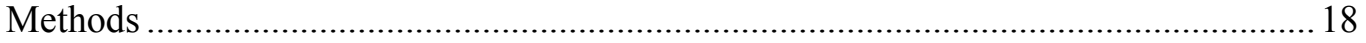

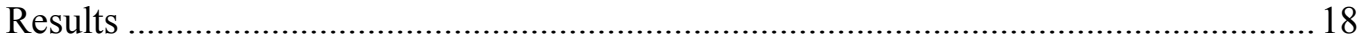

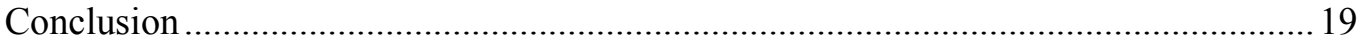

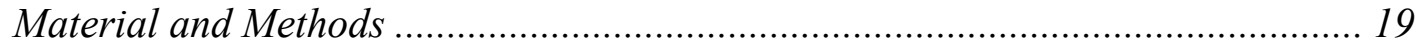

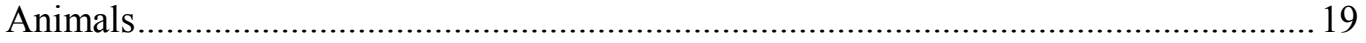

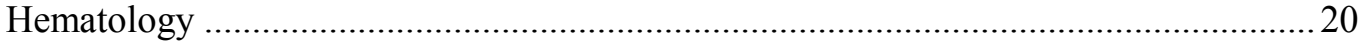

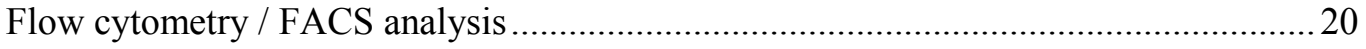

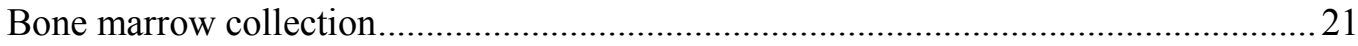

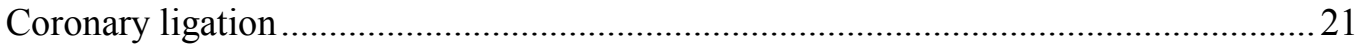

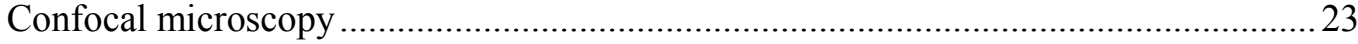

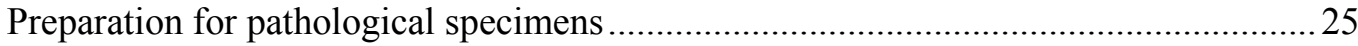

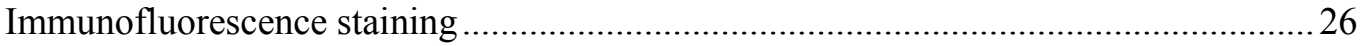

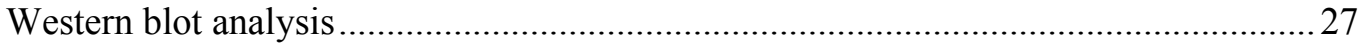

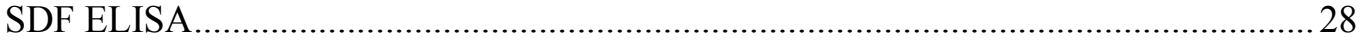

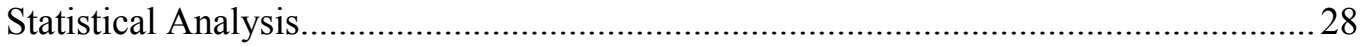

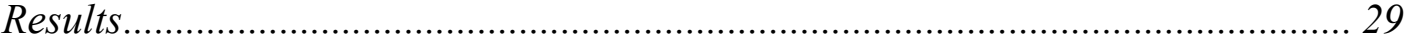

Cardiac specific overexpression of SDF decreases leukocytes in the peripheral blood and the BM.

Cardiomyocyte-specific overexpression of SDF increases gene-copy dependent CK1 $\alpha$ expression and AKT phosphorylation in the heart. ........................................................ 34

Cardiomyocyte-specific overexpression of SDF resulted in an increased number of c-kit ${ }^{+}-$

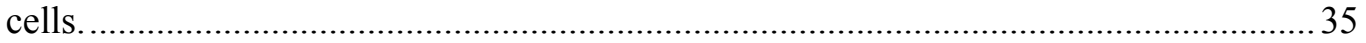

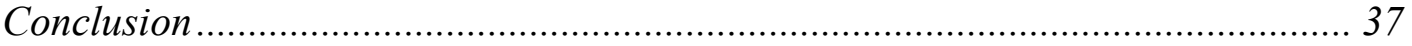

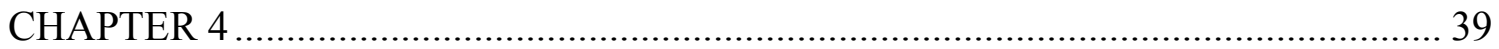

AIM II - TO DETERMINE WHETHER CASEIN KINASE 1A MEDIATES CARDIAC STEM / PROGENITOR CELLS AND NEONATAL CARDIOMYOCYTE PROLIFERATION. ...................... 39

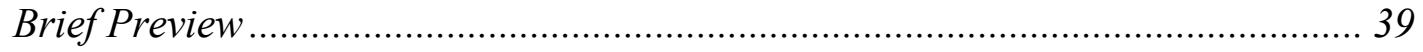

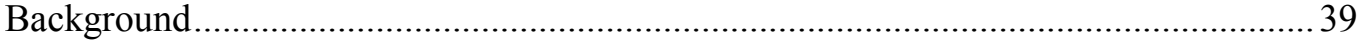

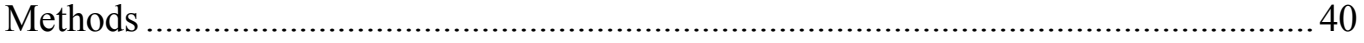

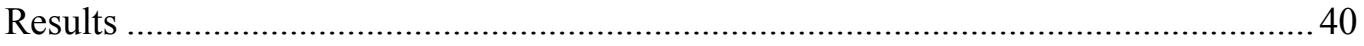

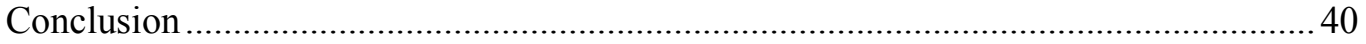




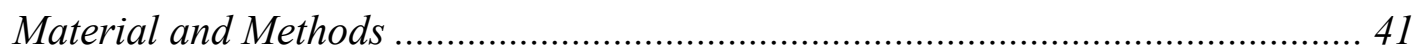

Isolation of human cardiac stem / progenitor cells .................................................... 41

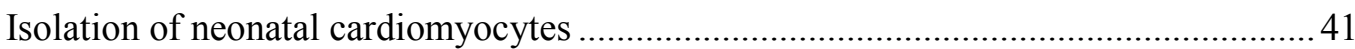

Transfection of neonatal cardiomyocytes and human CSPCs with CK1 $\alpha$ containing

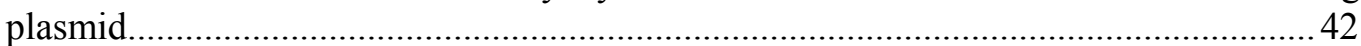

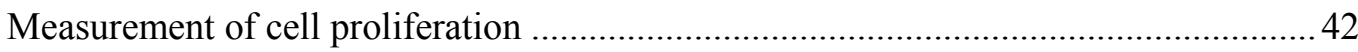

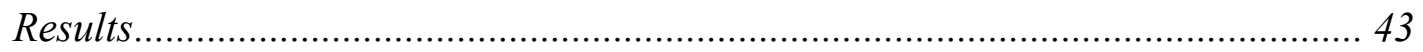

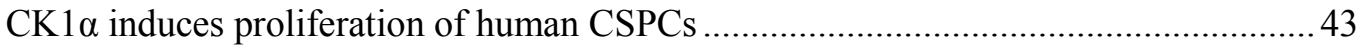

$\mathrm{CK} 1 \alpha$ induces neonatal cardiomyocyte proliferation .................................................... 43

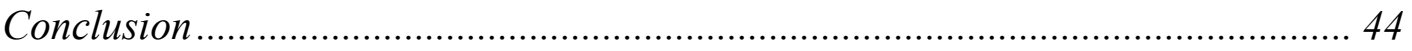

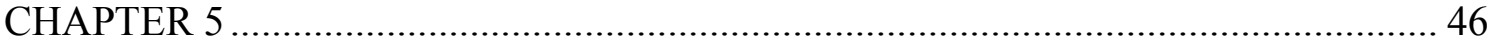

AIM III - TO DETERMINE WHETHER CARDIOMYOCYTE-SPECIFIC OVEREXPRESSION OF STROMAL CELL-DERIVED FACTOR 1 ACCELERATES MYOCARDIAL REGENERATION AFTER

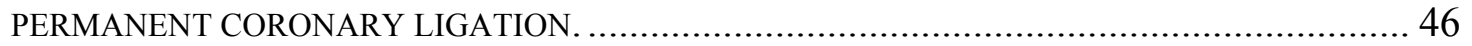

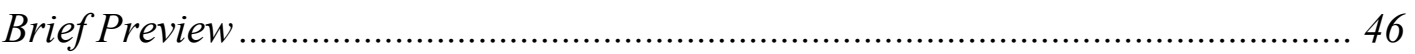

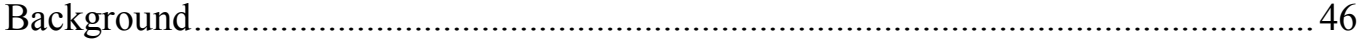

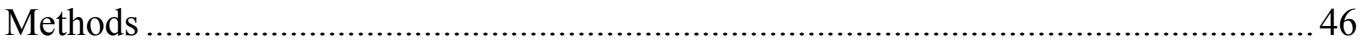

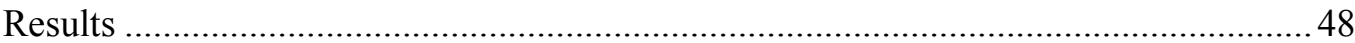

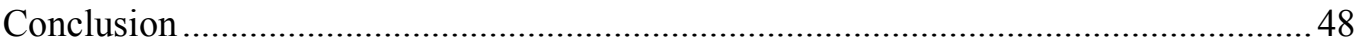

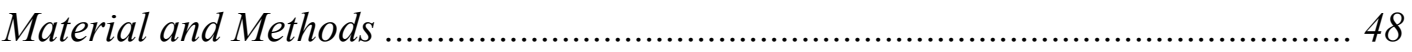

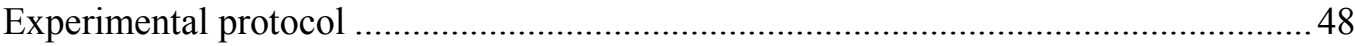

Assessment of myocardial injury after permanent ligation .........................................5 50

Triphenyltetrazolium-chloride- (TTC) staining ................................................ 50

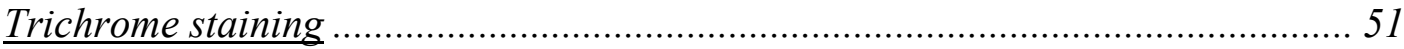

Measurement of cardiac regeneration by chronic administration of $\mathrm{BrdC}$....................52

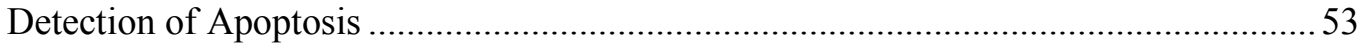

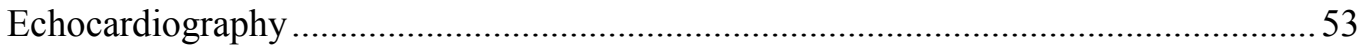

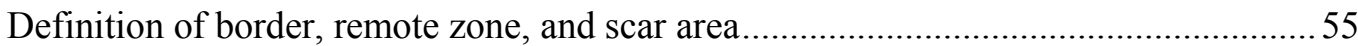

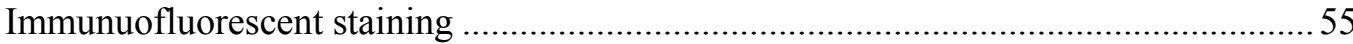

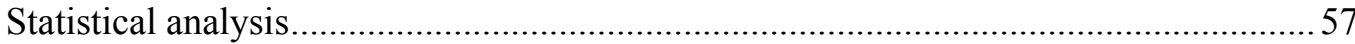

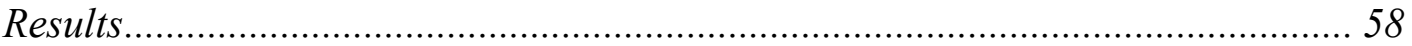

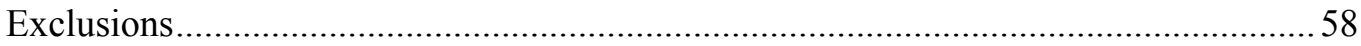

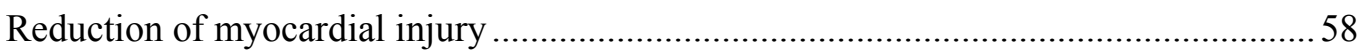

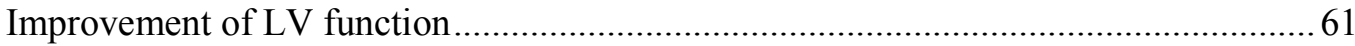




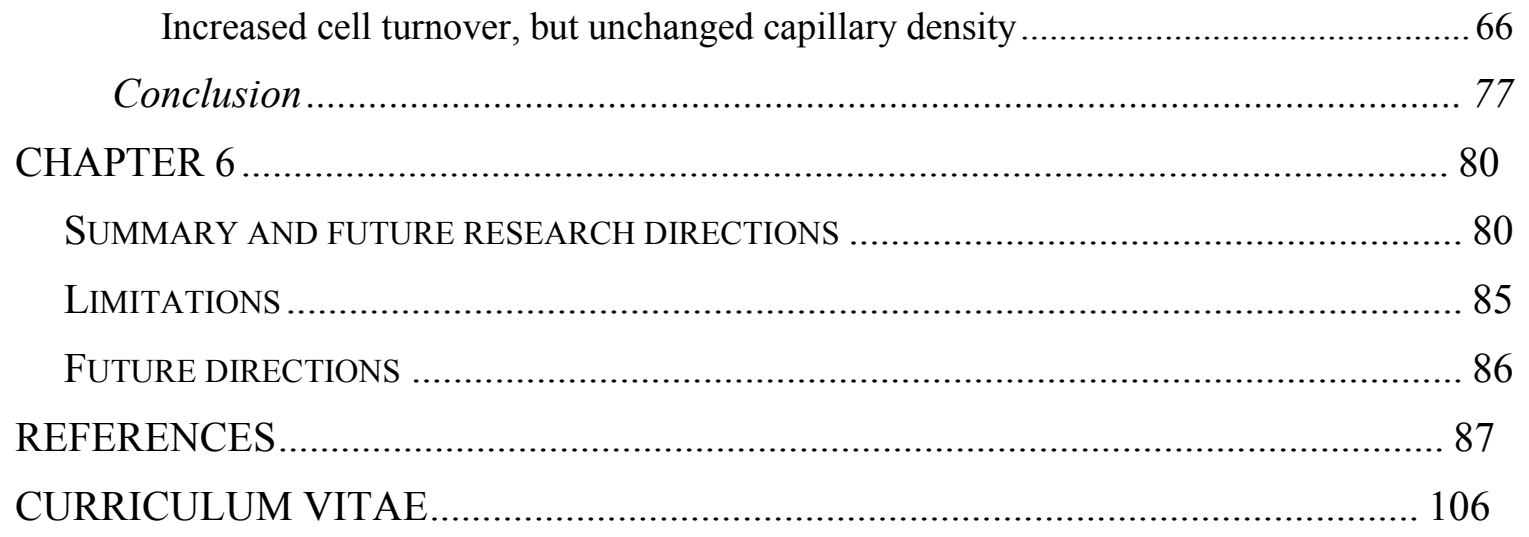




\section{LIST OF TABLES}

Table $1 \quad$ Breeding requirements to fullfil the proposed study

Table 2 Fluorophores used for detection of different antigens by confocal

microsco

25 


\section{LIST OF EQUATIONS}

Equation 1 LV expansion index $\quad 52$

$\begin{array}{lll}\text { Equation } 2 & \text { LV strain rate } & 54\end{array}$ 


\section{LIST OF FIGURES}

Figure I Characterization of the $\alpha$-MHC specific -Tet “off” SDF transgenic model

Figure II Myocardial SDF concentration before and after activation of the transgene

Figure III Confocal microscopy scheme

Figure IV WBCs, platelets and RBCs in the peripheral blood after five and weeks of cardiomyocyte-specific SDF overexpression

Figure V Time course of hematological changes after initation of SDF expression in WT and SDF high transgenic mice

Figure VI Bone marrow resident and circulating EPCs in WT and Tg high mice

Figure VII Gene-copy dependent protein expression of AKT and CK1 $\alpha$

Figure VIII c-kit ${ }^{+}$cell in WT and SDF high expressing transgenic mice

Figure IX Proliferation of human CSPC and neonatal rat cardiomyocytes after transfection with CMV-CK1 $\alpha$ vector

Figure $\mathrm{X} \quad$ Experimental protocol of permanent coronary ligation experiments

Figure XI Example of ligated WT heart and cardiac-cross section

Figure XII Morphometry in WT and SDF high 72 hours after permanent ligation 
Figure XIII Morphometry of WT and SDF high mice one week after permanent ligation

Figure XIV Morphometry in WT, SDF low and SDF high mice four weeks after permanent coronary ligation

Figure XV Baseline cardiac function in mice overexpressing SDF at five weeks and more than 30 weeks

Figure XVI LV function in WT and SDF high mice before and at different time points after permanent coronary ligation

Figure XVII Examples of radial and longitudinal strain in WT and SDF overexpressing mice before and four weeks after coronary artery ligation

Figure XVIII Regional wall function measured by speckle trecking

Figure XIX $\quad \mathrm{BrdU}^{+} / \alpha$-sarcomeric actin ${ }^{+}$cardiomyocytes in the border and remote zone four weeks after myocardial infarction in SDF high and WT mice

Figure XX $\mathrm{BrdU}^{+}$cardiomyocytes in the scar area of WT and SDF high mice four weeks after infarction

Figure XXI Dividing cardiomyocyte in the border zone of a SDF high overexpressing mouse

Figure XXII $\mathrm{Ki}^{+} 7^{+}$cardiomyocytes in the remote and border zone of WT and SDF high mice four weeks after infarction

Figure XXIII Capillary density in WT and SDF high mice after sham operation and four weeks permanent ligation in the remote and border zone

Figure XXIV TUNEL $^{+}$nuclei one and four weeks after permanent ligation

Figure XXV Wheat-germ agglutinin staining for measurement of myocytes crosssectional area

Figure XXVI Histogram of cardiomyocyte cross-sectional area 
Figure XXVII Adult phenotype of new generated myocyte one week after infarction 78 


\section{CHAPTER 1}

\section{INTRODUCTION}

Coronary artery disease resulting in myocardial infarction or ischemic cardiomyopathy presently remains one of the major causes of death. In the US one in four patients who suffered from myocardial infarction, dies due to heart failure. Heart failure in this context is the consequence of replacement of contractile myocytes with either fibrotic or scar tissue, resulting in an irreversible loss of functional tissue.

More than 10 years ago a major shift occurred in our understanding of cardiac physiology: Dr. Pierro Anversa has provided evidence to support the concept that the heart is not a post-mitotic organ and that myocyte turnover continues with the formation of new myocytes beyond the neonatal age in mammals. ${ }^{1,2}$ These initial observations suggests that the myocardium might have the potential to regenerate after ischemic injury by either activation of endogenous repair mechanisms or transplantation of stem cells. The vast number of patients suffering from heart failure after myocardial infarction demonstrates that endogenous repair mechanisms are obviously not sufficient to repair or regenerate lost myocardium, thus laying the groundwork for further exogenous therapeutic treatment to increase effectiveness. Stem cell therapy utilizing different types of stem cells, combinations of different cells, and different routes of stem cell administration have been 
reported recently. ${ }^{3,4}$ However, the most significant increase in myocardial ejection fraction (i.e. the most important variable of myocardial function) is achieved by transplantation of autologous ${\mathrm{c}-\mathrm{kit}^{+}}^{+}$cardiac stem cells in patients with ischemic cardiomyopathy. ${ }^{5}$ Nevertheless, transplantation of stem cells of any kind includes several caveats:

a) The number of cells remaining in the heart after transplantation is minimal. Using a highly sensitive RT-PCR method for detection of remaining cardiac stem cells after intramyocardial injection, revealed that only $43 \%$ of those cells stayed in the heart five minutes after injection, and that this number further decreased to eight percent (one day) and one percent (35 days) after injection, respectively. Unpublished data show similar numbers after intracoronary infusion (Dr. Kyong Hong, Ph.D., Institute of Molecular Cardiology, University of Louisville, KY, USA), suggesting that the route of delivery did not affect the fate of the cells within the heart. Considering the positive results reported for stem cell therapy and the probably lack of cells that form new myocytes based on these studies, it appears more likely that it is not cells, but factors released by them that are responsible for the improved function seen in clinical trials. ${ }^{6}$ Therefore, it remains controversial whether cells directly participate in cardiac regeneration or whether they are facilitators of the regeneration process by releasing paracrine factors.

b) Although compelling clinical data demonstrate safety of stem cell therapy, autologous stem cell transplantation remains a logistic challenge requiring isolation, culture, and purification of stem cells suitable for transplantation. In particular, culture and purification of different types of stem cells can result in an insufficient number of cells suitable for therapy. 
c) A recent meta-analysis reveals that even with the most commonly used stem cell, bone marrow-derived mononuclear cells (BMCs), an average improvement of left ventricular (LV) ejection fraction is only $4 \%{ }^{7}$ and with a reduction in infarct size of $4 \% .{ }^{8}$

Therefore, our laboratory focuses its research on stromal cell-derived factor $1 \alpha$ (SDF), one of the factors released from the myocardium or from injected cells after cardiac transplantation. Originally thought to play an important role in maintaining the stem cell niche microenvironment within the bone marrow (BM), it became clear that SDF by itself protects the heart when given prior to myocardial ischemia reperfusion. ${ }^{9}$ This contribution was further supported in studies where cardiac injury was exacerbated when signaling through SDF's receptor CXCR4 was blocked by chronic administration of AMD3100, demonstrating an important role of CXCR4 in cardiac homeostasis after myocardial infarction. $^{10}$

Pre-clinical and clinical studies documented that SDF is up-regulated after myocardial infarction, ${ }^{9,11-15}$ as part of the acute inflammatory response. This induction is mediated by hypoxia induced factor-1 $\alpha$ (HIF-1 $\alpha),{ }^{16}$ which has also shown to be responsible for up-regulation of CXCR4 on progenitor cells, promoting the recruitment of these cells towards myocardial injury. ${ }^{17}$ However, the induction of SDF is transient. It peaks 48 to 72 hours after myocardial infarction then returning quickly to low baseline levels, reflecting its tight control by hypoxic signaling and proteolytic proteins such as elastase, cathepsin G, CD26 / dipeptidylpeptidase IV (DPPIV), and metalloproteinases 2 and 9. Therefore, we asked whether chronic overexpression of SDF in the heart would accelerate cardiac repair beyond the acute inflammatory phase and produce a sustained state of augmented regeneration after myocardial infarction. 
Previous work from our laboratory has shown that SDF down-regulates casein kinase 1 alpha $(\mathrm{CK} 1 \alpha)$ in cardiac stem / progenitor cells (CSPC), which played an important role in CSPC cell cycle regulation, driving these cells towards a quiescent, nondividing state. As CSPCs are potentially important components during cardiac repair, factors affecting their ability to regenerate damaged myocardium are crucial components to consider. In addition, $\mathrm{CK} 1 \alpha$ is constitutively expressed in many tissues including cardiomyocytes, raising the question whether SDF overexpression will also affect cardiomyocyte cell cycle through CK1 $\alpha$.

Therefore, we created a transgenic mouse model in which cardiomyocyte-specific overexpression of SDF was induced four weeks before myocardial infarction and maintained throughout the entire recovery period, allowing us to not only study the acute effect on the heart but also its ability to facilitate cardiac regeneration.

This dissertation was therefore focused on

a) the effect of elevated cardiac SDF on heart, peripheral blood, and bone marrow homeostasis,

b) on its regulation of $\mathrm{CK} 1 \alpha$ as potential important regulator of cardiac progenitor and cardiomyocyte cell cycle, and

c) on SDF's potential to regenerate the heart after permanent coronary ligation. 


\section{BACKGROUND AND LITERATURE REVIEW}

Myocardial infarction as a consequence of coronary artery disease remains one of the major causes of death. After a critical loss of myocardium in the aftermath of an infarct, the remaining myocardium is unable to compensate for the reduced contractile mass resulting in increased myocardial stress. Without normalization, this increased myocardial stress leads to a progressive decline in function and profound neuroendocrine dysfunction ultimately leading to heart failure. There is increasing evidence that stem-cell mobilization to the heart and differentiation into cardiac myocytes is a naturally occurring process. However, with the potential loss of large areas of myocardium after myocardial infarction (MI) the extent of regeneration is too limited and takes place too slowly to be meaningful for the recovery of LV function. In a landmark publication, Dr. Pierro Anversa suggests that mammalian cardiomyocytes re-enter the cell cycle and subsequently undergo karyokinesis and cytokinesis. ${ }^{18,19}$ However, the number of newly generated cardiomyocytes differs significantly from $1.5 \%{ }^{20}$ to $40 \%{ }^{21}$ dependent on the publishing group as well as the method used. Despite these differences, it now seems clear that the heart maintains its capacity to regenerate, albeit, a very limited capacity. In retaining the functionality of stem cells to regenerate damaged myocardium, the therapeutic approach for patients with ischemic cardiomyopathy has dramatically changed: Current strategies acknowledge the loss of contractile mass and aim to replace the scar tissue with new viable, contractile myocardium. The release of factors that act in a paracrine function either directly from the injured myocardium or after stem cell therapy might be an important determinant of the extent of regeneration. SDF is one of the major factors released by injured myocytes after an ischemic insult. It binds to its receptors CXCR4 and CXCR7, 
which regulate cell homing, survival, proliferation, retention of stem cells in hematopoietic, lymphopoietic organs, and tissues affected by inflammation. ${ }^{22}$ Recent studies suggest that SDF also plays a significant role in myocardial ischemia reperfusion ${ }^{9,10}$ and cardiac regeneration.

\section{CLASSICAL ROLE OF SDF: HOMING FACTOR AND REGULATOR OF BONE MARROW HOMEOSTASIS}

Chemokines are chemotactic cytokines that play an essential role in directing leukocyte movement during homeostasis, organ development, and inflammatory

conditions - short, these molecules constitute the host defense against organ damage. ${ }^{23}$ More than 50 different chemokines and 20 different chemokine receptors have been cloned so far. The CXC chemokine, stromal cell-derived factor 1 (SDF or CXCL12), produced by multiple BM stromal cell types and by epithelial cells in many organs, ${ }^{24-29}$ mediates its action through the seven-transmembrane span G-protein coupled receptors CXCR4 and CXCR7 expressed on a variety of cell types. Knockouts of CXCR4, CXCR7, or SDF result in a diminished colonization of embryonic BM by hematopoietic stem cells and defect in the development of the heart, brain, and large vessels. ${ }^{30-35}$

As SDF has been shown to play a key role in several functions in homeostasis and injury, regulation of its expression and secretion are important. SDF expression has been found to be responsive to hypoxia. In a gradient hypoxia model Gurtner and colleagues show that SDF secretion increases in endothelial cells by hypoxia and as is a consequence of HIF-1 $\alpha$ induction. ${ }^{16}$ Specificity of this action was demonstrated by the presence of HIF$1 \alpha$ binding sites in the SDF promoter. ${ }^{16}$ Not surprising, SDF is increased in hypoxic / 
damaged tissues which serve as a chemoattractant for hematopoietic and other cells expressing CXCR4 (i.e. stem / progenitor cells). However, hypoxia can also result in upregulation of CXCR4 as its promoter also contains consensus binding sites for HIF- $1 \alpha$, suggesting autocrine activation of intracellular signaling pathways. ${ }^{36}$

\section{SDF AND CARDIOPROTECTION}

In addition to the long-known properties of SDF in BM homeostasis, recent evidence suggests that SDF also plays an important role in cardioprotection and regeneration of injured myocardium. Several studies demonstrate SDF1 / XCR4 mediated

mobilization of $\mathrm{BM}(\mathrm{BM})$-derived stem cells to sides of ischemic injury. ${ }^{12,13,24,37} \mathrm{Hu}^{9}$ demonstrated for the first time that ischemic preconditioning resulted in up-regulation of SDF in cardiomyocytes but not in fibroblasts and that administration of SDF prior to myocardial ischemia / reperfusion injury reduced the infarct size in vivo. SDF administration 25 minutes prior to global LV ischemia increases the recovery of the LV function after 40 minutes of reperfusion. ${ }^{38}$ Increased activation by SDF of signal transducer and activator of transcription (STAT3) after ischemia reperfusion injury and an abolished protection in STAT3 knockout mice suggest that STAT3 contributes to the SDF effect on ischemia reperfusion injury. ${ }^{38}$ Administration of SDF mediated survival in cardiac myocytes by activating extracellular regulated kinase (ERK) and AKT as we demonstrated in vitro and in vivo. ${ }^{9}$ Besides the effect on ischemia / reperfusion injury, the importance of SDF / CXCR4 during myocardial ischemic injury was elucidated in a permanent coronary artery ligation model ${ }^{10}$ in which blockade of CXCR4 by chronic administration of AMD3100 increased myocardial injury and reduced LV function. ${ }^{10}$ However, CXCR4 blockade increased the number of c-kit ${ }^{+}$progenitor cells in the area at risk four weeks after 
myocardial infarction, suggesting regulation of cardiac progenitor / stem cell proliferation by SDF / CXCR4.

For activation of SDF / CXCR4 after myocardial infarction to become a therapeutic option the above mentioned limitations (i.e. short half-life, rapid cleavage) need be resolved, and different groups tested four different approaches:

\section{Direct delivery of SDF}

A direct delivery approach was used by Saxena who injected SDF directly into the peri-infarct zone of mice that had undergone coronary ligation and found a reduction in apoptosis and increased neovascularization. ${ }^{39}$ To take advantage of both restoration strategies (i.e. cell therapy and delivery of SDF), Schuh injected in a rat model endothelial progenitor cells and SDF simultaneously into the border zone of the infarct four weeks after permanent coronary ligation. This approach increases LV function and increases vascularization two months after treatment. ${ }^{40}$ Finally, Abbott developed a SDF-AdV, which was injected into the peri-infarct zone causing a 2.5-fold increase in cardiac SDF concentration compared to a control virus 48 hours after injection and resulting in high recruitment of mesenchymal stem cells towards the infarct. ${ }^{13}$

\section{$\underline{\text { Transplantation of SDF overexpressing cells }}$}

Several groups used genetically modified cells overexpressing SDF to increase the local SDF concentration, using either SDF overexpressing cardiac fibroblasts in combination with G-CSF stimulated mobilization of $\mathrm{CD} 117^{+}$and $\mathrm{CD} 34^{+}$cells, ${ }^{12}$ or mesenchymal stem cells transfected with a SDF expression vector. ${ }^{41,42} \mathrm{LV}$ function and vascular density in the risk region increase using this approach. 
Inhibition of proteolytic cleavage of SDF

To overcome the rapid degradation of SDF, Segers developed a bioengineered SDF-fusion protein resistant to MMP2 and CD26 / DPPIV cleavage, which increases recruitment of stem cells and improves LV function after intra-myocardial delivery. ${ }^{43}$ Zaruba and colleagues followed the same approach by pharmacologically inhibiting DPPIV and therefore maintaining a higher SDF level after myocardial infarction. In combination with G-CSF${ }^{44}$ mediated stem cell mobilization these authors detect an increased angiogenesis and a decreased cardiac remodeling resulting in an improved LV function.

\section{Up-regulation of $C X C R 4$}

To increase the recruitment of stem / progenitor cells to the site of injury the last approach utilized retroviral-transduced ${ }^{45}$ or physiologically (i.e. hypoxic preconditioning) up-regulated ${ }^{17} \mathrm{CXCR} 4$ expression in mesenchymal- or cardiosphere-derived stem cells to accelerate the recruitment to the damaged myocardium. Both approaches result in increased recruitment of intravenous transfused cells and increase LV function.

In summary, most of the above listed studies focused on the chemoattractant properties of SDF and aimed to increase the recruitment of different types of stem / progenitor cells towards the injury site.

\section{SDF AS REGULATOR OF CELL CYCLE BY CASEIN KINASE $1 \alpha$ (CK1 $\alpha)$}

In addition to well known effects of SDF / CXCR4 on cell migration and survival, SDF has also been shown to play a role in regulating proliferation of subpopulations of hematopoietic progenitors and CSPC. In this side, SDF drives cells to withdraw from the 
cell cycle at the $\mathrm{G}_{0} / \mathrm{G}_{1}$ interface, resulting in quiescence of these cells. ${ }^{46}$ In the context of stem / progenitor homeostasis, this important mechanism preserves the cell population by limiting the number of times these cells divide. Studies in isolated CSPCs demonstrate that SDF established a quiescent, non-proliferative state that was dependent on CXCR4 ${ }^{46}$ These studies show down-regulation of CK1 $\alpha$, which is well known for its role in stablilizing $\beta$-catenin, and increase GSK3 $\beta$ activation resulted in an inhibition of cell proliferation through cycling D1 and Bmi-1 dependent mechanisms. These data confirmed previous work in hematopoietic stem cells, which required SDF or CXCR4 to maintain quiescent and provide mechanistic insight into cell cycle regulation. These findings also provide a mechanism which helps to explain the longevity of these cells in the BM niche to provide a stable stem cell pool.

\section{PHYSIOLOGICAL ROLE OF CK1 $\alpha$}

The protein kinase, CK1, has first been described in lactating mammary glands which determined the name of the kinase. However, CK1 is a monomeric serine / threonine protein kinase responsible for the regulation of several organ functions including membrane trafficking, cell cycle progression, chromosome segregation apoptosis, and cellular differentiation. Several isoforms (i.e. $\alpha, \beta, \gamma 1, \gamma 2, \gamma 3, \delta$, and $\varepsilon)^{47-52}$ in addition to several splice variants, differing in their kinase activity, have been described ${ }^{53} \mathrm{CK} 1 \alpha$ is constitutively active but treatment with insulin, viral transformation, and treatment of the cell with topoisomerase inhibitors increase the activity. ${ }^{54}$ Phosphotadylinositol-4, 5biphosphate (PIP2) reduces CK1 $\alpha$ activity in erythrocytes and neuronal cells and a RNA helicase DDX3 regulates CK1 $1{ }^{55}$ Furthermore, CK1 activity is inhibited by autophosphorylation of the c-terminal domain, which serves as a target of cellular phosphatases 
increasing CK1 activity. ${ }^{56} \mathrm{CK} 1 \alpha$ has been linked to cell cycle progression, spindle dynamics, and chromosome segregation. The studies in Aim II will expand on the previous findings in isolated CSPCs and extend our knowledge to include differentiated cardiomyocytes.

\section{STROMAL CELL-DERIVED FACTOR 1 TRANSGENIC MICE / GENOTYPING AND BREEDING}

Cardiac specific conditional transgenic mice were generated on the C57BL / mouse strain. To temporarily control the SDF overexpression we used a tetracycline (tet) transactivator tet-off controlled transgenic mouse line in which myocyte-specific SDF

overexpression was driven by the $\alpha$-myosin heavy chain $\operatorname{promoter}^{57}$ (Figure 1). This binary inducible transgenic model requiring mice that contain both of the following transgenes:

(1) A heterologous $\alpha$-myosin heavy chain ( $\alpha$-MHC)-cardiac-specific promoter driving the Tet-controlled trans-activator (tTA) sequence, consisting of a primer of a minimal activation domains derived from VP16 (FFF) ${ }^{58}$ and a rTetR, selected from a yeast screen for optimized sensitivity and inductive range, placed into a cardiac-specific $\alpha$ myosin heavy chain-specific promoter construct;

(2) A full-length $\alpha$-MHC promoter in which three GATA sites and two tetracycline response elements (TRE) were ablated and the remaining cis-acting regions important for cardiac-specific expression were left intact. The Tet responsive element consists of seven repeats of the TetO sequence adjacent to the TATA box. ${ }^{57}$ 
A

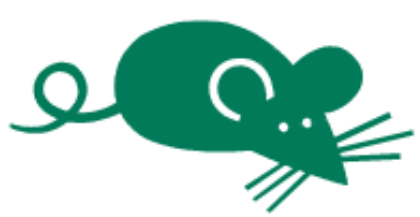

$\begin{gathered}\text { mouse aMHC- } \\ \text { promoter }\end{gathered}$
rTetR-S2M2FFF 2 FGH polyA
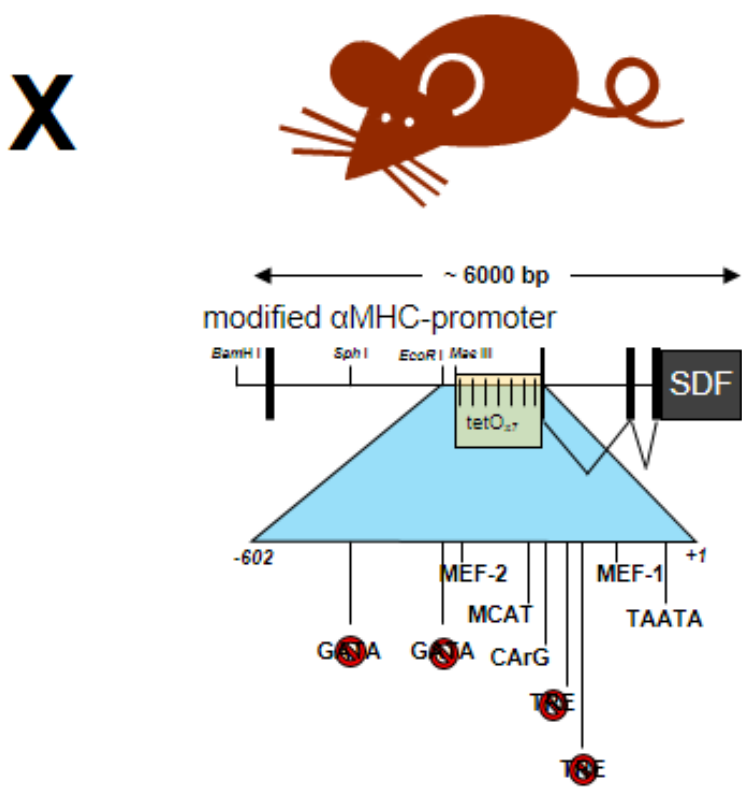

- doxycycline
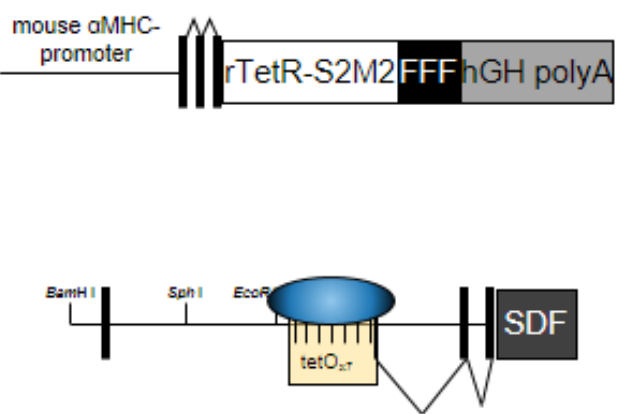

Binding of tTA-VP16 to tetO SDF gene transcription
No binding of tTA-VP16 to tetO No SDF gene transcription

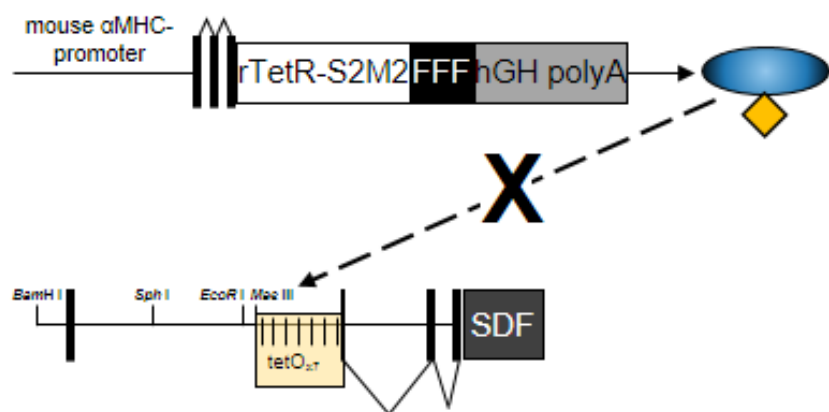

Figure I Characterization of the $\alpha$-MHC specific -Tet "off" SDF transgenic model SDF was overexpressed in double transgenic mice containing a modified (A, left side) $\alpha$ MHC driven tetracycline activator gene and an $\alpha-\mathrm{MHC}$ modified tetracycline response element directing the expression of the SDF1 $\alpha$ gene. (A, right side)

In the presence of doxycycline the transcription of SDF is driven by a minimal promoter sequence and "switched off" (B, left side). However, in the absence of doxycycline tTA (blue cycle) can bind to the tetO binding site and accelerate SDF expression. 
This chimeric promoter is ligated to the SDF gene, which is then conditionally controlled: In the presence of tetracycline or its analogue doxycycline, the transcription of SDF is only driven by the very low basal activity of the minimal promoter and "switched off" while in its absence tTA can bind to the TetO, allowing the VP16 transactivator to increase the expression of SDF, driven by the heterologous $\alpha$-MHC promoter, and therefore "switched on". The tet-off model allowed us to determine the time of gene overexpression, and we removed doxycycline from the drinking water at eight weeks of age when mice become adolescent. We detected increased gene-overexpression three weeks after doxycycline withdrawal determined by PCR and western blot analysis (Figure 2), and therefore performed our experiments in 12-14 weeks old mice with a one week "safety margin".

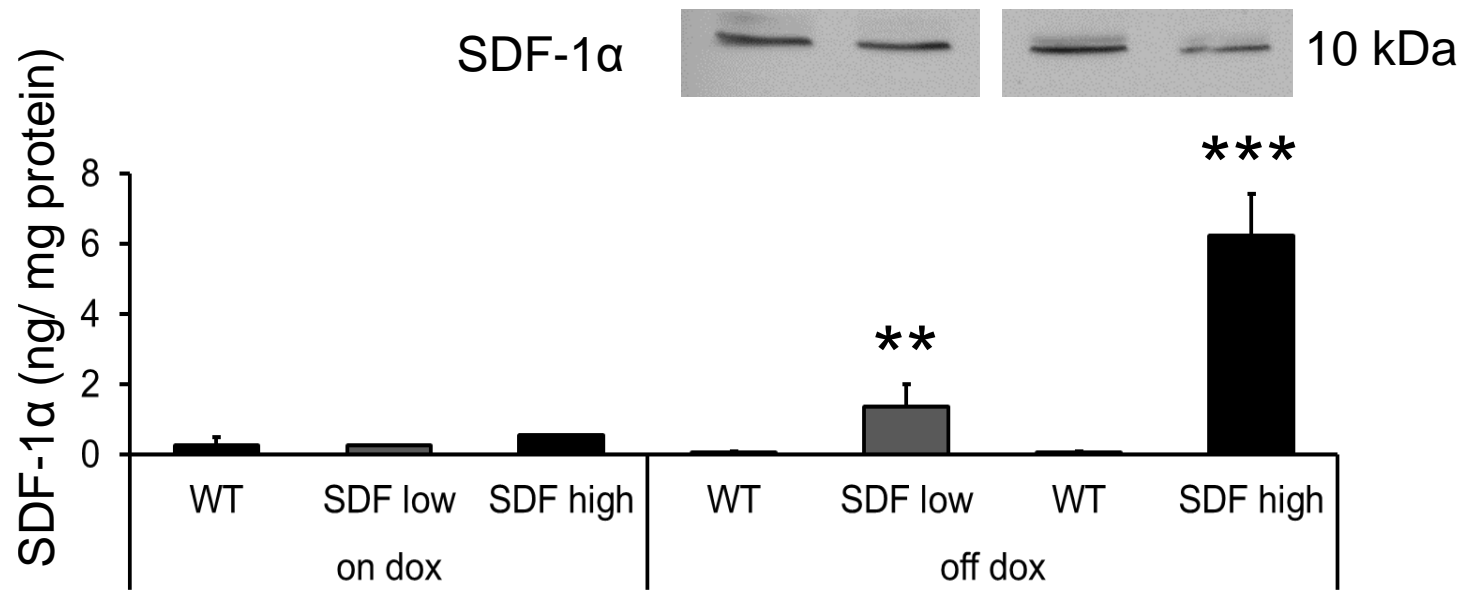

Figure II Myocardial SDF concentration before and after activation of the transgene Myocardial SDF concentration in wild-type (WT) and in "low" (SDF low) and "high" (SDF high) expressing transgenic mice. Mice were euthanized while receiving doxycycline ("on dox") and three weeks after induction of cardiomyocyte-specific SDF overexpression (“off dox"). ( $\mathrm{N}=3-7 . * *, \mathrm{P}<0.01$, *** $\mathrm{p}<0.001$, Student's t-test). 
Assuming a Mendelian pattern of inheritance, one in four offspring would carry both transgenes. We used exclusively male mice for the ligation experiments to avoid any estrogen cycle dependent impact on the size of injury. Therefore, $12.5 \%$ of all offspring mice were available for ligation experiments (Table 1), resulting in a total of 725 mice assuming a $75-80 \%$ survival rate after one week post-ligation and four weeks post-ligation, respectively.

\section{Table 1 Breeding requirements to fullfil the proposed study}

\begin{tabular}{|c|c|c|c|c|c|c|}
\hline Treatment groups & $\begin{array}{l}\text { WT } \\
\text { sham }\end{array}$ & $\begin{array}{l}\text { WT } \\
\text { ligated }\end{array}$ & $\begin{array}{l}\text { Tglow } \\
\text { sham }\end{array}$ & $\begin{array}{l}\text { Tglow } \\
\text { ligated }\end{array}$ & $\begin{array}{l}\text { Tgnigh } \\
\text { sham }\end{array}$ & $\begin{array}{l}\text { Tgnbn } \\
\text { ligated }\end{array}$ \\
\hline \multicolumn{7}{|l|}{ Group size } \\
\hline 1 wk & 5 & 8 & & & 5 & 8 \\
\hline 4 wks & 8 & 18 & 8 & 18 & 8 & 18 \\
\hline \multicolumn{7}{|l|}{ estimated survival rate (\%) } \\
\hline $1 \mathrm{wk}$ & 95 & 80 & & & 95 & 80 \\
\hline 4 wks & 95 & 70 & 95 & 70 & 95 & 70 \\
\hline \multicolumn{7}{|l|}{ estimated mice needed for experiments } \\
\hline 1 wk & 5.3 & 10.0 & & & 5.3 & 10.0 \\
\hline 4 wks & 8.4 & 25.7 & 8.4 & 25.7 & 8.4 & 25.7 \\
\hline $\begin{array}{l}\text { Male double transgenic mice (yield assuming Mendelian } \\
\text { pattern of inheritage) }(\%)\end{array}$ & 87.5 & 87.5 & 12.5 & 12.5 & 12.5 & 12.5 \\
\hline \multicolumn{7}{|l|}{ Breeding effort: } \\
\hline $1 \mathrm{wk}$ & 6.0 & 11.4 & & & 42.1 & 80.0 \\
\hline \multirow{2}{*}{4 wks } & 96 & 29.4 & 67.4 & 2057 & 67.4 & 2057 \\
\hline & 15.6 & 40.8 & 67.4 & 205.7 & 109.5 & 285.7 \\
\hline $\begin{array}{l}\text { Total number of mice needed to perform ligation } \\
\text { experiments: }\end{array}$ & 724.7 & & & & & \\
\hline
\end{tabular}




\section{CHAPTER 2}

\section{UNDERLYING PROBLEM}

Myocardial infarction is a prevalent consequence of cardiovascular disease (CVD) contributing to one in four deaths in the US. Unfortunately, there is no therapy to reverse effects of lost myocardium due to myocardial infarction, only therapies to deal with the consequences. Although stem cell therapy seems to be promising to regenerate damaged myocardium, current approaches lack efficiency. It is essential that a better understanding of mechanisms associated with regeneration is obtained and then utilized to develop more effective therapeutic approaches to alleviate the significant burden of CVD and improve patient quality of life.

\section{PROPOSED EXPERIMENTS}

This thesis will evaluate the effect of chronic SDF overexpression on cardiac regeneration after permanent coronary ligation. In particular, we will focus on the effect of SDF on the myocardium and its regeneration potential and how BM homeostasis is affected. One of the key challenges in the proposed studies will be to demonstrate changes in infarct size that are a consequence of myocardial regeneration. We will use two indices to assess infarct size, scar size, and viable myocardium and accompany these with immunofluorescent detection of new myocytes by BrdU incorporation. We will further 
evaluate whether CK1 $\alpha$ plays an important role in cardiac regeneration and whether it serves as a mediator of SDF induced cardiac regeneration.

\section{HYPOTHESIS}

Cardiomyocyte-specific overexpression of SDF accelerates cardiac regeneration after permanent coronary ligation by increasing $\mathrm{CK} 1 \alpha$ mediated cardiomyocyte division.

\section{SPECIFIC AIMS}

I) To determine the effect of chronic cardiomyocyte-specific overexpression of SDF on cardiac and bone marrow homeostasis.

II) To determine whether casein kinase $1 \alpha$ mediates cardiac stem / progenitor cells and neonatal cardiomyocyte proliferation.

III) To determine whether cardiomyocyte-specific overexpression of SDF increases myocardial regeneration after permanent coronary ligation. 


\section{CHAPTER 3}

\section{AIM I - TO DETERMINE THE EFFECT OF CHRONIC CARDIOMYOCYTE-SPECIFIC OVEREXPRESSION OF SDF ON}

\section{CARDIAC AND BONE MARROW HOMEOSTASIS}

\section{BRIEF PREVIEW}

\section{Background}

The proposed studies focus on changes in the heart (i.e. cardiomyocytes) and in the BM as a major source of progenitor cells. As a chemoattractant, BM derived SDF helps to retain diverse population of hematopoietic precursors including $\mathrm{CD} 34^{+}$stem / progenitor cells (HSCs / HPCs) in the BM and serves as an "anchor" for leukocytes within the BM niche. Stressors or injury that alter the homeostatic influence of SDF would impact this balance leading to decreased retention and mobilization of these cells, leading to increased circulating levels. Therefore, we asked whether an "imbalance" due to myocardial overexpression of SDF would shift the homing preference of circulating HSPCs / endothelial progenitor cells (EPCs) towards the heart and subsequently affect the circulating stem cell pool. SDF / CXCR4 interaction promotes neovascularization in different types of tissue injury by recruiting endothelial progenitor cells. ${ }^{59,60}$ For that reason, we measured the number of leukocytes in the peripheral blood and endothelial progenitor cells (EPCs, Sca- $1^{+} /$Flk-1 $1^{+}$cells) in the peripheral blood and the BM. 
Since recently published data demonstrates that SDF regulates the cardiac stem / progenitor cells' (CSPC, c-kit ${ }^{+}$cells) cell cycle through $\mathrm{CK} 1 \alpha^{46}$, we also determined the expression of cardiac CK1 $\alpha$ and the number of CSPCs in WT and SDF transgenic (Tg) mice. Previously we demonstrated that SDF administration was associated with an increase in ERK and AKT. ${ }^{9}$ Therefore, we determined AKT under baseline condition in WT and SDF overexpressing mice.

\section{Methods}

Two lines of cardiomyocyte-specific SDF Tg mice expressing "low" (SDF low) and "high" (SDF high) levels of SDF were used in the described studies. Cardiac SDF levels were determined by ELISA before and three weeks after activation of the transgene in "high" and "low" SDF overexpressing mice. Protein levels of CK1 $\alpha$ and AKT were determined by western blot analyses using standard protocols. The number of leukocytes was determined by an automatic hematology analyzer five and 30 weeks after initiation of cardiac SDF overexpression and the number of circulating EPCs detected by FACS analysis.

\section{$\underline{\text { Results }}$}

Interestingly, the number of leukocytes decreased in the peripheral blood five and 30 weeks after the removal of doxycycline from the drinking water and induction of SDF overexpression in the heart while there was no change in the number of platelets and red blood cells in the peripheral blood. To verify this unexpected result we performed a second set of experiments to determine the time course of these hematological changes, confirming lower numbers of leukocytes in the peripheral blood of SDF Tg mice compared to WT 
mice. The number of EPCs was lower in SDF Tg mice in the BM and the peripheral blood. While we saw an increase in EPCs 72 hours after permanent coronary ligation in SDF Tg mice, numbers in WT mice remained unchanged.

Overexpression of SDF resulted in a concentration dependent increase of cardiac CK1 $\alpha$ and phosphorylation of AKT and an increase in CSPCs determined by immunopathology. Interestingly, BrdU staining indicated a reduced number of dividing CSPCs.

\section{$\underline{\text { Conclusion }}$}

Although SDF overexpression was cardiomyocyte-specific, the level of SDF was sufficient to affect the periphery and reduce circulating leukocytes and diminish the number of EPCs in the peripheral blood and the BM. CK1 $1 \alpha$ increased in SDF overexpressing mice, affecting proliferation of CSPCs.

\section{MATERIAL AND METHODS}

\section{$\underline{\text { Animals }}$}

SDF Tg mice were bred, maintained, and used in described studies at the University of Louisville under protocols approved by the Animal Care and Use Committee and adhered strictly with the Guide for the Care and Use of Laboratory Animals (NIH Publication No. 86-23, Revised 1996). For the proposed experiments in Aim I female mice were used from SDF Tg lines overexpressing low and high SDF concentrations (as outlined above) and their WT littermates served as age matched controls. A diurnal 12 hour day / night cycle was maintained. At the age of eight weeks, removal of doxycycline from the drinking water successfully induced SDF overexpression (Figure 2). A second set of 
experiments was performed in elderly mice (60 weeks of age) to determine the effect of chronic SDF overexpression (i.e. at least 30 weeks) on the number of circulating leukocytes.

\section{Hematology}

Two sets of experiments were performed to establish the effect of SDF on hematopoiesis: In a first set of experiments, blood samples were taken from mice of different ages (15 and 60 weeks old) and the number of leukocytes (WBCs), red blood cells (RBCs) and platelets was determined. In a second set of experiments, we established a fiveweek time-course of individual changes in $\mathrm{WBC}, \mathrm{RBC}$, and platelet numbers in the peripheral blood before and after the removal of doxycycline from the drinking water. Blood samples were taken at time "0" (eight week old mice receiving doxycycline) and eight, 16, 24, and 32 days after doxycycline removal. Blood was collected by puncturing the retrobulbar plexus and collecting $\sim 150 \mu 1$ of blood into a microvette EDTA coated tube (Sarstedt Inc., Newton, NC, USA) stored on ice. The daytime of the blood collection was kept constant throughout the entire experimental period to avoid circadian changes in cell numbers. The corpuscular blood composition was determined within 30 minutes using an automatic hematology analyzer (Cell DYN 3500, Abbott Diagnostics, Princeton, NJ, USA).

\section{Flow cytometry / FACS analysis}

The number of circulating and resident BM EPCs was determined from whole blood samples collected, as described above. After automatic cell counting the samples were treated with an erythrocyte lysis buffer (Roche) for one minute at room temperature. 
Samples were then washed twice to remove the cell debris and transferred to a staining buffer (PBS supplemented with 5\% fetal bovine serum (FBS), 1\% bovine serum albumin (BSA)). Cells were stained 45 minutes in the dark for stem cell antigen (Sca-1, Antibody, FITC conjugated) as a hematopoietic stem cell marker and for fetal liver kinase 1 (Flk-1, APC Rat anti-mouse, BD Pharmingen), the receptor for vascular endothelial growth factor as an endothelial cell marker. After two subsequent washing steps, FACS analysis was performed (Accuri C6, Becton Dickinson Bioscience, San José, CA, USA).

\section{$\underline{\text { Bone marrow collection }}$}

Mice were euthanized by $\mathrm{CO}_{2}$ inhalation followed by cervical dislocation, then both femurs were removed and placed in sterile phosphate buffered saline (PBS) solution. Soft tissue was removed from the bone with a fine forceps to avoid the contamination of the BM sample. The bone shaft was then flushed with PBS using a 23-gauge needle and a ten

milliliter syringe. Cells were further dissociated by careful repeated passage of the flushed BM through the 23-gauge needle. The cell suspension was filtered through a $70-\mu$ m nylon mesh filter to remove clumps, counted with a hemocytometer and then transferred to a FACS staining buffer for further processing, as described above.

\section{Coronary ligation}

All animal procedures were approved by the University of Louisville IACUC in accordance with the NIH Guide for the Care and Use of Laboratory Animals (DHHS publication No. [NIH] 85-23, rev. 1996). After inhalational induction of anesthesia (3-5 Vol.\% Isoflurane (Abbott Laboratories, Abbott Park, IL, USA) in an induction chamber, the trachea was intubated with a 22-gauge intravenous catheter. The successful intubation 
was verified by bilateral chest movement after connection to a small rodent ventilator (Harvard Apparatus, Holliston, MA, USA). The lung was volume controlled ventilated at a rate of 150-200 strokes / minute and a tidal volume of $200 \mu 1$. Having shaved the chest with an electric razor, the mice were placed on an adjustable temperature (TCAT-2LV controller, Physiotemp, Clifton, NJ, USA) heating pad with a $37^{\circ} \mathrm{C}$ setup. All procedures were performed under a surgical microscope (MZ95, Leica Microsystems, Buffalo Grove, IL USA), using a sterile surgical technique. After opening the thoracic cavity between the fourth intercostal space and dissection of the pericardium, the left descending coronary artery was identified and subsequently ligated by a single stich ligation with an 8.0 suture (Nylon, AA-0145, Surgical Specialties Corp, Vancouver, BC, Canada) about 2-3 mm below the aortic root. The successful ligation was confirmed by epicardial cyanosis and bulging of the myocardium during systole. The chest was subsequently closed in layers, using a 5.0 Vicryl suture (PC-1, 1855G, Ethicon, Cincinnati, OH, USA). After extubation the mice recovered for 30 minutes to one hour in an oxygen chamber $\left(\mathrm{FiO}_{2}=0.8\right)$ before they returned to an animal cage, being placed on a heading pad overnight. 


\section{Confocal microscopy}

One limitation of conventional microscopy for achieving high-resolution images is based on the physical properties of the emitted light:

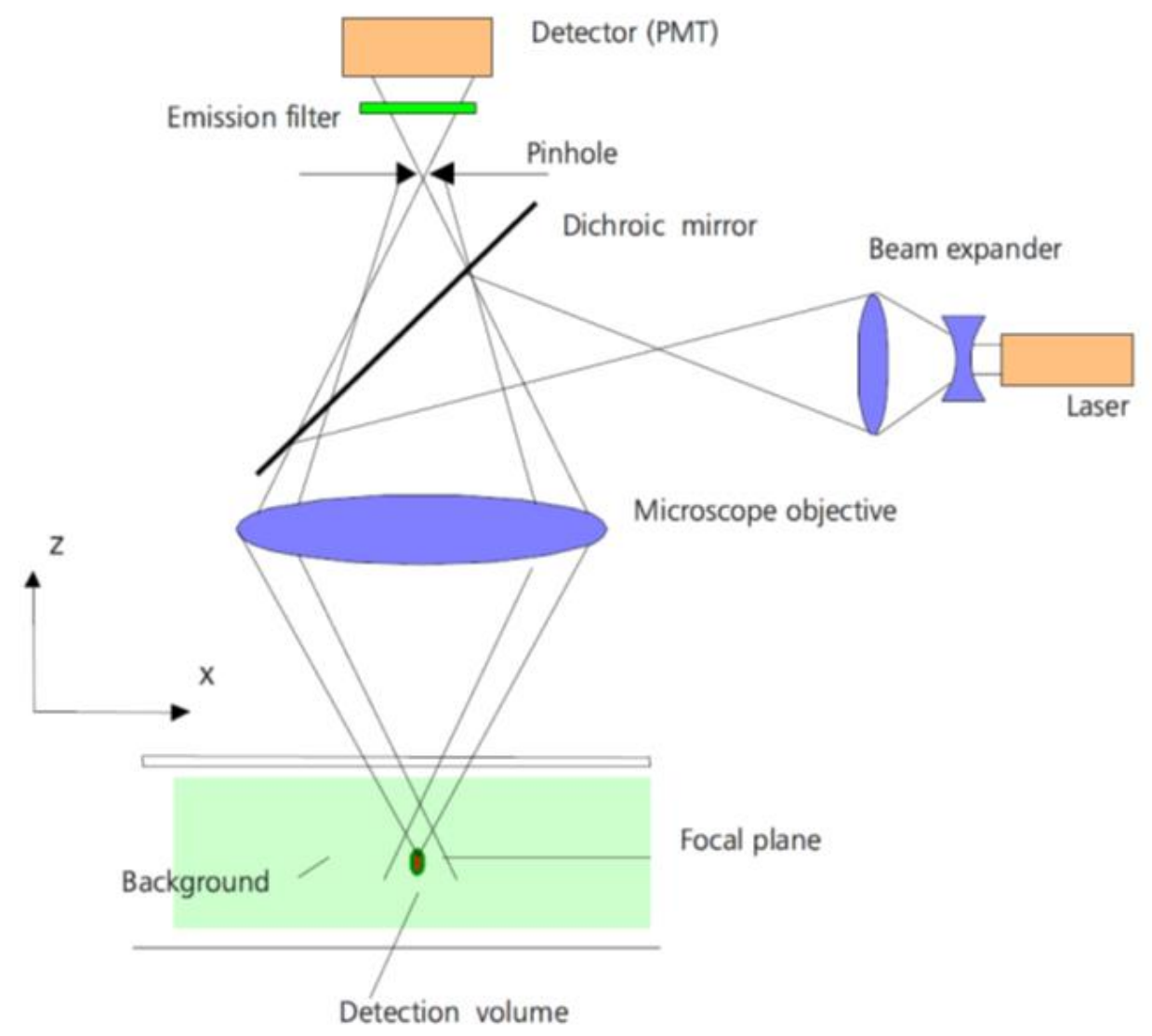

Copyright Carl Zeiss, Germany.

\section{Figure III Confocal microscopy scheme}

A microscope objective is used to focus a laser beam onto the specimen, where it excites fluorescence. The fluorescent radiation is collected by the objective and efficiently directed onto the detector via a dichroic beamsplitter. The interesting wavelength range of the fluorescence spectrum is selected by an emission filter, which also acts as a barrier blocking the excitation laser line. The pinhole is arranged in front of the detector on a plane conjugate to the focal plane of the objective. Light coming from planes above or below the focal plane is out of focus when it hits the pinhole, so most of it cannot pass the pinhole and therefore does not contribute to forming the image (Copyright Carl Zeiss, Jena, Germany). 
In thick tissue sections, like the myocardium, the focus area is always greater than the wave-optical depth of the specific sample. Therefore, the in-focus information of the image is mixed with surrounding out of focus image information, reducing the contrast of the image. Using multiple fluorescence dyes result in a mixture of signals into different color channels, limiting conclusions about co-localization of the labeled structures. In contrast, confocal imaging uses an optical aperture, which only collects data within the focal plane while rejecting outside reflections from the sample. Using LASER (Light Amplification by Stimulated Emission of Radiation) light featuring a high spatial and temporal coherence, confocal microscopes are capable of scanning tissue samples with a single color (wavelength) and a high spatial resolution. In addition, sample images can be acquired in a single plane (i.e. slice), which result in a stack of images when moved along the $\mathrm{z}$-axis in defined increments, allowing to assemble a 3-dimensional reflection of the specimen. (Figure 3). The Zeiss LSM510 confocal microscope (Carl Zeiss, Jena, Germany) is equipped with three different LASER types: An Argon / Krypton laser (emitting wavelength: 458 / 488 / $514 \mathrm{~nm}$ ), an UV laser (405 nm), and a Helium laser (633 $\mathrm{nm})$. The laser light is directed towards a dichroic mirror through a specific objective onto the specimen where specific fluorophores are excited and subsequently emit light of a different wavelength back towards a dichroic beamsplitter, which allows the passage of light of a define wavelength towards a detector via a precisely aligned pinhole. In our experiments, we used up to four different fluorophores to identify and detect colocalization of our antigen-targets (Table 2). 
Table 2 Fluorophores used for detection of different antigens by confocal microscopy

\begin{tabular}{|l|c|c|c|}
\hline Fluorophores & $\begin{array}{c}\text { Excitation } \\
\text { wavelength (nm) }\end{array}$ & $\begin{array}{c}\text { Emission } \\
\text { wavelength (nm) }\end{array}$ & Spectrum \\
\hline $\begin{array}{l}\text { Fluorescein } \\
\text { (FITC) }\end{array}$ & 495 & 519 & Green \\
\hline $\begin{array}{l}\text { Tetramethylrhodamine } \\
\text { (TRITC) }\end{array}$ & 547 & 572 & Red \\
\hline Cyan (Cy5) & 649 & 670 & Cyan \\
\hline $\begin{array}{l}\text { 4'6-diamidino-2-phenylindole } \\
\text { (DAPI), nuclear stain }\end{array}$ & 345 & 455 & Blue \\
\hline
\end{tabular}

\section{Preparation for pathological specimens}

At the end of each recovery period (i.e. one or four weeks), the mice were reanesthetized, and the heart was arrested in diastole by injecting a filtered saturated $\mathrm{KCl}$ ( 3 M) and cadmium (Cd, 0.1 M, Sigma Aldrich, St. Louis, MO, USA) solution through the apex into the LV cavity. Thereafter, the aorta was cannulated, and the heart retrograde perfused at a rate of $0.5-1 \mathrm{ml} /$ minute with $37^{\circ} \mathrm{C}$ warm PBS. After five to ten minutes and complete blood removal, the perfusion was switched to $10 \%$ buffered formalin solution. The solution was infused under constant pressure $(80 \mathrm{mmHg})$ for an additional 10-15 minutes. The LV cavity pressure during the fixation period was kept constant at $13 \mathrm{mmHg}$ by infusing formalin through a 26-gauge needle inserted into the cavity through the LV apex. After subsequent fixation in $10 \%$ buffered formalin for up to seven days atrial appendices were removed, hearts were weighted and cut into two millimeter thick crosssectional slices in a mouse heart tissue slicer (Zivic Instruments, Pittsburgh, PA, USA). 
After tissue processing for paraffin embedding (Tissue-Tek VIP, Miles Scientific), tissue samples were cut (rotary microtome RM2155, Leica Microsystems, Buffalo Grove, IL, USA) into four micrometer thick sections for histological and immunofluorescent staining. Sections were stored at $4^{\circ} \mathrm{C}$ until their final usage. Prior to histological staining, sections were de-paraffinized and rehydrated to distilled water using a standard graded xyleneethanol series.

\section{Immunofluorescence staining}

Formalin containing fixatives cause cross-linking of proteins and mask antigen sites in tissue sections, making those unavailable for detection by antibodies. Therefore, we used a basic EDTA buffer ( $\mathrm{pH}$ 8.0) in which tissue sections were boiled for 15 minutes in a microwave oven, followed by a 30 minutes cool-down period. Thereafter, sections were equilibrated in $\mathrm{TN}$ buffer $(0.1 \mathrm{M}$ Tris- $\mathrm{HCl}, 0.15 \mathrm{M} \mathrm{NaCl}, 0.05 \%$ Tween 20$)$ for five minutes, followed by quenching of endogenous peroxidase with $3 \% \mathrm{H}_{2} \mathrm{O}_{2}$ for 10 minutes at room temperature. After threefold washing in TN buffer, sections were blocked with TB buffer containing $0.5 \%$ blocking agent (FP1020, PerkinElmer Inc., Waltham, MS, USA) and subsequently incubated overnight with a c-kit antibody $(1: 100$, mouse stem cell factor receptor / c-kit, AF1356, R\&D systems, Minneapolis, MN, USA). To develop the final signal, sections were incubated with bovine anti-goat horseradish peroxidase (HRP) antibody (1:200, Cat.\# 805-035-180, Jackson Immunoresearch, West Grove, PA, USA) for one hour at room temperature followed by five washing steps and four minutes incubation in amplification working buffer (1:50 diluted TRITC fluorophore in amplification buffer, TSA Plus TMR kit, PerkinElmer, Inc.). To exclude hematopoietic, c-kit ${ }^{+}$cells from our analysis, sections were incubated with a CD45 antibody (CD 45, 1:50 in 1\% BSA and 10\% 
donkey serum, cat.\# 610265, BD transduction Laboratories) for 30 minutes at $37^{\circ} \mathrm{C}$ and then stained with a donkey-anti-mouse IgG FITC conjugated secondary antibody 1:100, Cat.\# 715-095-151, Jackson Immunoresearch, West Grove, PA, USA). Finally, a 15 minutes incubation in a DAPI solution [1:1000 in Dulbecco's PBS (DPBS)] marked the nuclei. Prior to mounting cover glasses, tissue auto-fluorescence was blocked by a 30 minutes incubation in Sudan black B solution (Cat\# 199664, $1 \mathrm{mg} / \mathrm{ml}$ in 70\% ethanol, Sigma Aldrich, St. Louis, MO, USA,). CSPC proliferation was determined in a second set of tissue sections, measuring BrdU incorporation (see page 52). After c-kit staining, these sections were incubated with an anti-BrdU primary antibody (1:50, clone BMG $6 \mathrm{H} 8 \mathrm{IgG})$ for two hours at $37^{\circ} \mathrm{C}$, washed five times for six minutes in DPBS, and stained with a FITC conjugated secondary anti-mouse IgG antibody (5-Bromo-2'deoxy-uridine labeling and detection kit I, Roche Diagnostics GmbH, Mannheim, Germany).

\section{$\underline{\text { Western blot analysis }}$}

The mice were euthanized as previously described, and their hearts were quickly removed and washed in ice-cold PBS. Half of the tissue was used for western blot analysis performed as previously described. ${ }^{9}$ Briefly, the tissue was immediately homogenized in lysis buffer containing (in mmol / L): 25 Tris- $\mathrm{HCl}, \mathrm{pH}$ 7.5, $100 \mathrm{NaCl}, 0.5$ EDTA, 0.5 EGTA, 1\% phosphatase inhibitor cocktail 2 (P5726, Sigma Aldrich), 1\% phosphatase inhibitor 3 (P0044, Sigma Aldrich), 0.1\% Triton X100, and 2\% protease inhibitor cocktail (P8340, Sigma Aldrich). Thereafter, the tissue homogenate was cleared by centrifugation at $14,000 \mathrm{x} g$ for ten minutes, followed by determination of the protein concentration in the supernatant (Biorad Protein Assay, Bio-rad, Hercules, CA, USA). Sample aliquots were stored at $-80^{\circ} \mathrm{C}$ until used or were denaturated for three minutes at $95^{\circ} \mathrm{C}$ for immediate 
usage. Gels for SDF PAGE were loaded with equal amounts of protein per lane, followed by a transfer to the Hybond ECL membrane (GE Healthcare Life Science, Piscataway, NJ, USA). After overnight incubation with primary antibodies at $4^{\circ} \mathrm{C}$, proteins were detected with HRP-conjugated anti-mouse or anti-rabbit antibodies (1: 10000, Cell Signaling Technology, Beverly, MA, USA) and the ECL plus chemiluminescent detection system (GE Healthcare Life Science, Pittsburgh, PA, USA).

The following primary antibodies were used: CK1 $\alpha$ (Cell signaling, 1:1000), AKT (Cell signaling, 1:1000), phosphor-AKT (Cell signaling, 1:1000), and GAPDH (Cell signaling, 1:1000). Densitometry analysis was performed using a Typhoon scanner (GE Healthcare Life Science, Pittsburgh, PA, USA).

\section{$\underline{\text { SDF ELISA }}$}

Tissue homogenates of "high" and "low" SDF overexpressing mice were collected before and three weeks after induction of the transgene. Samples were prepared as described above and further handled according to the manufacturer's recommendation (Cat. No. McX120, mouse CXCL12 / SDF-1 $\alpha$ immunoassay, RD systems). Optical density was measured at $450 \mathrm{~nm}$ with a wavelength correction at $570 \mathrm{~nm}$. Results were calculated from a standard curve generated by dilutions of known amount of recombinant SDF protein, as previously described. ${ }^{9}$ Levels of SDF were normalized to total protein and expressed in pg / $100 \mathrm{ug}$ protein (mean $\pm \mathrm{SEM})$.

\section{$\underline{\text { Statistical Analysis }}$}

All data are expressed as mean \pm SEM. Differences were analyzed using unpaired Student's t-test or two-way ANOVA [group effect (i.e. genotype) and time effect (time 
after initiating SDF overexpression)] with Bonferroni's correction for multiple comparisons. The statistical significance was defined as $\mathrm{P}<0.05$ or in case of multiple comparisons adjusted by dividing 0.05 by the number of comparisons. The statistical analyses were performed using PRISM software (Vers. 6.0e for MAC OSX, Graphpad Software, La Jolla, CA, USA).

\section{RESULTS}

Cardiac specific overexpression of SDF decreases leukocytes in the peripheral blood and the BM.

Blood samples from mice overexpressing cardiac SDF for five or 30 weeks, respectively, revealed a reduction in WBCs after five weeks (WT: $9.8 \pm 1.3 \times 10^{3} / \mathrm{ml}$ vs. SDF: $\left.6.2 \pm 0.7 \times 10^{3} / \mathrm{ml}, \mathrm{P}<0.05\right)$ while the number of RBCs and platelets did not change (Figure 4). In contrast, all three lineages of hematopoiesis (i.e. erythropoiesis, lymphopoesis and myelopoiesis) were depressed after long- term overexpression of SDF in the peripheral blood (WBCs, WT: $5.8 \pm 0.7 \times 10^{3} / \mathrm{ml}$ vs. SDF high: $3.9 \pm 0.5 \times 10^{3} / \mathrm{ml}$, $\mathrm{P}=0.08$; RBCs, WT: $8.9 \pm 0.3 \times 10^{3} / \mathrm{ml}$ vs. SDF high: $8 \pm 0.3 \times 10^{3} / \mathrm{ml}, \mathrm{P}<0.05$; platelets, WT: $1147 \pm 62 \times 10^{3} / \mathrm{ml}$ vs. SDF high: $\left.900 \pm 109 \times 10^{3} / \mathrm{ml}, \mathrm{P}=0.05\right)$. Serial experiments with repeated blood collection per mouse confirmed the WBC data. Although the data did not reach statistical significance at a specific time point, the two-way ANOVA indicated significant influence of genotype and time on WBC numbers with a reduction in WBC in the SDF Tg mice. (Figure 5). Interestingly, we did not find any difference in RBC and platelet count in this set of experiments. 

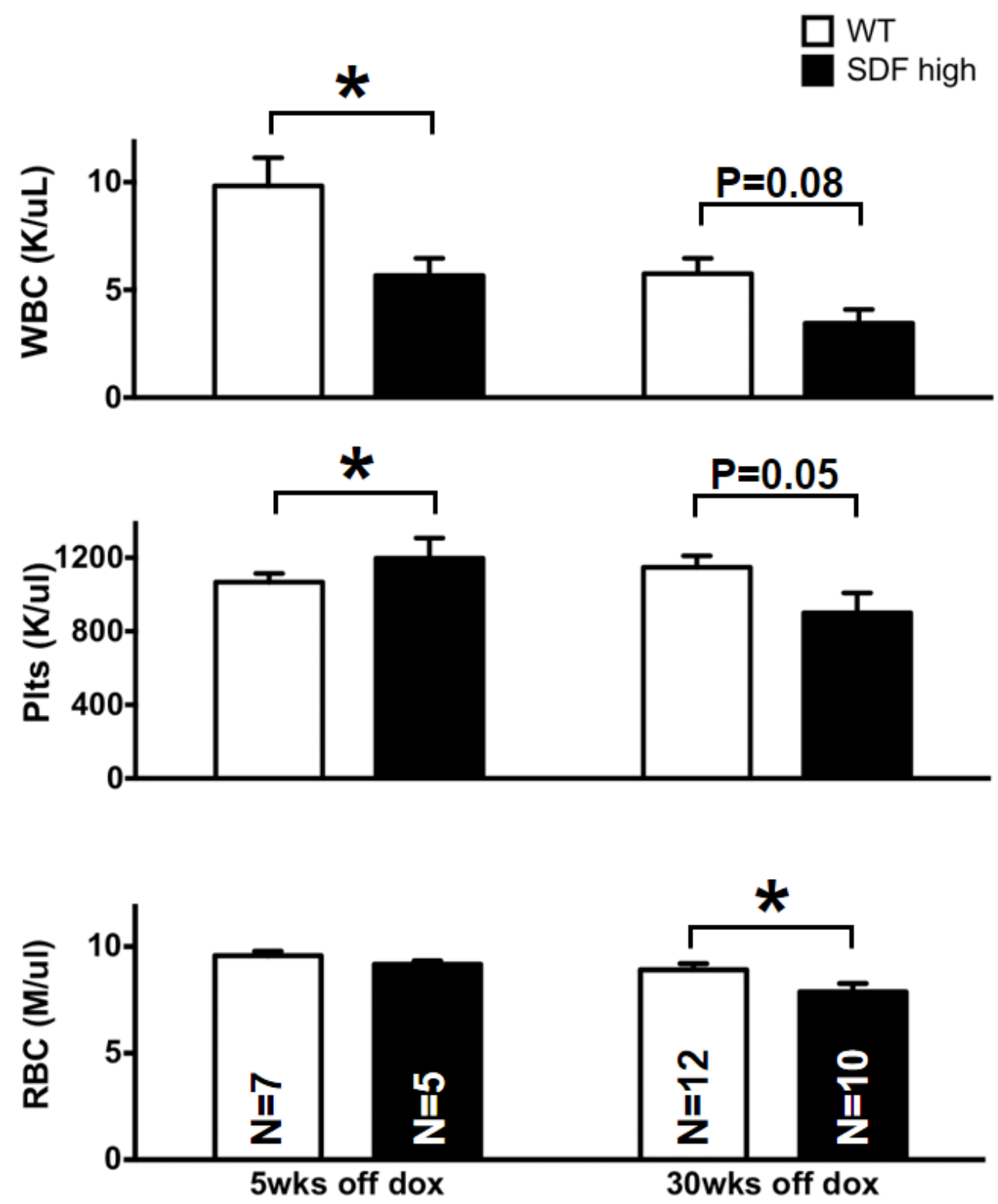

Figure IV WBCs, platelets and RBCs in the peripheral blood after five and 30 weeks of cardiomyocyte-specific SDF overexpression

Barplot represents data from WT $(\mathrm{n}=7)$ and high expressing (SDF high) transgenic mice 5 weeks (left side) and 30 weeks (right side) after initiating transgene expression. SDF overexpression depressed WBCs counts at both time points while the number of RBCs was only diminished in the elderly mice. Interestingly, platelet count was initially higher in the transgenic mouse, but became depressed after 30 weeks of SDF expression. Samples were taken at a single time point. Comparisons are done as unpaired t-test, $* \mathrm{P}<0.05$. 
The changes in hematopoiesis were further investigated, and we measured the number of EPCs in the BM and peripheral blood. SDF overexpression resulted in a trend towards decreased circulating and BM resident EPCs under baseline conditions compared to that in WT mice (Figure 6). The number of EPCs almost doubled in the peripheral blood 72 hours after permanent coronary ligation with no change in numbers in the BM, demonstrating a reversal of impact of MI on mobilization of EPCs. However, based on the limited number of experiments $(n=3)$ we did not reach statistical significance limiting the value of this finding. 

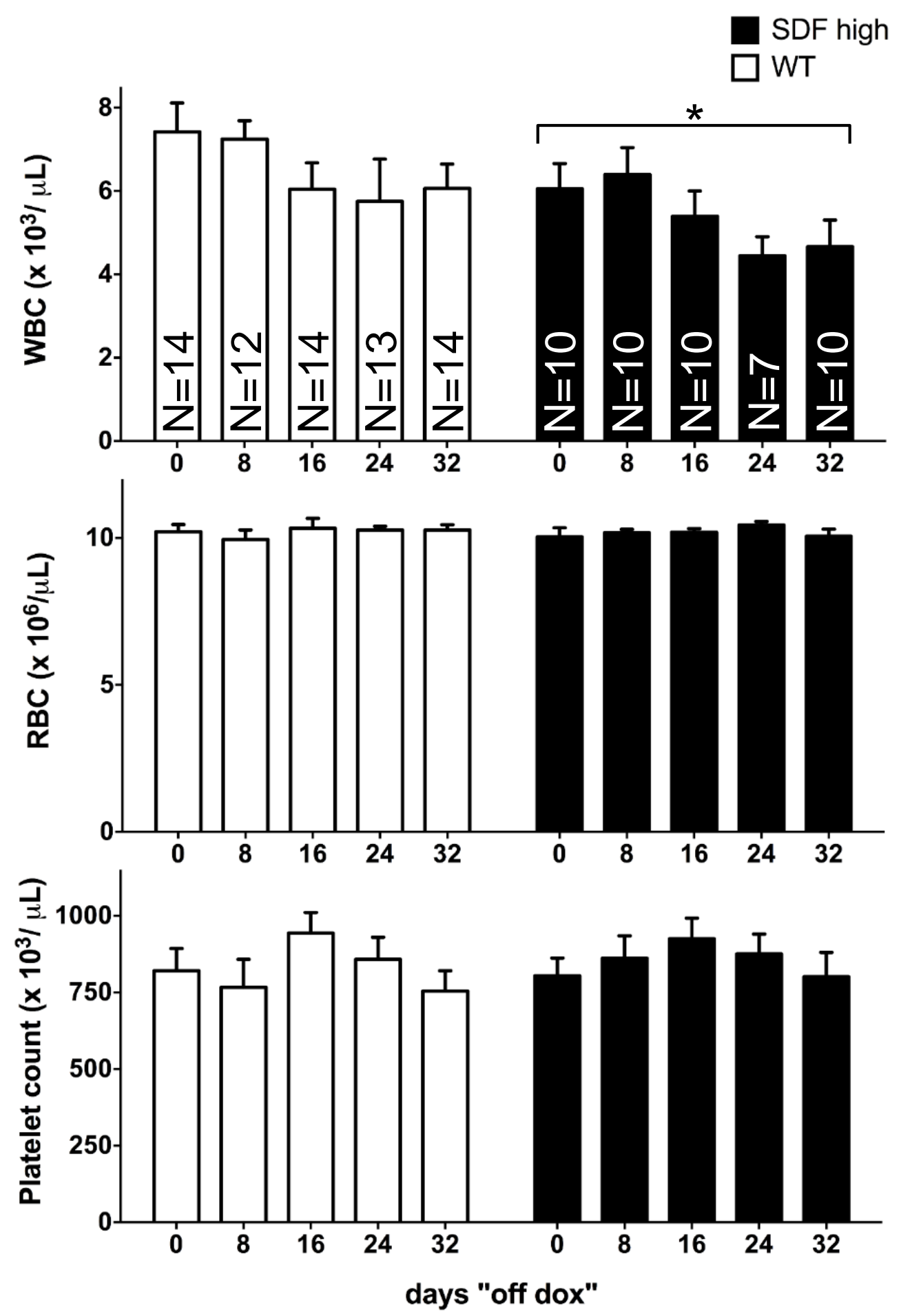

Figure V Time course of hematological changes after initation of SDF expression in WT and SDF high transgenic mice

Doxycycline was removed from the drinking water and blood samples were subsequently collected in WT and SDF high mice. 


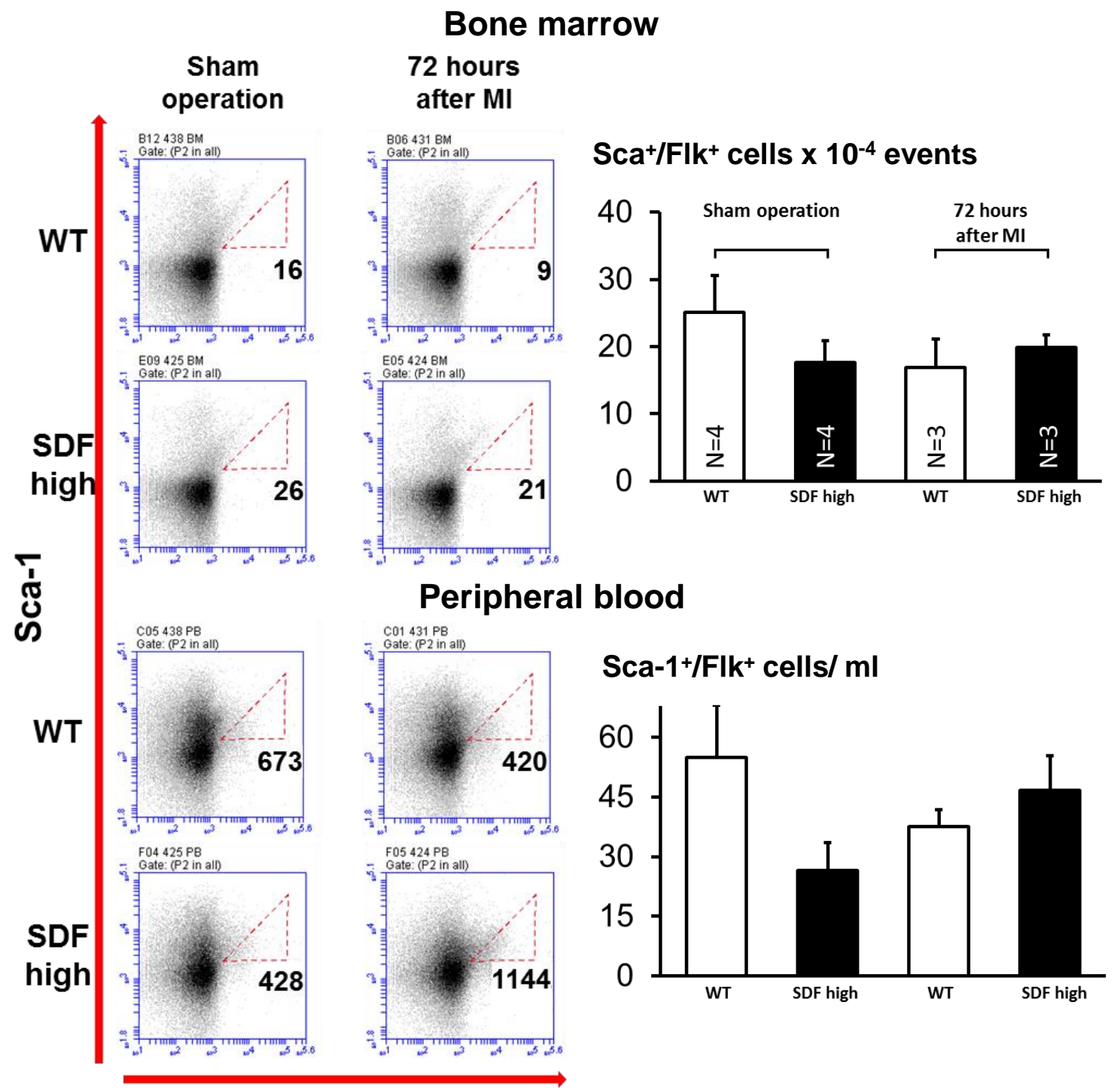

Flk-1

Figure VI Bone marrow resident and circulating EPCs in WT and Tg high mice 14 weeks old mice underwent sham operation or permanent coronary ligation. Blood and BM samples were collected 72 hours later. Samples were stained for Sca-1 and Flk-1 and measured by FACS analysis. 
Cardiomyocyte-specific overexpression of SDF increases gene-copy dependent CK1a expression and AKT phosphorylation in the heart.

We determined the expression of CK1 $\alpha$ in whole heart homogenates and found that CK1 $\alpha$ was gene-copy number dependent increased. (Figure 7 right side). Similarly, total AKT increased parallel to the SDF expression level in the heart, while phosphorylation of AKT did not change. (Figure 7 left side).
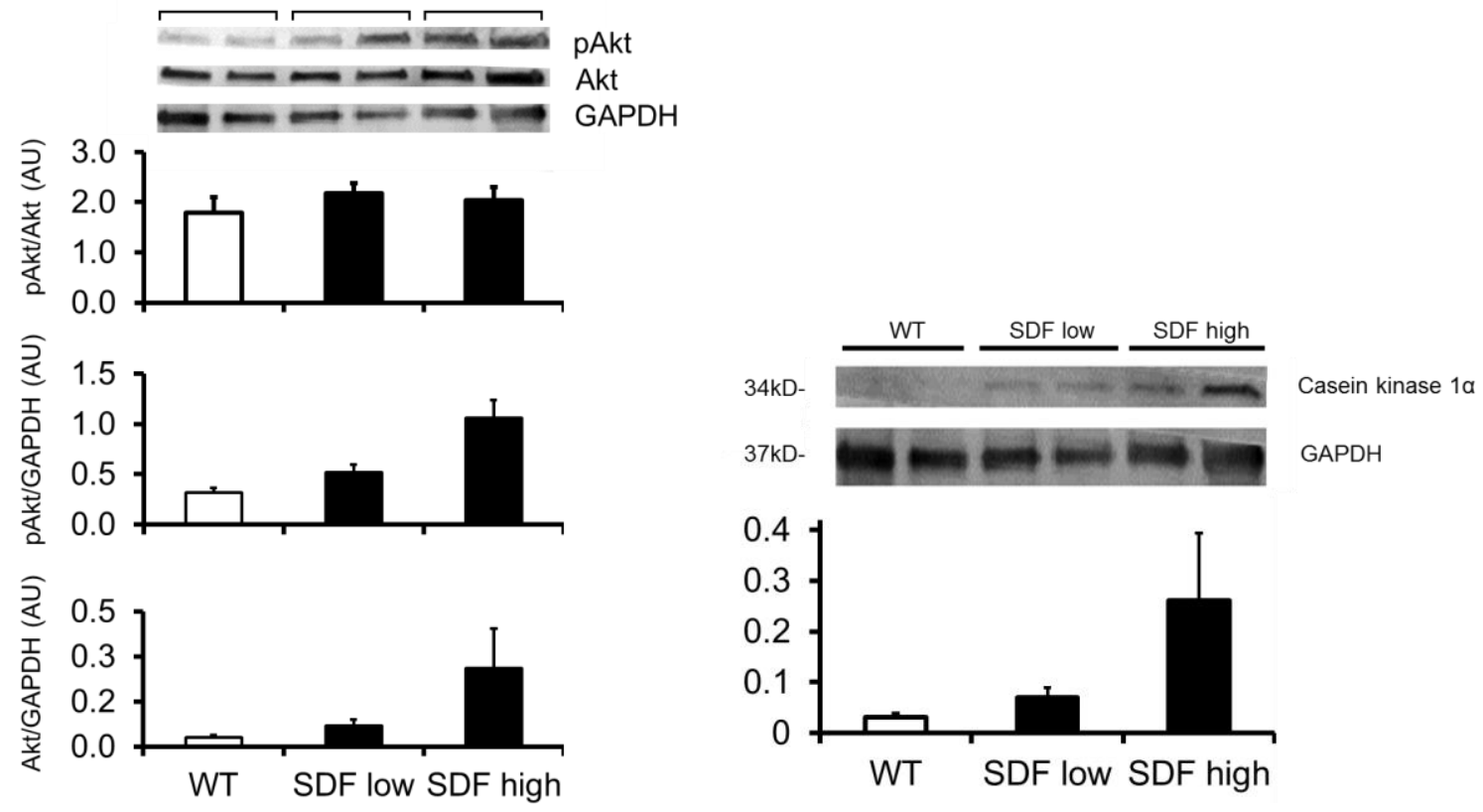

\section{Figure VII Gene-copy dependent protein expression of AKT and CK1a}

SDF overexpression resulted in gene-copy dependent increase in total AKT (left panel) while pAKT was unchanged. SDF overexpression increases CK1 $\alpha$ expression gene-dose dependent. Total heart protein was collected five weeks after initiation of SDF overexpression. The data represent two independent experiments demonstrating similar results. 
Cardiomyocyte-specific overexpression of SDF resulted in an increased number of c-kit ${ }^{+}-$ cells.

Sections of sham-operated WT and SDF high mice were stained for the stem cell factor receptor c-kit. The number of c-kit ${ }^{+}$positive cells in the LV wall was higher in SDF overexpressing mice four weeks after sham operation, while the number of c-kit ${ }^{+} / \mathrm{BrdU}^{+}$ cells was similar to WT mice. Interestingly, the proportion of $\mathrm{c}-\mathrm{kit}^{+}$cells which were $\mathrm{BrdU}^{+}$ was lower in SDF high hearts (one third) than in WT mice (one half). With the current number of experiments, these differences were not statistical significant, but might indicate a decreased proliferation of $\mathrm{c}-\mathrm{kit}^{+}$cells under the influence of SDF overexpression. 

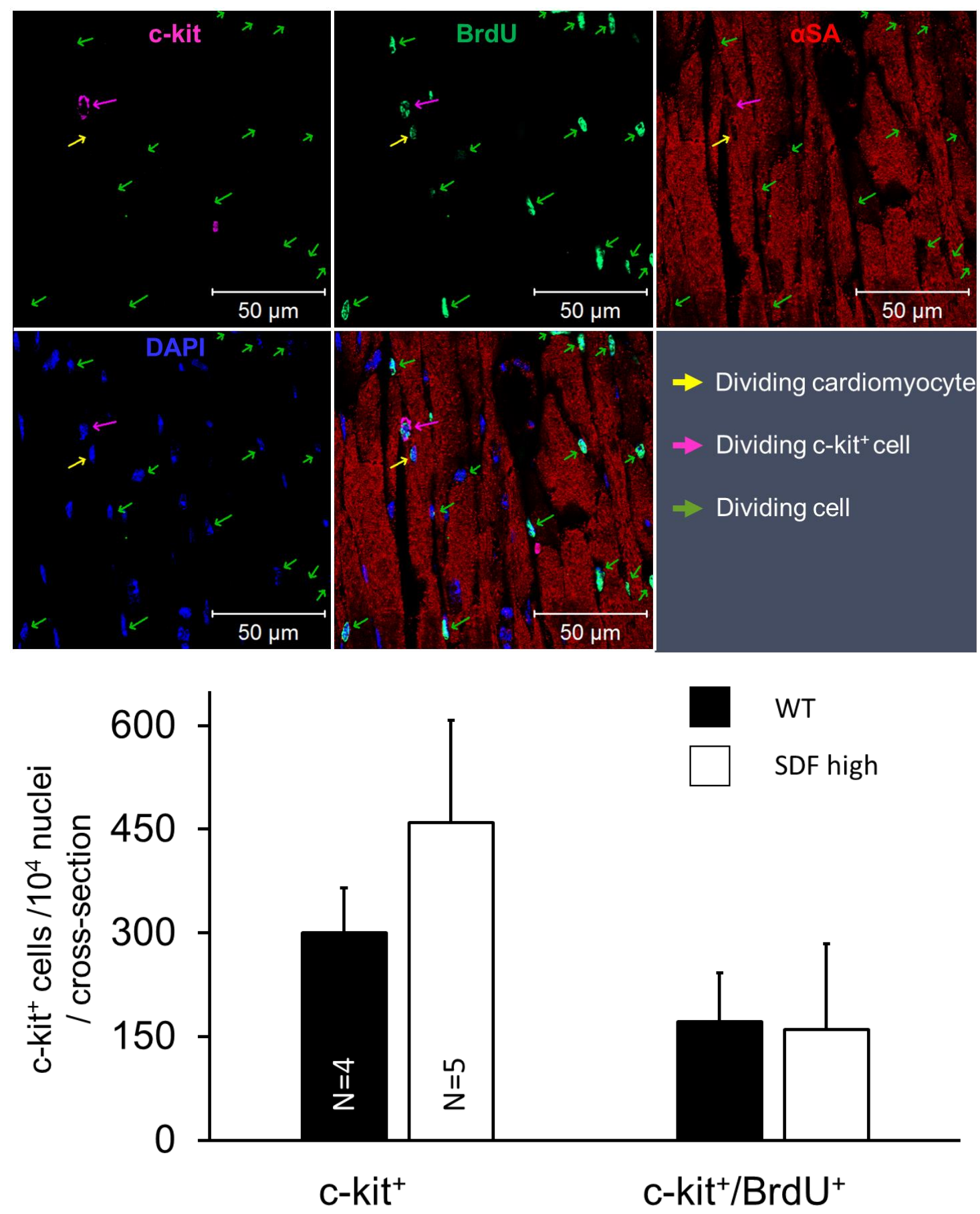

Figure VIII c-kit ${ }^{+}$cell in WT and SDF high expressing transgenic mice

The upper panel presents an example of a c-kit ${ }^{+}$CSPC, while the lower panel presents on the left side the total number of c-kit ${ }^{+}$cells and the right side the number of $\mathrm{BrdU}^{+} / \mathrm{kit}^{+}$ cells. With the current number of experiments, there was no statistical significance between WT and SDF high mice. 


\section{CONCLUSION}

Our data indicate for the first time, that chronic cardiomyocyte-specific SDF overexpression affects $\mathrm{BM}$ derived hematopoiesis as we found a reduction in circulating leukocytes accompanied lower, but not statistical significant, numbers of EPCs both in the peripheral blood and the BM. These results are surprising, considering a relatively short half-life of SDF when released into the peripheral blood. CD26 $6^{61,62}$, and serum proteases ${ }^{63}$ quickly cleave SDF, which is reflected by failure to detect SDF in the serum of "high" level SDF expressing mice (data not shown). In fact, others also failed to detect SDF in the blood plasma $^{64}$ in a model using a RSV-promoter to drive SDF expression in all or most tissues, presumably reaching higher SDF levels than in our model. However, the authors describe an enhanced progenitor cell cycling, resulting in higher absolute numbers of CFU-GM, BFU-E, and CFU-GEMM in the spleen, and to a lesser extent in the BM, where SDF significantly increase GM-CSF-responsive CFU-GM and M-CSF-responsive CFU-M. ${ }^{64}$ These data stand in contrast to our findings as we rather see a decrease in leukocytes.

Our data are limited considering the total number of experiments and animals included taking the variation in WBC numbers into account, even under physiological conditions. The lower number of leukocytes and EPCs in the peripheral blood can be interpreted as a change in homeostatic equilibrium between the BM and the periphery, which would diminish the ability of the BM to participate as cell source in a cardiac regeneration process.

SDF overexpression leads to an increase in $\mathrm{CK} 1 \alpha$. CK1 $\alpha$ has been suggested to be constitutively active, widely expressed and without significant regulation. ${ }^{53}$ Data from our laboratory suggest that the SDF-mediated decrease in CK1 $\alpha$ decreases CSPCs cell 
proliferation. ${ }^{46}$ According to this concept we found less c-kit ${ }^{+}$BrdU ${ }^{+}$cells in SDF high mice compared to WT mice, suggesting a more quiescent status of CSPC.

In combination with the increased phosphorylation of AKT known to provide a powerful survival signal for the heart, we conclude that cardiac overexpression of SDF might provide a cardioprotective phenotype, including an increase pool of non-cycling CSPCs.

The implications of our data are limited based on the small number of experiments and the lack of statistical significance. Therefore, these data should be interpreted with caution until confirmed by additional experiments. 


\title{
CHAPTER 4
}

\begin{abstract}
AIM II - TO DETERMINE WHETHER CASEIN KINASE 1A MEDIATES
CARDIAC STEM / PROGENITOR CELLS AND NEONATAL

CARDIOMYOCYTE PROLIFERATION

BRIEF PREVIEW
\end{abstract}

Background

Although SDF induces quiescence in hematopoietic progenitors and stem cells, ${ }^{65,66}$ SDF has been shown to increase proliferation under specific experimental conditions. In the presence of thrombopoietin, SDF induces megakaryocyte progenitor cells (CFU-MK) proliferation ${ }^{67}$ and in human circulating $\mathrm{CD} 34^{+} / \mathrm{CXCR}^{+}$cells, 48 hour incubation with SDF increased the percentage of cells in $\mathrm{S} / \mathrm{G}_{2} / \mathrm{M}$ phases compared to untreated controls. ${ }^{68}$ The later effect was augmented in the presence of cytokines. ${ }^{68}$ Previous data from our group suggested that SDF facilitates CSPCs quiescence by blocking cell cycle progression at the $\mathrm{G}_{0}$ to $\mathrm{G}_{1}$ transition. ${ }^{46}$ In CSPCs, we showed that SDF decreased the expression of CK1 $1 \alpha$, a protein kinase considered constitutively active in multiple tissues and to this point without any known regulation. The gene dose dependent increase in CK1 expression in the SDF Tg hearts was in contrast to that seen in CSPCs. To determine whether increased CK1 $\alpha$ expression in CSPCs and cardiac myocytes increased proliferation CK1 $\alpha$ was overexpressed and proliferation measured in vitro. 


\section{Methods}

The effect of CK $1 \alpha$ overexpression on un-differentiated and differentiated cells was determined in human CSPCs [kindly provided by Dr. Roberto Bolli, M.D. (Institute of Molecular Cardiology, University of Louisville)] and cultured rat neonatal cardiomyocytes, respectively. Cells were cultured and transfected with pCMV-CK1 $\alpha$. CK1 $\alpha$ protein expression was measured 48 hours later with western analysis. Control treated cells were transfected with the equivalent of pCMV-mCherry. Cell proliferation was determined by measuring BrdU incorporation 48 hours after labeling in BrdU containing medium.

\section{$\underline{\text { Results }}$}

Transfection of human CSPCs and neonatal rat cardiomyocytes with pCMV-CK1 $\alpha$ resulted in increased expression of CK1 $\alpha$ that was dependent on the amount of input vector. Importantly, increased $\mathrm{CK} 1 \alpha$ expression correlated with increased proliferation in both human CSPCs and myocytes, and proliferation increased with increasing $\mathrm{CK} 1 \alpha$ expression.

\section{$\underline{\text { Conclusion }}$}

These experiments indicated that the cell cycle was regulated by CK $1 \alpha$. Previous data suggested that SDF regulates CSPCs cell cycle through down-regulation of CK1 $\alpha$. The current experiments provided evidence that up-regulation of CK1 $\alpha$ caused the reverse effect and accelerated cell proliferation in un-differentiated and differentiated cells. Therefore, our data established CK1 $\alpha$ as an important regulator of cardiomyocyte cell cycle and its up-regulation after myocardial infarction would accelerate cardiac regeneration. 


\section{MATERIAL AND METHODS}

\section{Isolation of human cardiac stem / progenitor cells}

Human cardiac stem cells were isolated during the SCIPIO trial and stored in liquid nitrogen until used. For our experiments cells were thawed, plated, and cultured in supplemented stem cell medium containing (DMEM / F12, LIF, ITS, bFGF, Glutamine) up to 4 passages in T75 flasks. An adequate purity of the cell culture was achieved when

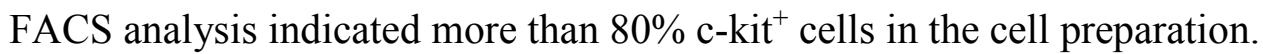

\section{Isolation of neonatal cardiomyocytes}

Neonatal cardiomyocytes were obtained from Sprague-Dawley rats on the day of birth and about 10 pups were used for each cardiomyocyte preparation. After cleaning the rat with $70 \%$ ethanol, a quick decapitation was performed and the thorax was opened with scissors. The hearts were removed and quickly placed in calcium- and bicarbonate-free Hanks with Hepes buffer containing in $\mathrm{mM}\left(138 \mathrm{NaCl}, 5.8 \mathrm{KCl}, 0.8 \mathrm{Mg}, 0.8 \mathrm{PO}_{4}, 5.5\right.$ Dextrose, 20.06 HEPES, pH 7.4) and heparin $(0.15 \mathrm{ml})$ for subsequent dissection. After incubation in trypsin and DNAse for 20 minutes, the tissue was slowly further dissected towards a single cell suspension. Cells were then transferred to MEM Eagles with Hanks containing penicillin, B12 and 5\% calf serum medium, filtered through a cell strainer, and pre-plated for 30 minutes at $37^{\circ} \mathrm{C}$ to remove non-myocytes. Cells from the supernatant were then plated in 96 well plates in MEM Eagles with Hanks containing B12, 5\% calf serum and $\operatorname{BrdU}(0.1 \mathrm{mM})$ for 48 hours. 
Transfection of neonatal cardiomyocytes and human CSPCs with CKI containing plasmid

Human CSPCs and neonatal cardiomyocytes $\left(2 \times 10^{4}\right.$ cells / well) were transferred to 96 well plates and transfected using a cationic liposome formulation (Lipofectamine 2000 with plus reagent, Invitrogen / LifeTechnologies, Grand Island, NY, USA) and 0.5 $\mu \mathrm{L}$ lipofectamine LTX reagent to transfect cells with different plasmid DNA concentrations (i.e $0.25,0.5,0.75,1.0,1.5$, and $2.0 \mu \mathrm{g} / \mu \mathrm{l})$. CK1 $\alpha$ protein expression was measured after 48 hours by western blot analysis.

\section{Measurement of cell proliferation}

The cell proliferation was measured using a commercially available BrdU detection kit (Calbiochem, QIA 58). The transfected cells were cultured in BrdU (1:2000) containing opti-Mem medium for 48 hours, and the extent of BrdU incorporation was reflected by the intensity of the absorbance in a final staining reaction: After 48 hours the cells were fixed and the DNA denaturated. After adding anti-BrdU antibody (1:100), the cells were incubated for one hour at room temperature. After a subsequent washing step a secondary HRP-conjugated antibody was added and incubated for 30 minutes at room temperature. The plates were washed again and $200 \mu \mathrm{L}$ of substrate added to each well. After a 15 minute incubation in the dark stop solution was added. The supernatant of each well was transferred to a different 96 well plate, and the absorbance measured by platereader (Synergy 4, Biotek, Winooski, VT, USA) at dual wavelengths (450 nm and $595 \mathrm{~nm}$ ). 


\section{RESULTS}

\section{CKla induces proliferation of human CSPCS}

After 48 hours of incubation, western blot analysis revealed a concentration dependent increase in CK1 $\alpha$ expression in transfected CSPCs. CK1 $\alpha$ also increased concentration dependent BrdU incorporation indicating accelerated proliferation after administration of CK1 $\alpha$ (Figure 9A).

\section{CKla induces neonatal cardiomyocyte proliferation}

The western blot analysis of protein samples from neonatal cardiomyocytes harvested 48 hours after transfection revealed a similar increase (data not shown) as seen in CSPCs. Furthermore, we detected a concentration dependent augmentation of BrdU incorporation, suggesting increasing proliferation with increasing CK1 $\alpha$ expression (Figure 9B). 

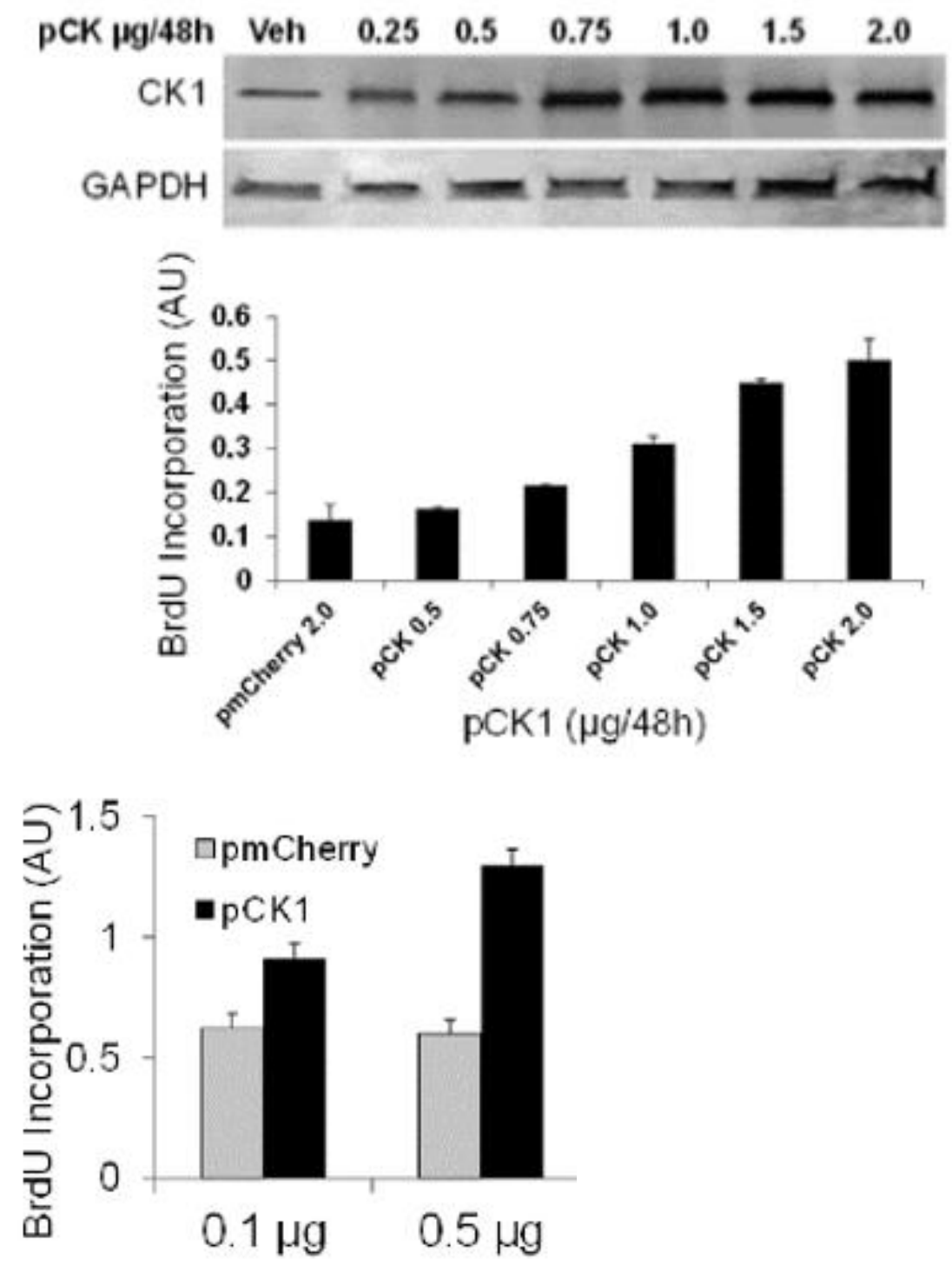

Figure IX Proliferation of human CSPC and neonatal rat cardiomyocytes after transfection with CMV-CK1 $\alpha$ vector

9A: Proliferation of human CSPCs and 9B, proliferation of rat neonatal cardiomyocytes. Each panel reflects the average of two experiments.

\section{CONCLUSION}

The cellular function of $\mathrm{CK} 1 \alpha$ is not well understood. Here we provide evidence that $\mathrm{CK} 1 \alpha$ facilitates concentration dependent cell proliferation in human CSPCs and in 
neonatal cardiomyocytes. These data confirmed our previous finding ${ }^{46}$ and suggested CK1 $\alpha$ as a novel regulator of cell cycle in the CSPCs and cardiomyocytes.

The presented data reflect the results of two independent experiments in two different kind of tissues (human CSPCs and rat neonatal cardiomyocytes) suggesting the same effect of CK1 $1 \alpha$. Despite the lack of statistical significance caused by the limited number of experiments we feel confident that CK $1 \alpha$ is a novel regulator of cell cycle in cardiomyocytes and CSPCs. 


\title{
CHAPTER 5
}

\section{AIM III - TO DETERMINE WHETHER CARDIOMYOCYTE-SPECIFIC OVEREXPRESSION OF STROMAL CELL-DERIVED FACTOR 1}

\author{
ACCELERATES MYOCARDIAL REGENERATION AFTER
}

\section{PERMANENT CORONARY LIGATION}

\section{BRIEF PREVIEW}

\section{Background}

In addition to other investigators, our group has previously shown that SDF, given before myocardial ischemia / reperfusion, protected the heart in a preconditioning-like manner $^{9}$ and that blockade of CXCR4 by AMD3100 accelerated myocardial injury. ${ }^{10}$ Several previous studies have shown that increasing SDF in the heart by either preventing protease mediated cleavage ${ }^{43,69}$ or increasing SDF concentration through transplantation transfected fibroblasts ${ }^{12}$ or SDF overexpressing mesenchymal stem cells ${ }^{13}$ improves myocardial function. Whether SDF facilitated myocardial regeneration was not assessed in any of these models.

\section{Methods}

The regeneration potential in SDF and WT mice was evaluated at different time points after permanent coronary ligation. The earliest infarct size measurement was 
performed three days after permanent coronary ligation to ensure an equivalent degree of injury between the mouse strains. At this early time point, we stained hearts with triphenyltetrazolium chloride (TTC) to determine the infarct size. Subsequently, we sacrificed mice after seven and 30 days to assess the LV remodeling process. At these time points, Masson's trichrome staining was utilized for infarct size assessment. During the recovery period, mice received 5-bromo-2 deoxycytidine $(\mathrm{BrdC})$ allowing us to determine the amount of proliferation within the myocardium through detection of incorporated BrdU derived from BrdC. These data were verified by Ki67 staining, a marker of cell mitosis, reflecting the amount of cells undergoing cell division at the point of sacrifice. In addition to the regenerative aspect of remodeling, we determined the apoptosis rate by deoxynucleotidyl-transferase-mediated dUTP nick end-labeling (TUNEL) staining. Furthermore, we determined the capillary density in the border zone and the remote area as indicators of neovascularization. Staining for the stem cell factor receptor c-kit determined the number of CSPCs.

To verify the long-term effect of SDF overexpression on cardiac remodeling, elderly mice underwent the same permanent ligation / 30 days recovery protocol.

All morphological analyses were supported by echocardiographic determination of LV function. The assessments were performed before and during the recovery period after two, 14, and 30 days, respectively. Regional myocardial function was measured with the help of speckle-tracking strain analysis. 
$\underline{\text { Results }}$

Permanent coronary ligation resulted in an equivalent injury in WT and SDF overexpressing mice. However, the outcome of cardiomyocyte-specific SDF overexpression was a reduction in infarct size and improved LV ejection fraction four weeks after myocardial infarction. This protection sustained when SDF was overexpressed for a period of at least 30 weeks (elderly mice). SDF overexpression markedly accelerated myocardial remodeling indicated by increased numbers of $\mathrm{BrdU}^{+}$cardiomyocytes in the border- and scar area of the LV and an augmented apoptosis rate. Interestingly, we did not detect any capillary density difference in WT and SDF Tg mice after sham operation or permanent coronary ligation.

\section{$\underline{\text { Conclusion }}$}

Our data indicated that cardiomyocyte-specific overexpression of SDF facilitates myocardial regeneration after permanent coronary ligation. Surprisingly, this effect was not related to an increase in vascularization but rather to a direct effect on cardiomyocyte proliferation. The number of new cardiomyocytes appears to be too small to explain the improvement in LV function detected by echocardiography; therefore, it is likely that other paracrine effects of SDF contributed to the increase in ejection fraction.

\section{MATERIAL AND METHODS}

\section{Experimental protocol}

To investigate the early and late effect of chronic SDF overexpression on myocardial regeneration we performed two sets of permanent ligation experiments, 
gathering hearts for pathology evaluation after one and four weeks, respectively (as described below, Figure 10).

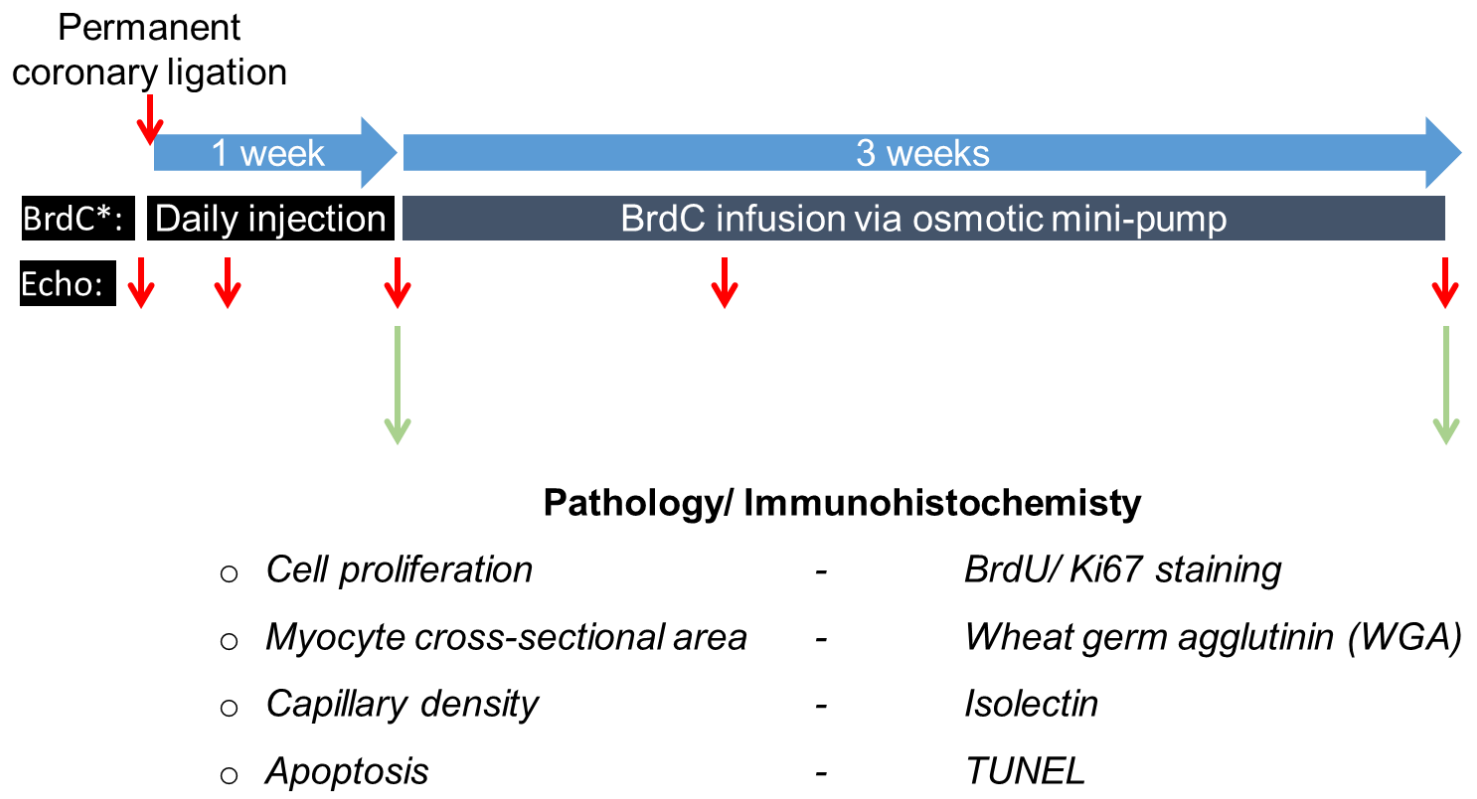

Figure X Experimental protocol of permanent coronary ligation experiments

C57 / B6 WT, SDF low, and SDF high mice (12 weeks old / four weeks off dox) were used to perform the permanent ligation experiments. Mice were followed for either one or four weeks after permanent coronary ligation prior to pathological examination. BrdC, 5Bromodeoxycytidine was used as DNA labeling agent, which is deaminated prior to incorporation into DNA as BrdU, because its greater solubility in PBS and a slower rate of metabolism in rats and mice resulting in larger intracellular supply. Echo, Echocardiography performed before ligation, at day 2, 7, 14, and 30, respectively.

WT and "high" expressing SDF (SDF high) Tg mice were monitored during both periods, while experiments in "low" expressing SDF Tg mice (SDF low) were only performed with a four-week recovery period. To confirm whether the duration of SDF overexpression will affect the size of injury, we performed an additional set of experiments in SDF high mice for more than 30 weeks (i.e. mice of 45-50 weeks of age). 
Assessment of myocardial injury after permanent ligation

\section{TRIPHENYLTETRAZOLIUM-CHLORIDE- (TTC) STAINING}

Triphenyltetrazolium staining was used to identify viable and dead myocardium. The staining principle is based on the presence of membrane bound diaphorases that use NADH (NADPH) as electron donor to reduce tetrazolium chloride to a red formazan pigment, allowing the distinction between viable and dead tissue. ${ }^{70}$ We assessed the initial injury 72 hours after permanent coronary ligation: Mice were anesthetized with pentobarbital ( $0.4 \mathrm{mg}$ i.p.), the chest was opened and hearts were arrested in diastole by injection of $0.1 \mathrm{ml} \mathrm{Cd}-\mathrm{KCl}(0.1 \mathrm{M} \mathrm{Cd}, 3 \mathrm{M} \mathrm{KCl})$ into the $\mathrm{LV}$ cavity. The heart was removed and the aorta was cannulated with a 14-gauge blunted needle and perfused retrograde using the Langendorff method to remove intracoronary blood. The coronary bed was perfused with heparin (100 IU) containing Krebs-Henseleit buffer at a constant rate (1 $\mathrm{ml} /$ minute) for ten minutes. Thereafter, the perfusion solution was changed to 10\% Evans blue (E2129, Sigma Aldrich, St. Louis, MO, USA) solution to stain the remote area. After infusing one to two milliliters at a constant rate $(0.5 \mathrm{ml} /$ minute $)$, excessive blue stain was removed by washing the hearts in PBS. Subsequently, hearts were transferred to a heart slicer and cut into one millimeter cross-sections. The staining was finalized by incubating the sections in $1 \%$ triphenyltetrazolium solution for 15 minutes at $37^{\circ} \mathrm{C}$, demarking viable myocardium (red) from damaged myocardium (pale, unstained). To intensify the staining results, tissue sections were fixed in $4 \%$ paraformaldehyde for 20 minutes. The staining results were digitalized by a camera mounted on a surgical microscope. The infarct size was then measured by planimetry, taking both sides of each slice into account, and expressed as percentage of dry LV weight. 


\section{TRICHROME STAINING}

The sections were de-paraffinized and rehydrated to distilled water using a standard graded xylene-ethanol series before staining. The infarct size was measured after Masson's trichrome (HT15-1KT, Sigma Aldrich, St. Louis, MO, USA) staining, based on the interaction of ionized acid dyes reacting with ionized basic tissue and distinguishing collagen, scar, and muscle fibers. After an overnight incubation of the tissue sections in Bouin's solution to intensify the final coloration, the nuclei were stained with Weigert's iron hematoxylin, and the cytoplasm and the muscle with Bierbrich scarlet-acid fuchsin solution (Sigma Aldrich, HT15-1). A subsequent treatment with phosphotugstic (Sigma Aldrich, HT15-2) and phosphomolybdic acid (Sigma Aldrich, HT15-3) removed the plasma stain (Bierbrich scarlet-acid fuchsin) from collagen, which then appeared paler than the muscle stain. Then an aniline blue solution, which has a molecular weight between the plasma stain and the poly-acids, was applied to mark collagen. After 15 minutes of incubation, collagen stained blue without affecting the plasma stain. Subsequently, the sections were rinsed in acetic acid, rendering the shades of color more delicate and transparent. ${ }^{71}$ Photos of the stained sections were digitally acquired on an inverted microscope equipped with a digital camera. The LV planimetry was performed using publicly available software (NIH Image J, 1.48s ver.) and the LV area, risk region, remote region, border zone, LV cavity area, and infarct zone were determined as previously described. ${ }^{3}$ To quantify the degree of LV dilatation and the degree of infarct wall thinning, the LV expansion index was calculated using a modification of the method of Hochman and Choo: ${ }^{72}$ 


$$
\text { Expansion index }=\frac{\mathrm{LV} \text { cavity }}{\text { Total area }} \times \frac{\text { Non }- \text { infarcted region wall thickness }}{\text { Risk region wall thickness }}
$$

\section{Equation $1 \quad L V$ expansion index}

\section{Measurement of cardiac regeneration by chronic administration of BrdC}

To measure the cardiac regeneration 5-bromo-2 deoxycytidine (BrdC, MP Biomedicals, Solon, OH, USA) was injected i.p. daily for seven days, and afterwards continuously infused until the end of the experiment. BrdC is rapidly deaminated prior to incorporation into DNA as 5-bromo-2'-deoxyuridine ( $\mathrm{BrdU})$, a thymidine analogue frequently used to detect proliferation of cells that can be passed to daughter cells upon replication. ${ }^{73}$ The physical properties of BrdC (higher solubility in PBS and its slower metabolism in mice) made it more suitable for intracellular BrdU supply for DNA labeling in our experiments. During the first seven days after coronary ligation, BrdC (2 ug / g / h i.p.) was injected daily. After surviving the initial recovery phase, the mice were reanesthetized and an osmotic minipump (Alzet type 2004, Alzet, Cupertino, CA, USA) was implanted subcutaneously between the scapulae to deliver $\operatorname{BrdC}(0.7 \mathrm{ug} / \mathrm{g} / \mathrm{h})$ until the end of the experiment. ${ }^{74}$ Incorporated BrdU was determined by immunohistochemistry methods (see below).

BrdU incorporation as an indicator of cell proliferation has been criticized because cells undergoing DNA repair might also incorporate BrdU into their DNA.${ }^{75}$ However, the level of BrdU incorporation with DNA damage is orders of magnitude less than that during DNA synthesis and replication. ${ }^{76}$ The final number of BrdU positive cells reflected the entire amount of cells undergoing DNA repair and / or cell division. To provide additional support for DNA synthesis and cell division sections were also stained for Ki67 (VP-RM- 
4, Vector labs, Burlingame, CA, USA): The nuclear antigen Ki67 is expressed in all phases of the cell cycle except for $\mathrm{G}_{0}{ }^{77} \mathrm{Ki} 67$ is not involved in DNA repair ${ }^{78}$ and therefore a specific marker for cells undergoing mitosis as mainly apparent in the late $\mathrm{S}$ phase and increased in $\mathrm{G}_{2}$ until pro- and metaphase. Measuring Ki67 positive cells in our samples allowed us to determine the number of dividing cells at the time of sacrifice.

\section{Detection of Apoptosis}

Heart failure as a consequence of myocardial infarction is characterized by progressive cell loss. ${ }^{79}$ Previous data suggest that SDF might abolish programmed cell death. ${ }^{80}$ Therefore, TUNEL staining was used to identify double-stranded DNA fragmentation within the scar, border, and remote zone after myocardial infarction.

\section{Echocardiography}

Echocardiographic studies were performed before the ligation experiment (baseline) and 72 hours, 14 days, and 30 days after the infarct to assess the initial injury and the progression to heart failure (14 days and 30 days, respectively) using a VEVO2100 echocardiography system (FUJIFILM VisualSonics, Toronto, Ontario, Canada) equipped with a MS400 (18-38 MHz) cardiovascular ultra-high frequency linear-array transducer probe. To ensure good quality images for speckle-tracking based strain analyses, all images were acquired at a rate of more than 200 frames / second, providing an optimal temporal resolution and minimizing artifacts. The mice were anesthetized with isoflurane (2-3 Vol.\%) and the anterior chest was shaved. The mice were placed on a heated pad in the supine position and the body temperature was measured by a rectal probe to maintain $37^{\circ} \mathrm{C}$. Throughout the study, the anesthesia depth was adjusted with isoflurane ( $1 \mathrm{Vol} \%)$ to 
achieve a heart rate between $450-500 \mathrm{bpm}$. Animals with a heart rate out of the target range were excluded from the analysis. Standard parasternal long- and short-axis views were performed to obtain two-dimensional, M-mode, and speckle-tracking analysis images. ${ }^{81}$ An average of five cardiac cycles was used for each analysis.

\section{$\underline{\text { Strain analysis }}$}

The strain is a dimensionless variable reflecting the deformation of the heart in circumferential, radial, and longitudinal dimension. As an angle-independent method the quantification is less operator dependent. The method is based on the estimation of velocity vectors by tracking segmental tissue motions in multiple planes and axes serially over the cardiac cycle, providing detailed information about global and regional LV function. Thereby, a negative strain reflects shortening (or thinning) while a positive strain reflects elongation (or thickening) of a LV wall segment. Based on the anatomic orientation of LV fibers the systolic radial strain results in positive values under physiological conditions, whereas the systolic longitudinal strain results in negative values. In addition, the temporal derivative of the strain (i.e. the strain rate) reflects the rate of deformation similar to the shortening velocity per fiber length. ${ }^{82}$

$$
\varepsilon=\frac{\Delta l}{l} \approx \frac{v(r)-v(\Delta \mathrm{r}+\mathrm{r})}{\Delta r} \Delta \mathrm{t}=\mathrm{SR} \Delta \mathrm{t}
$$

\section{Equation 2 LV strain rate}

The strain rate was measured in six different areas of the LV wall: The posterior and anterior wall were divided into a basal, middle, and apical segments. For each segment the radial and longitudinal strain rate was measured, allowing us to determine precise areas of increased or decreased contractility. 
The LV mass $=1.05 \times\left([\text { anterior wall thickness }+ \text { LVEDD + posterior wall thickness }]^{3}-\right.$ LVEDD $^{3}$ ) was calculated by M-mode cubic method where the specific gravity of cardiac muscle is $1.05 \mathrm{~g} / \mathrm{L} .{ }^{83}$

\section{Definition of border, remote zone, and scar area}

Three different areas of each cross section were evaluated: The border zone was defined as an area reaching one millimeter from the end of the scar towards "healthy tissue" in one direction and "scar tissue" in the opposite one. The remote zone represents the area of the none-infarcted ventricular wall between the border zones. The scar area is defined as the fibrotic area between the edges of the border zone (Figure 11).

\section{Immunuofluorescent staining}

As previously described, the sections were prepared except for the following modifications: The antigen retrieval was modified dependent on the target: For staining of c-kit and surface markers like CD45 we used a basic EDTA buffer (pH 8.0), as this buffer is suitable for detection of rare and sensitive antigens. In all other cases, we used citrate buffer (sodium citrate buffer, citrate buffer, $\mathrm{pH}$ 6.0). Staining for c-kit ${ }^{+}$CSPCs and BrdU was performed as described above. Cardiomyocyte cross section area was determined after staining with a FITC-labeled wheat germ agglutinin antibody (WGA, Molecular Probes, Eugene, OR, USA). To quantify cardiomyocyte size, images were captured with a $40 \mathrm{X}$ objective and only myocytes captured in cross-sections were used for measurement. 


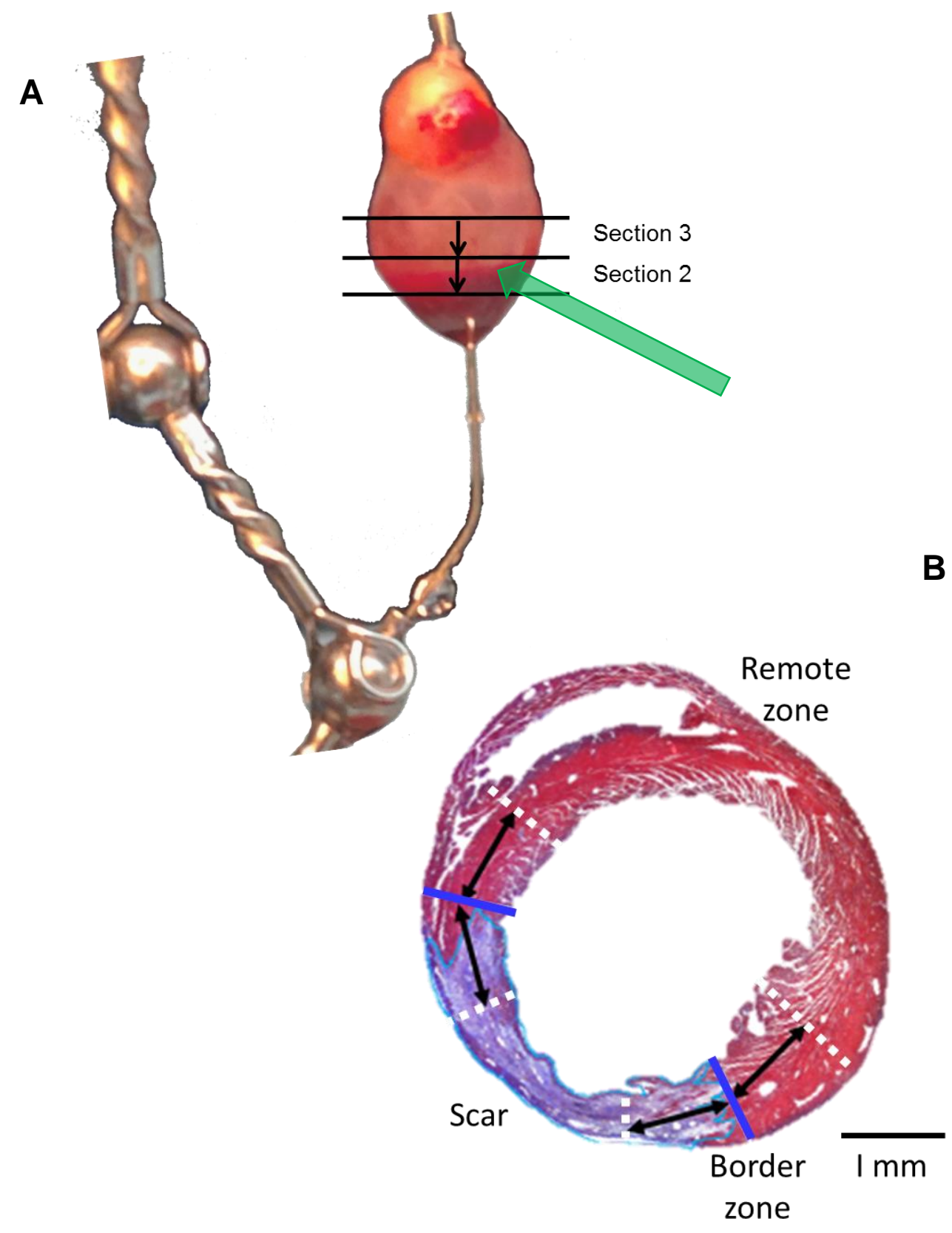

Figure XI Example of ligated WT heart and cardiac-cross section

A: Heart of a WT mouse four weeks after permanent ligation mounted on a perfusion cannula. The green arrow indicates the level of remaining blood visible through the thin, infarcted anterior wall. Black bars indicate sectional area of four total sections of which section two and three were used for analysis. B: Typical cross section after trichrome staining. The blue marked area reflects the scar region. The area including the scar between the two blue bars marked the area at risk. The area between the which dotted lines was considered as border zone. 
Myocytes with nuclei of round morphology were selected to ensure those with true cross sectional orientation were included and those at oblique angles which would skew data were excluded. The capillary density in the border and remote zone was determined after staining with the endothelium-specific, FITC conjugated isolectin B4 antibody (FL1201, Vector labs, Burlingame, CA, USA). The number of apoptotic nuclei was detected after TUNEL staining (DeadEnd TUNEL Fluorometric System, Promega, Madison, MI, USA). Cardiomyocytes were counterstained with $\alpha$-sarcomeric actin (Sigma, St. Louis, MO, USA).

\section{$\underline{\text { Statistical analysis }}$}

All data were expressed as mean \pm SEM and the differences were analyzed using unpaired Student's t-test or a two-way ANOVA [group effect (i.e. genotype) and time effect (time after initiating SDF overexpression)], facilitating Bonferroni's correction for

multiple comparisons. The statistical significance was defined as $\mathrm{P}<0.05$ or in cases of multiple comparisons adjusted by dividing 0.05 by the number of comparisons. The statistical analyses were performed using PRISM (Vers. 6.0e for MAC OSX, Graphpad Software, La Jolla, CA, USA). The immunopathology assessment was performed in one to two LV cross sections by confocal microscopy. The data represented in the analysis reflecting results of five to 15 images taken at $63 \mathrm{X}$ magnification for each area as described above. Per treatment group, the number of animals included in each staining step reached seven to 18 mice. 


\section{RESULTS}

\section{Exclusions}

From the pool of mice undergoing ligation or sham operation, $18 \%$ died before the proposed end of the experiment and 13\% were excluded due to technical problems (i.e. missed ligation, anesthesia complications) resulting in an overall survival rate of $69 \%$.

\section{Reduction of myocardial injury}

Following the American Heart Association's ${ }^{84}$ expert committee guidelines we measured the infarct 72 hours after permanent coronary ligation to ensure that the initial injury was consistent between the mouse strains (Figure 12). The LV weight of SDF high was significantly smaller compared to WT mice; nevertheless, we did not detect a difference in infarct size (WT: $36 \pm 3 \%$ vs. SDF high: $42 \pm 2 \%$ of the area at risk, $\mathrm{P}>0.05$ ), suggesting that the initial injury was equivalent between both groups. Re-evaluation of the infarct size after one week revealed the same result [i.e. no difference in infarct size between WT (59 $\pm 7 \%)$ and SDF high: $53 \pm 5 \%$ of the area at risk, $\mathrm{P}>0.05)]$ while the risk area was similar (WT: $49 \pm 8 \%$ vs. SDF high: $55 \pm 1 \%$ of the LV, Figure 13). In contrast, four weeks after permanent ligation the infarct size (percentage of LV) was significantly reduced in SDF high $(13 \pm 2 \%)$ compared to WT $(23 \pm 3 \%), \mathrm{P}<0.01)$ and SDF low mice $(23 \pm 5 \%, \mathrm{P}<0.05)$, respectively. Despite the presence of the same scar size the infarct expansion index was almost significantly reduced in SDF low (1.7 \pm 0.2$)$ compared to WT (2.4 $\pm 0.4, \mathrm{P}=0.07$ ), reflecting an increased anterior (SDF low: $1.1 \pm 0.1 \mathrm{~mm}$ vs. WT: $0.8 \pm 0.1$ $\mathrm{mm}, \mathrm{P}<0.05$ ). Similar results were obtained in elderly mice overexpressing SDF for more 
than 30 weeks: The infarct size was reduced from $24 \pm 4 \%$ (WT, $n=5$ ) to $8 \pm 2 \%$ of the LV (SDF high, $\mathrm{n}=5, \mathrm{p}<0.01$, Figure 14).
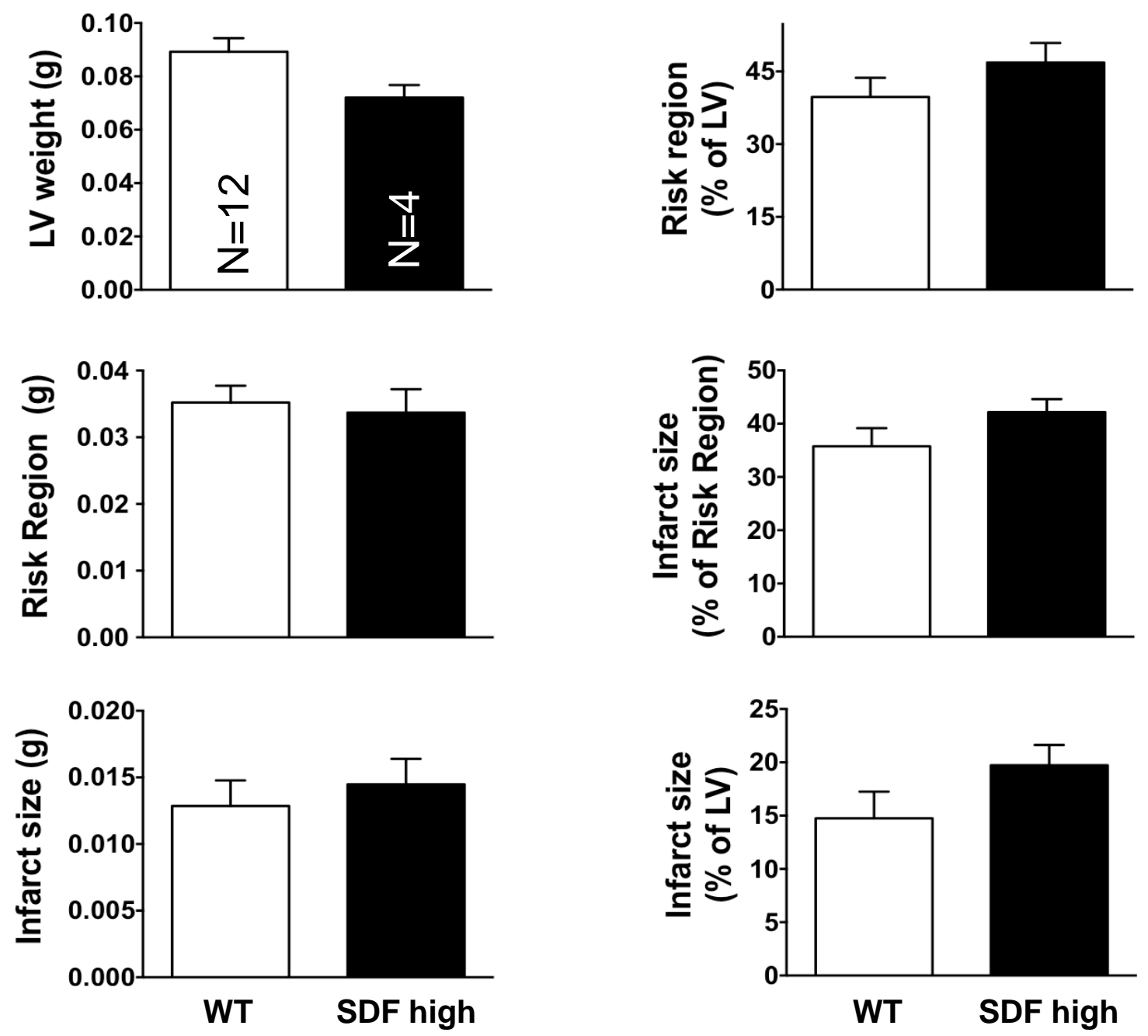

Figure XII Morphometry in WT and SDF high 72 hours after permanent ligation 
A

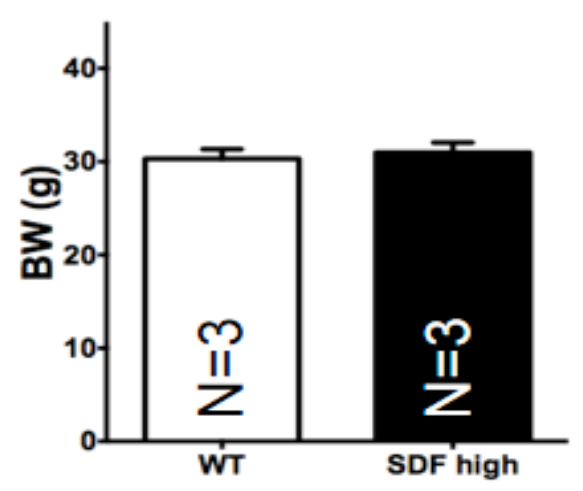

C

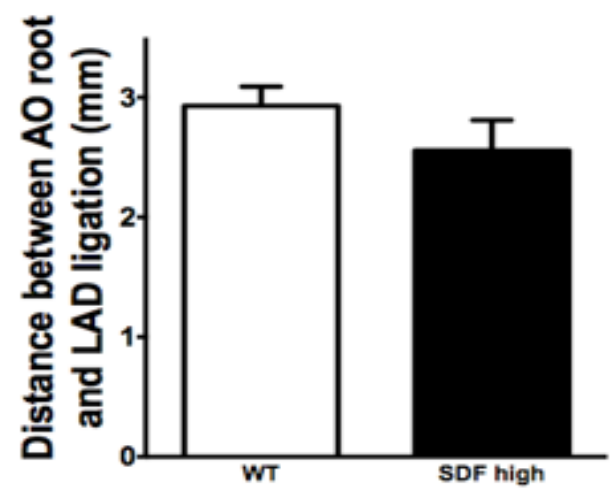

E

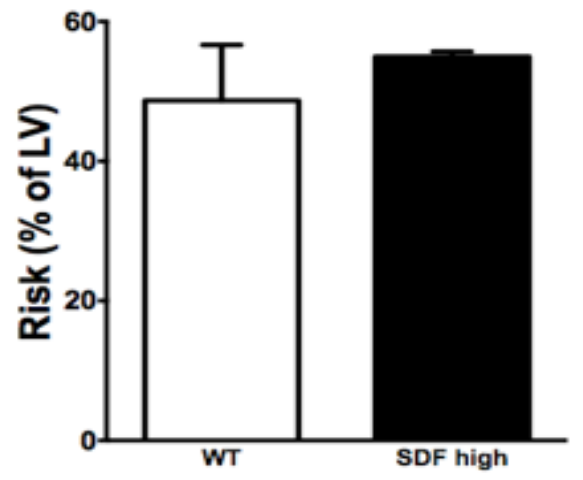

G

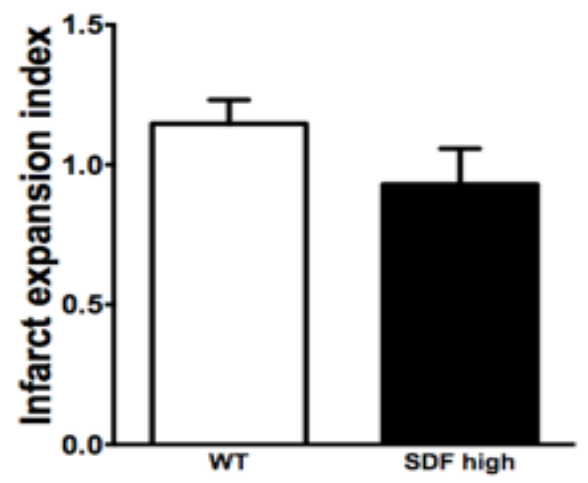

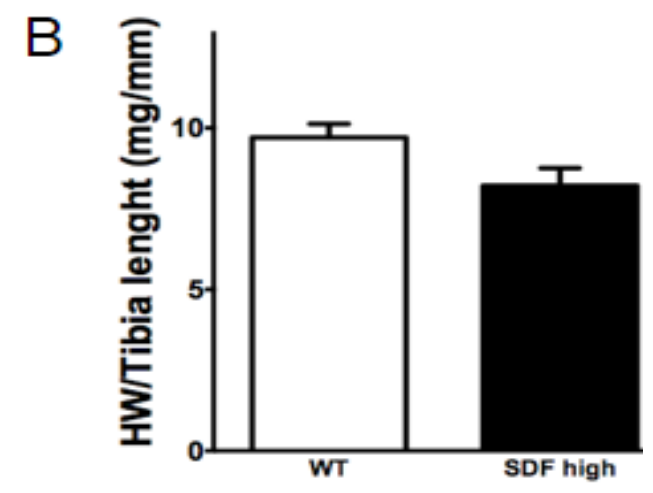

D
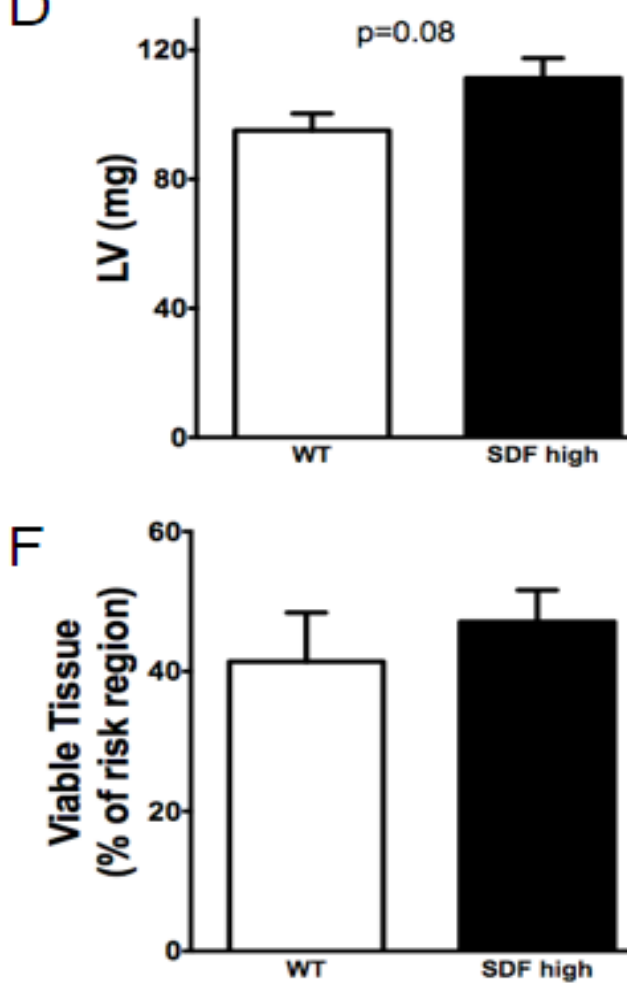

$\mathrm{H}$

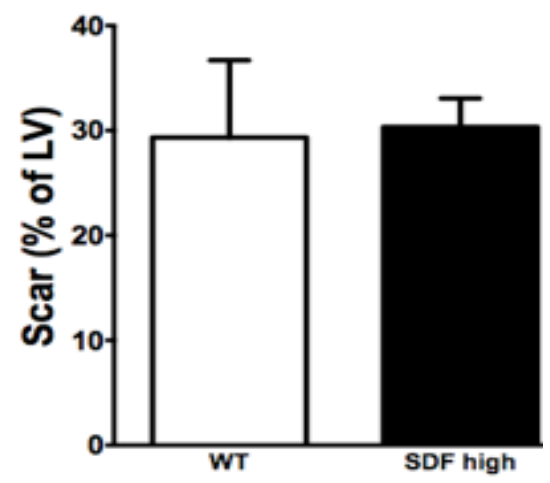

Figure XIII Morphometry of WT and SDF high mice one week after permanent ligation 

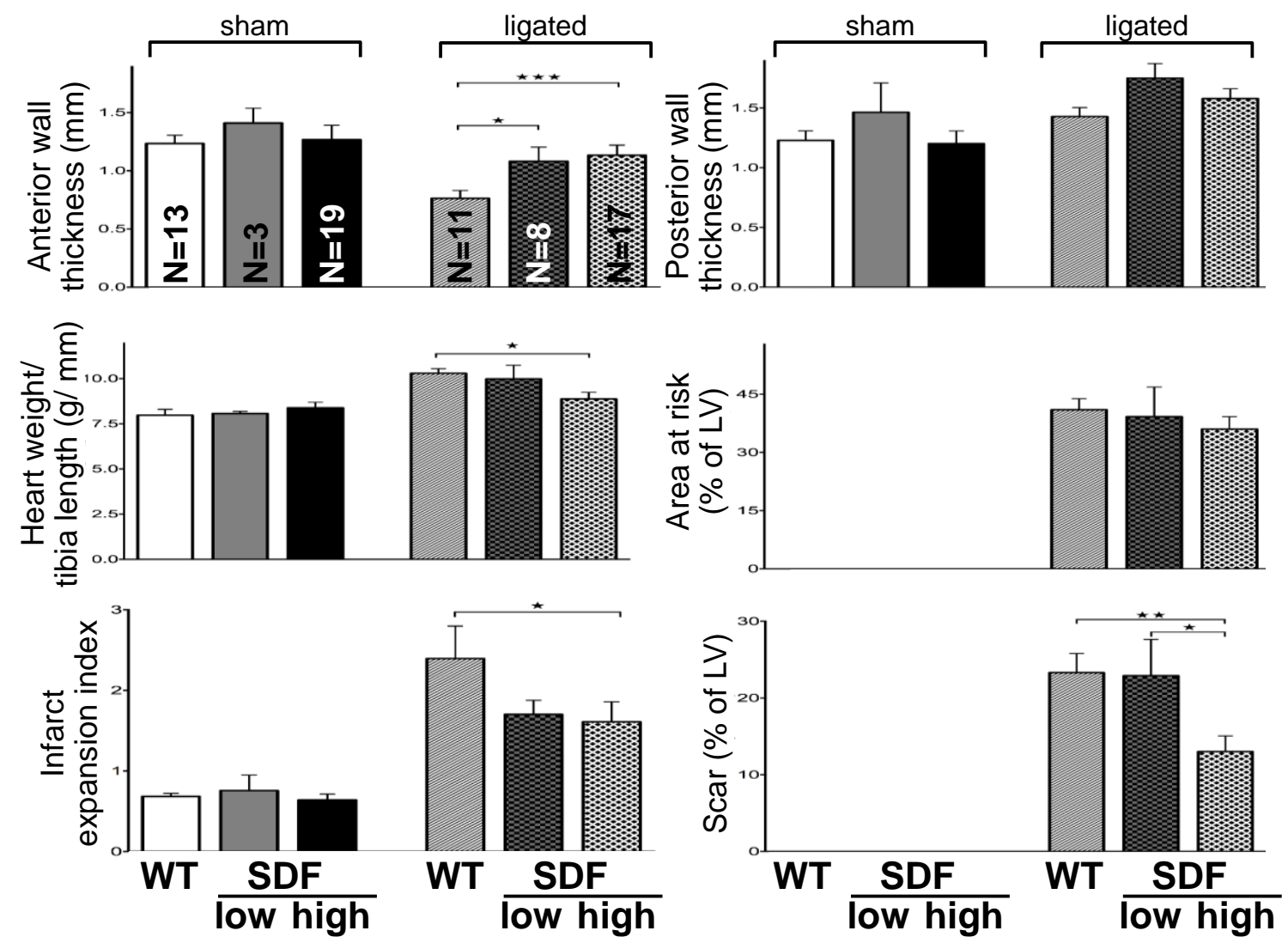

Figure XIV Morphometry in WT, SDF low and SDF high mice four weeks after permanent coronary ligation

The permanent ligation resulted in significant reduction in anterior wall thickness in WT mice compared to SDF low and SDF high, and a significant reduction of infarct size and infarct expansion index in SDF high compared to WT mice.

\section{Improvement of LV function}

The echocardiographic evaluation in young and elderly mice revealed that expression in SDF low and SDF high mice neither changed the regional wall (data not shown) nor the global LV function (Figure 15). However, in contrast to a progressive reduction in the LV function in WT mice, SDF mice maintained the cardiac function on the level reached two days after infarction, resulting in a significant difference in the 
ejection fraction (WT: $29 \pm 4 \%$ vs. SDF high: $47 \pm 5 \%, \mathrm{P}<0.05$ ) at the end of the experimental period. The regional wall motion was improved indicated by a trend towards an increased wall thickening fraction of the anterior wall (Figure 16). In addition, regional changes within the LV were analyzed by strain rate (Figure 17) indicating increased longitudinal and radial strain rate of the mid and apical wall sections of the anterior, infarcted wall (Figure 18). 
A
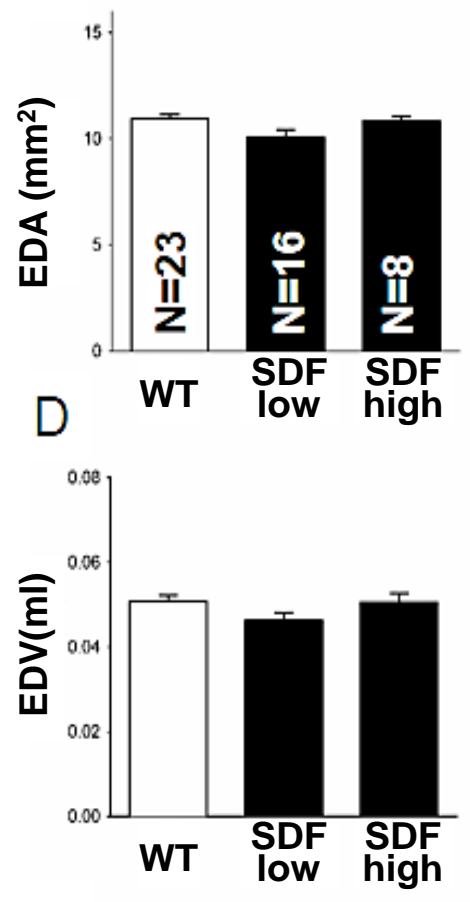

G
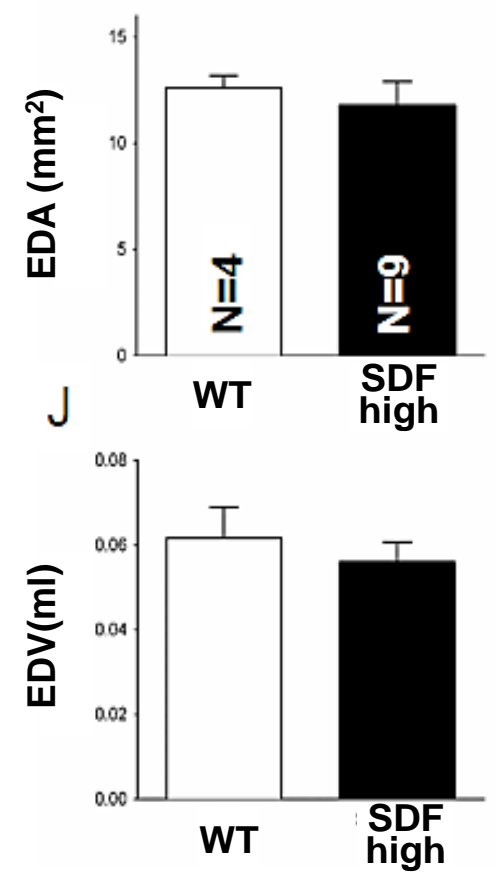

B
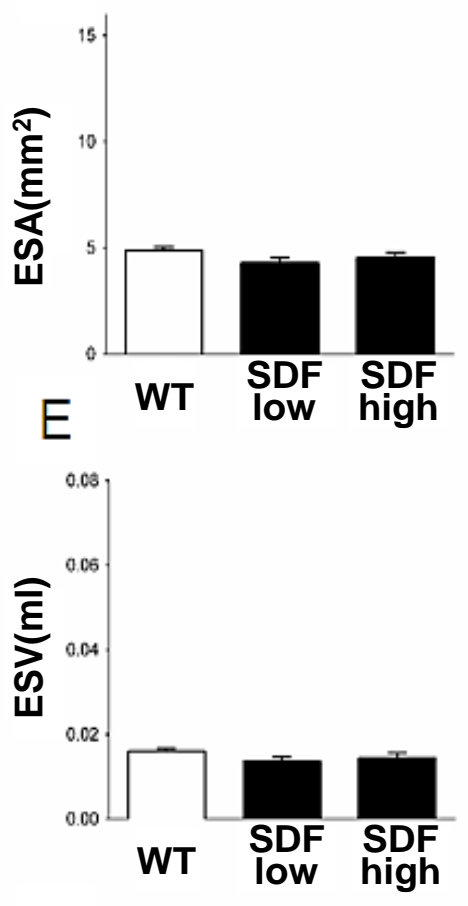

$\mathrm{H}$
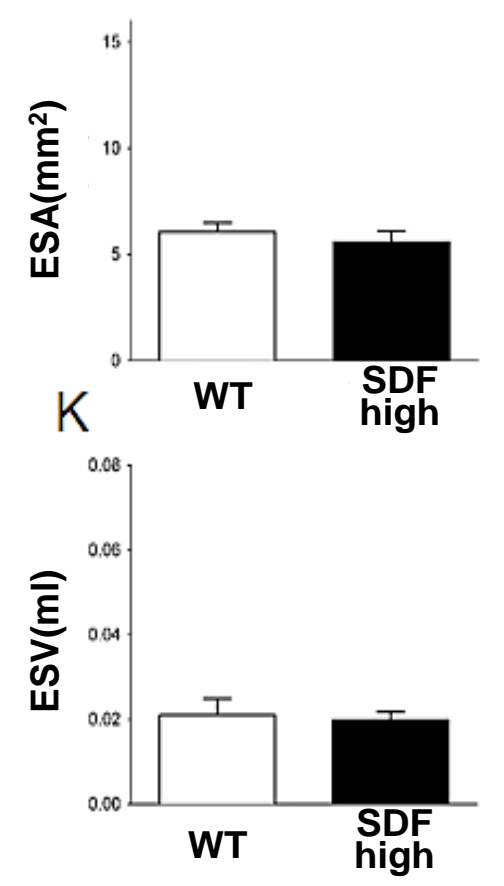

C
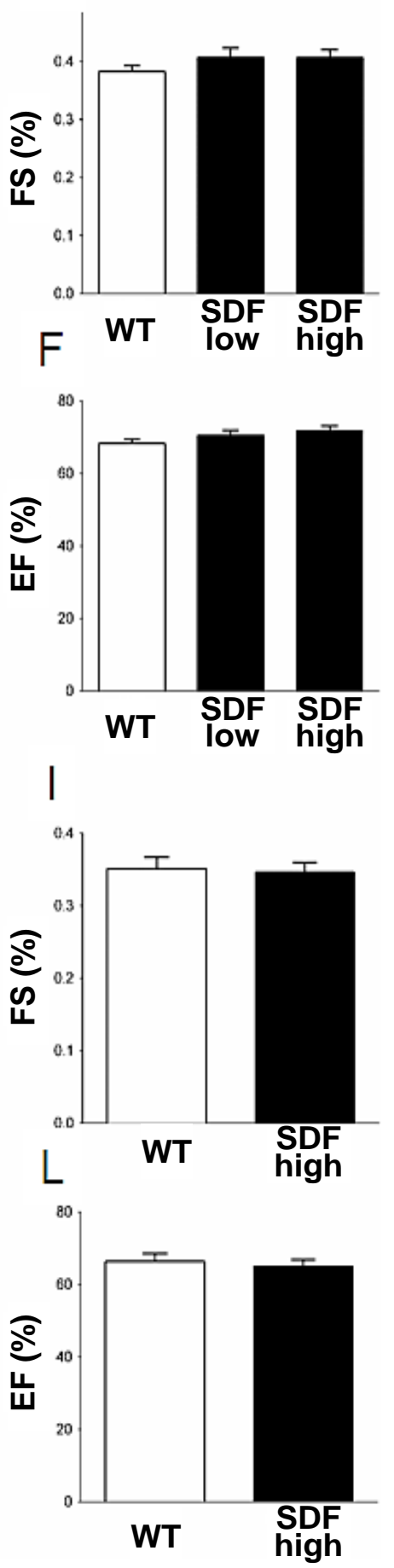

Figure XV Baseline cardiac function in mice overexpressing SDF at five weeks and more than 30 weeks

A-F: LV function variables in WT and SDF high mice overexpressing SDF for five weeks. G-L: LV function variables WT and SDF high mice overexpressing SDF for more than 30 weeks. EDA: end-diastolic area, ESA: end-systolic area, EDV: end-diastolic volume; ESV: end-systolic volume, FS: fractional shortening, EF: ejection fraction 


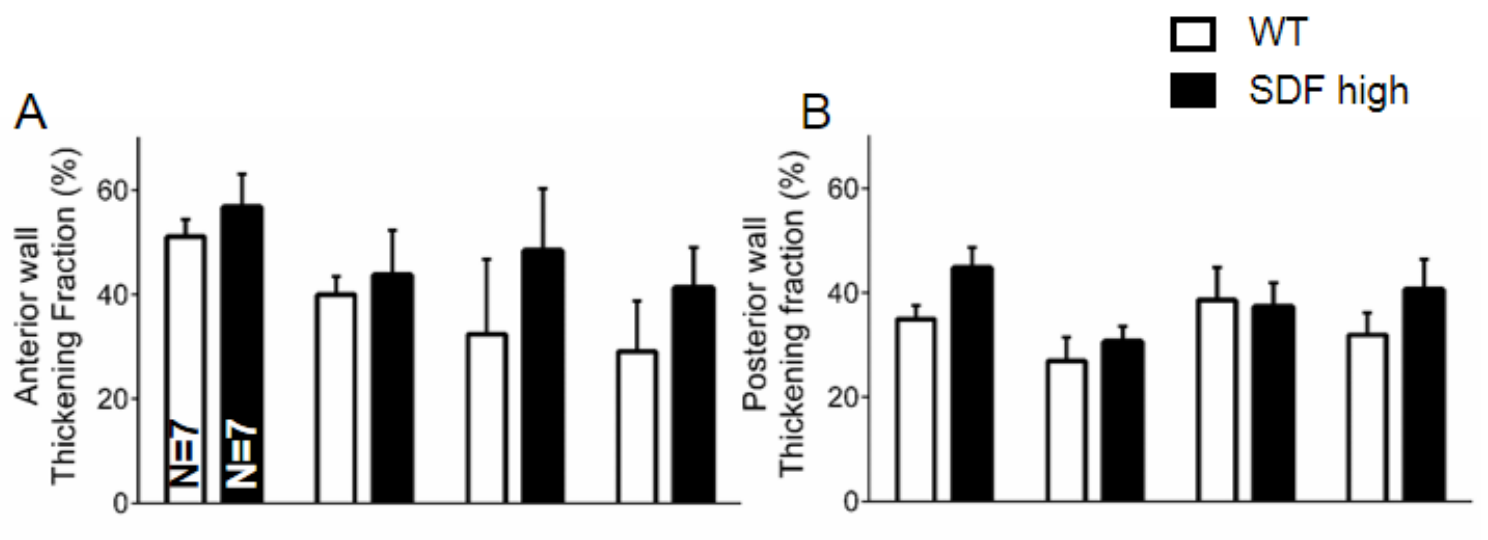

C
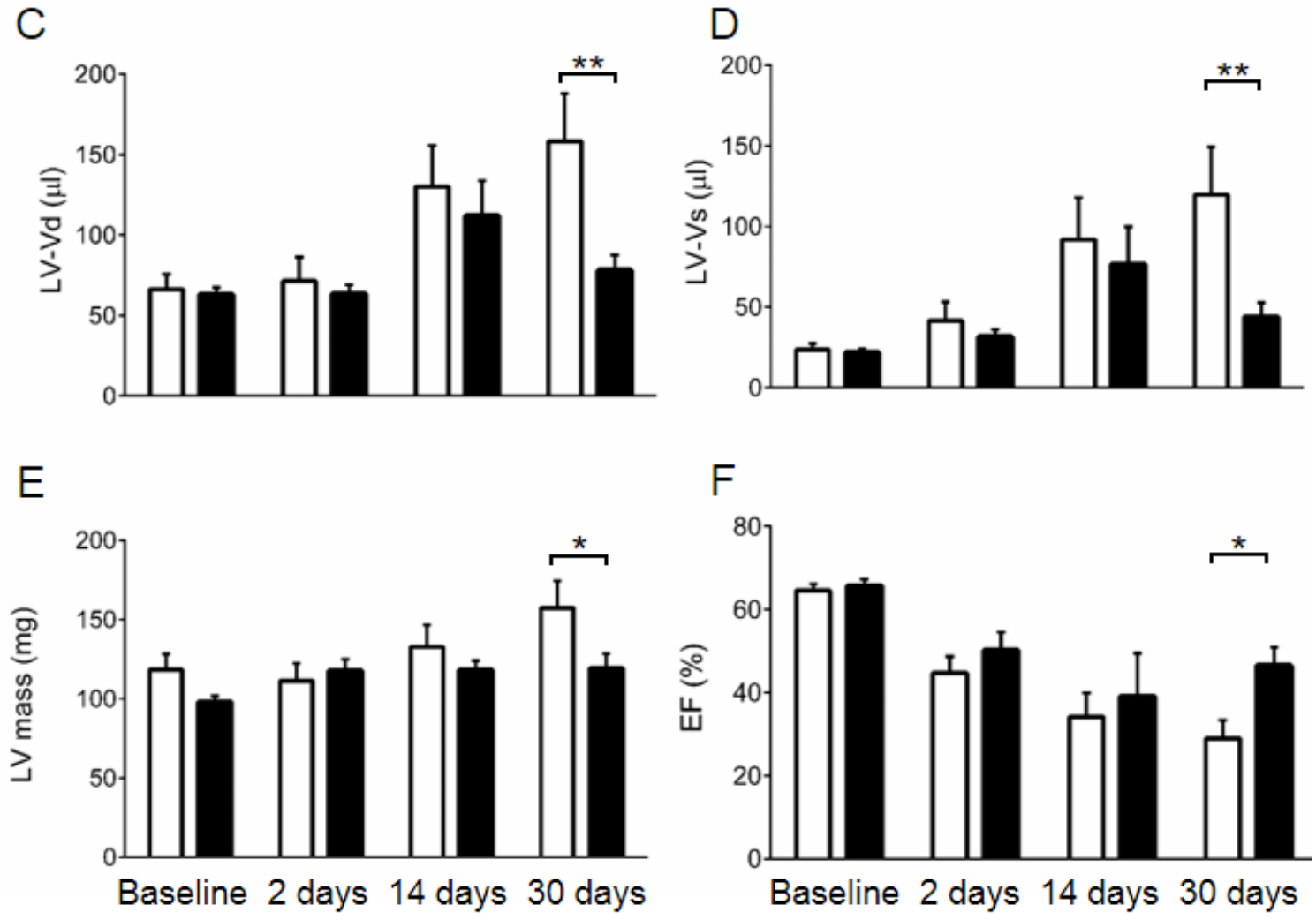

Figure XVI LV function in WT and SDF high mice before and at different time points after permanent coronary ligation

LV-Vd: end-diastolic LV volume, LV-Vs: end-systolic LV volume, EF: left-ventricular ejection fraction. ${ }^{*}, \mathrm{p}<0.05, * * \mathrm{p}<0.01$, Two-way ANOVA with Bonferroni correction for multiple comparisons. 
A
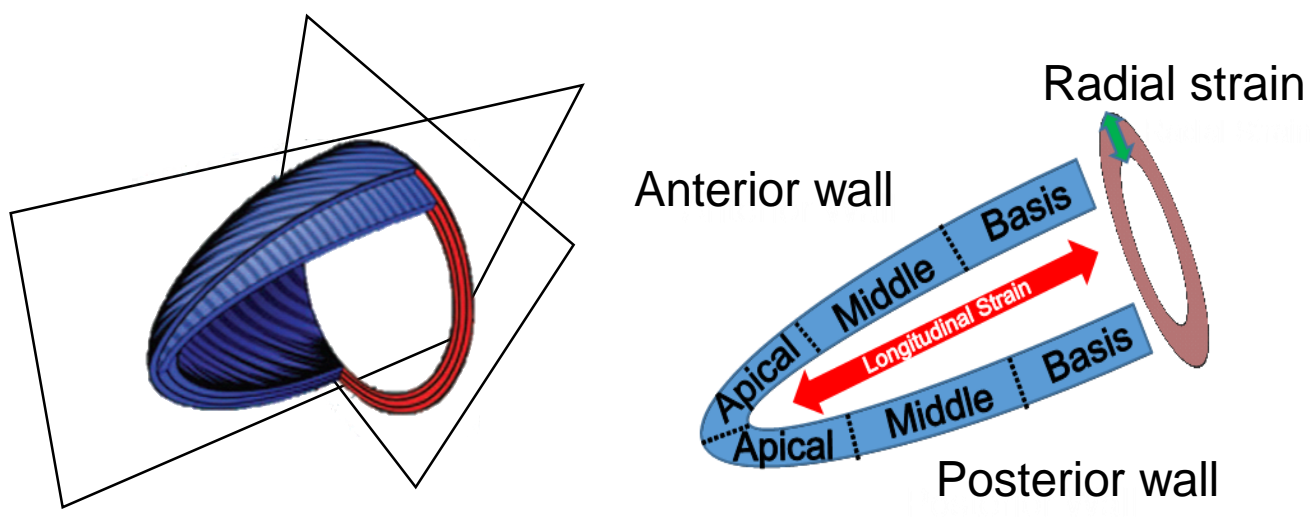

B

Baseline

4 weeks after MI
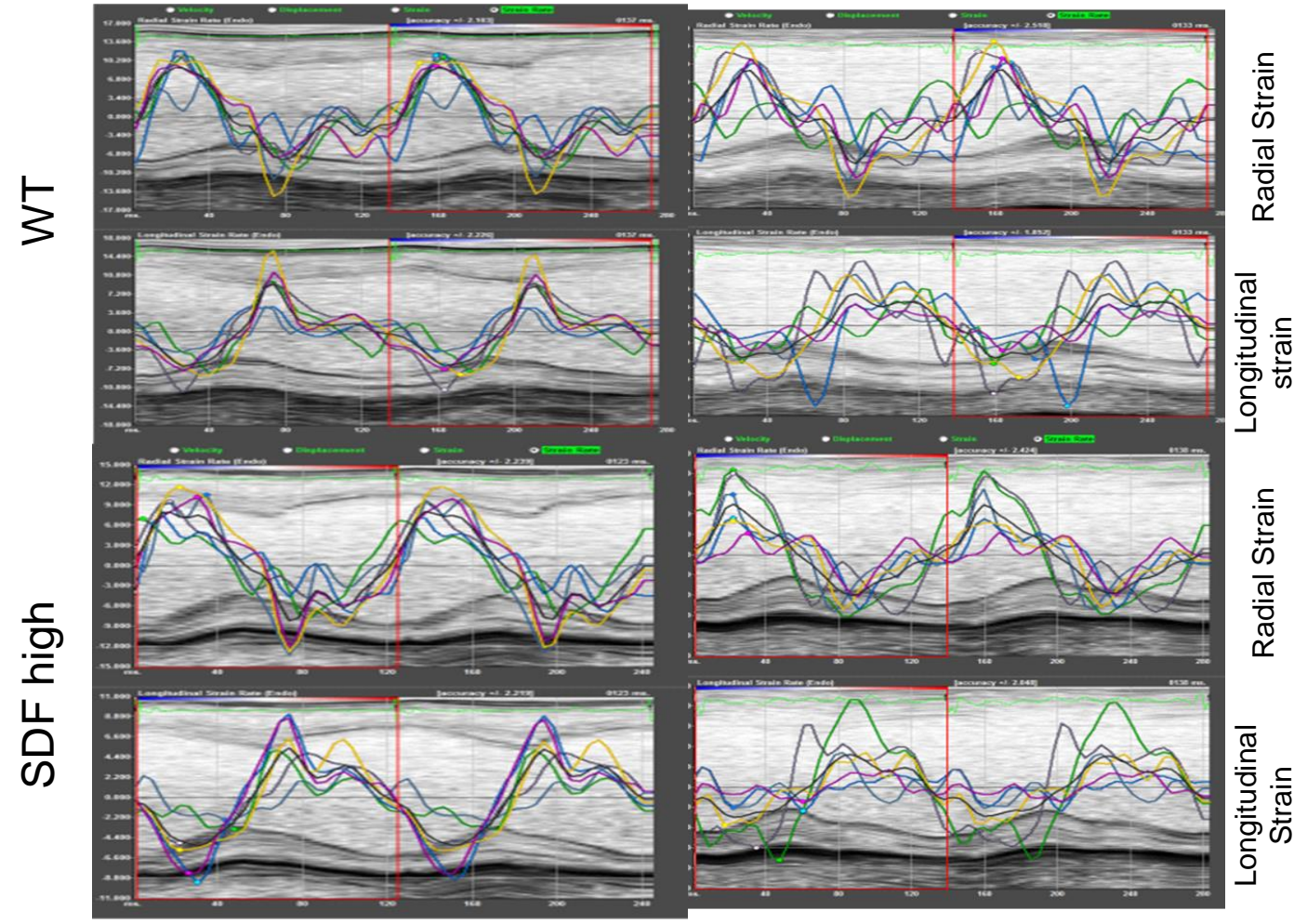

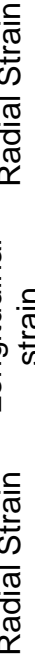

C

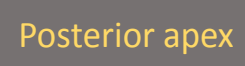

Anterior middle

Posterior middle

Figure XVII Examples of radial and longitudinal strain in WT and SDF overexpressing mice before and four weeks after coronary artery ligation

A: Six different areas were used for longitudinal and radial strain rate analysis. B: Example of radial and longitudinal strain rate of a WT mouse before (left) and four weeks after coronary ligation (right), which resulted in asynchronous contraction. C: Color code used in $B$, indicating different areas of the left ventricle. 
Posterior wall
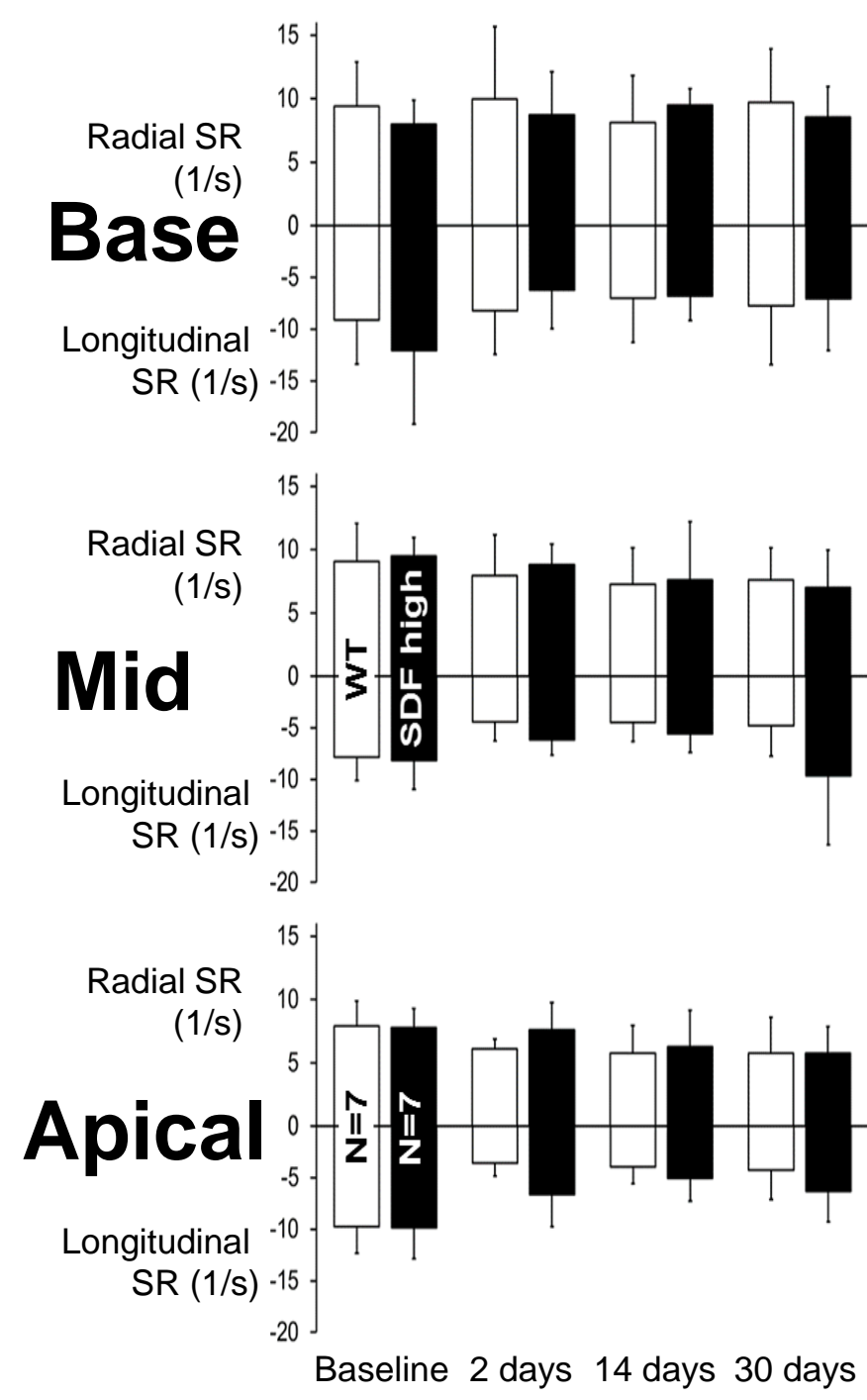

Anterior wall
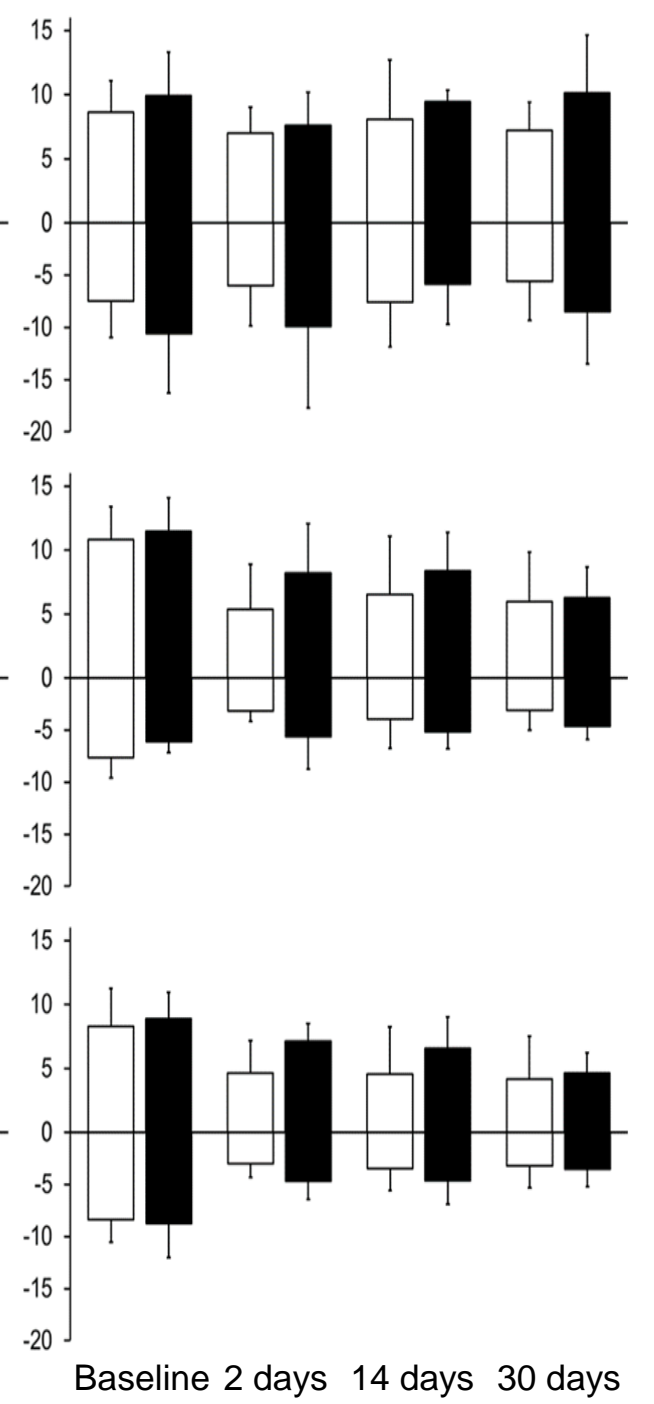

Figure XVIII Regional wall function measured by speckle trecking

Longitudinal and radial strain rate (SR) in apical, middle (mid) and base section of anterior and posterior wall in WT and SDF high mice at baseline and at different time points after permanent coronary ligation.

\section{Increased cell turnover, but unchanged capillary density}

The staining for BrdU showed that the number of $\mathrm{BrdU}^{+}$cardiomyocytes increased in the remote, border, and scar area of the LV in SDF high mice (Figures 19, 20, and 21). The data were confirmed by an increased number of Ki $67^{+}$cardiomyocytes four weeks after 
myocardial infarction (Figure 22). Measurement of the capillary density indicated no difference between WT and SDF high, sham and permanent coronary ligated mice (Figure 23). Surprisingly, similar to the increase in cell proliferation (BrdU staining, Ki67 staining) we detected an increase in $\mathrm{TUNEL}^{+}$nuclei after one and four weeks in SDF high, reflecting an increase in apoptosis (Figure 24). However, cardiomyocyte cross-sectional area was smaller in SDF high mice than in WT controls, indicating less hypertrophy four weeks after myocardial infarction (Figures 25 and 26). 

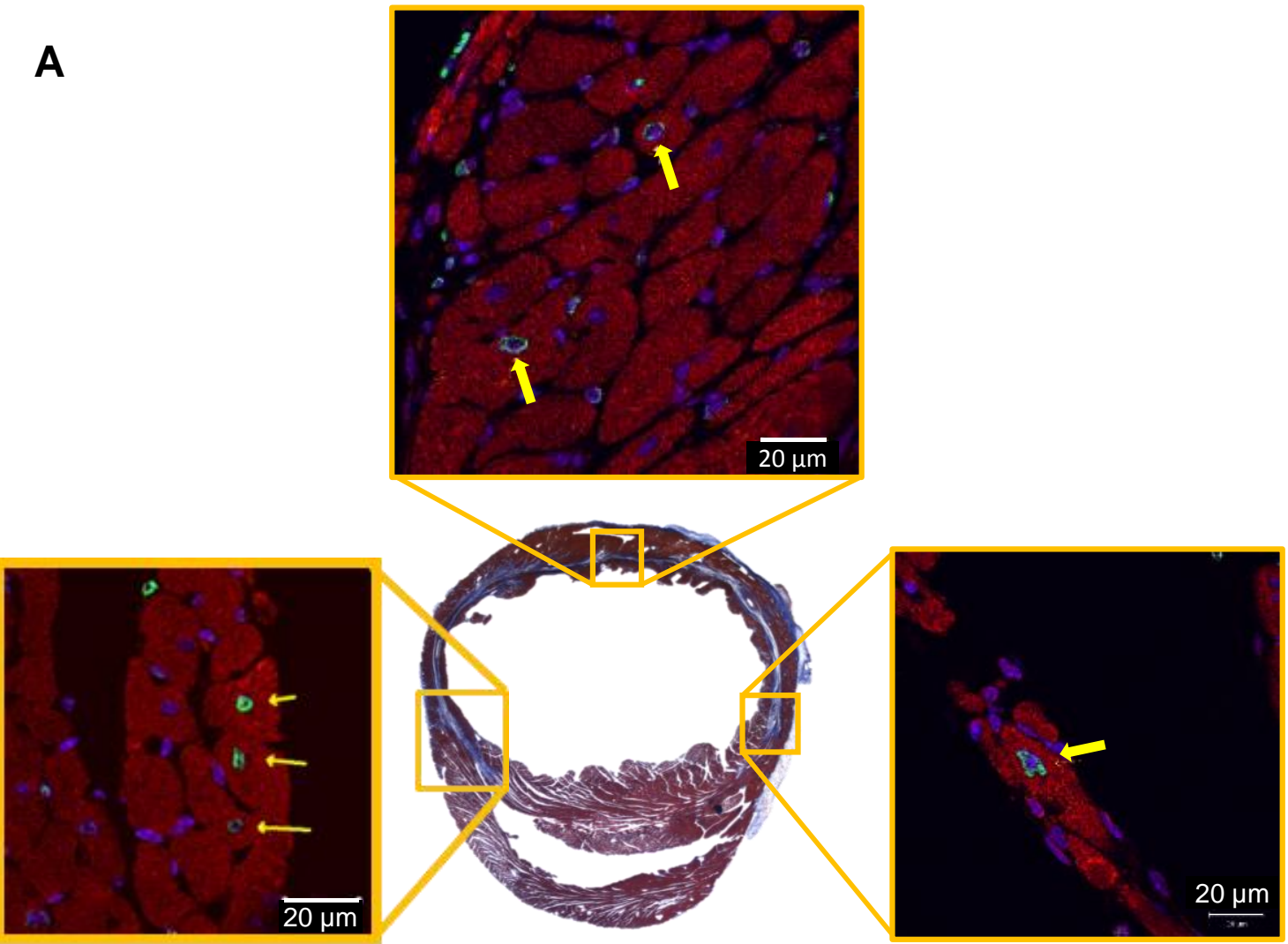

B $\quad \mathrm{BrdU}^{+}$cardiomyocytes

(\% of cardiomyocytes)
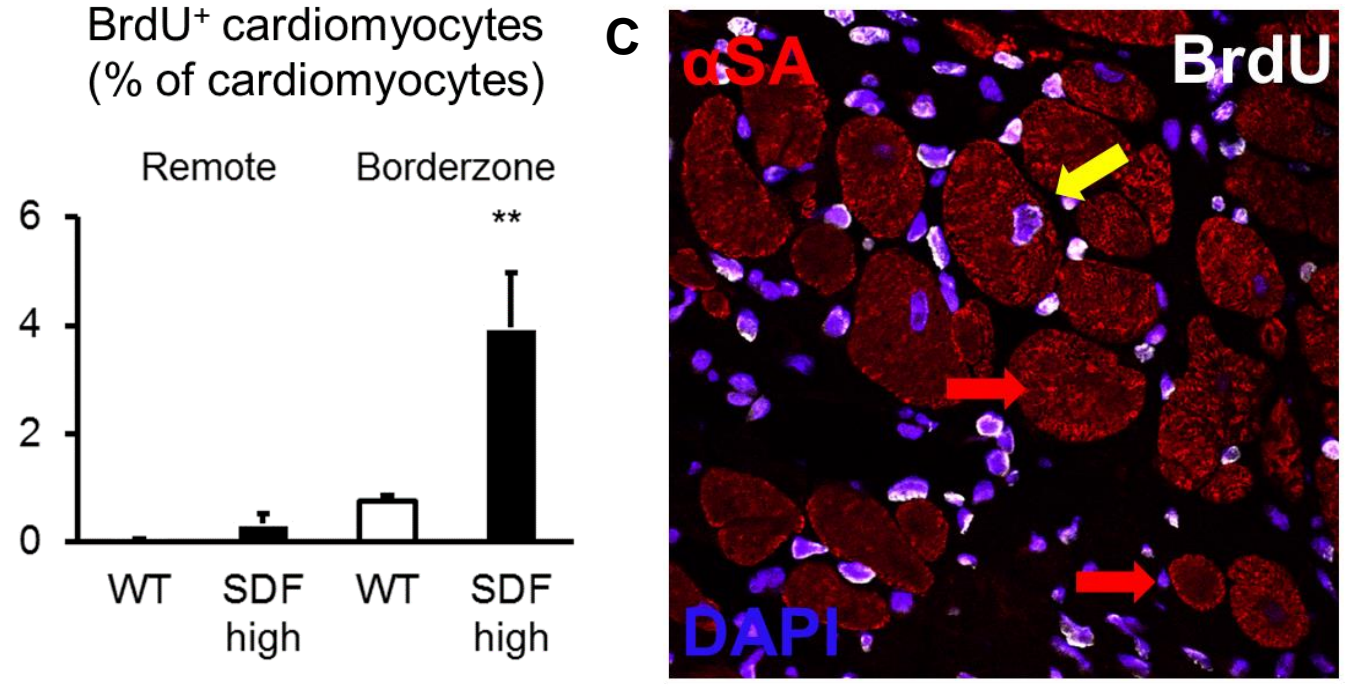
D

\section{$\mathrm{BrdU}^{+}$nuclei \\ ( $\%$ of cardiomyocyte nuclei)}

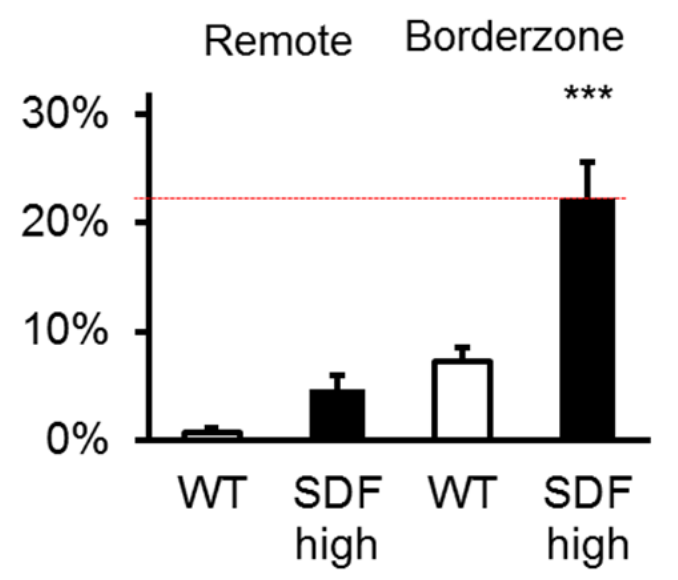

Figure XIX $\mathrm{BrdU}^{+} / \alpha$-sarcomeric actin ${ }^{+}$cardiomyocytes in the border and remote zone four weeks after myocardial infarction in SDF high and WT mice

A: Representative cross-section with inserts reflecting $\mathrm{BrdU}^{+} / \alpha$-sarcomeric actin $(\alpha \mathrm{SA})^{+}$ cardiomyocytes in border- and scar area (yellow arrows). B: Number of $\mathrm{BrdU}^{+}$ cardiomyocytes expressed as percent of all cardiomyocytes. C: typical cross-section within the border-zone indicating the presence of cardiomyocytes with (yellow arrow) and without nuclei (red arrows). D: $\mathrm{BrdU}^{+}$nuclei, expressed as cardiomyocyte nuclei. (BrdU': FITC $=$ green, $\alpha \mathrm{SA}: \quad$ TRITC $=$ red, DAPI $=$ blue). $\quad \mathrm{N}=10-12, * *, \mathrm{p}<0.01, * * *, \quad \mathrm{p}<0.001$, unpaired student t-test. 

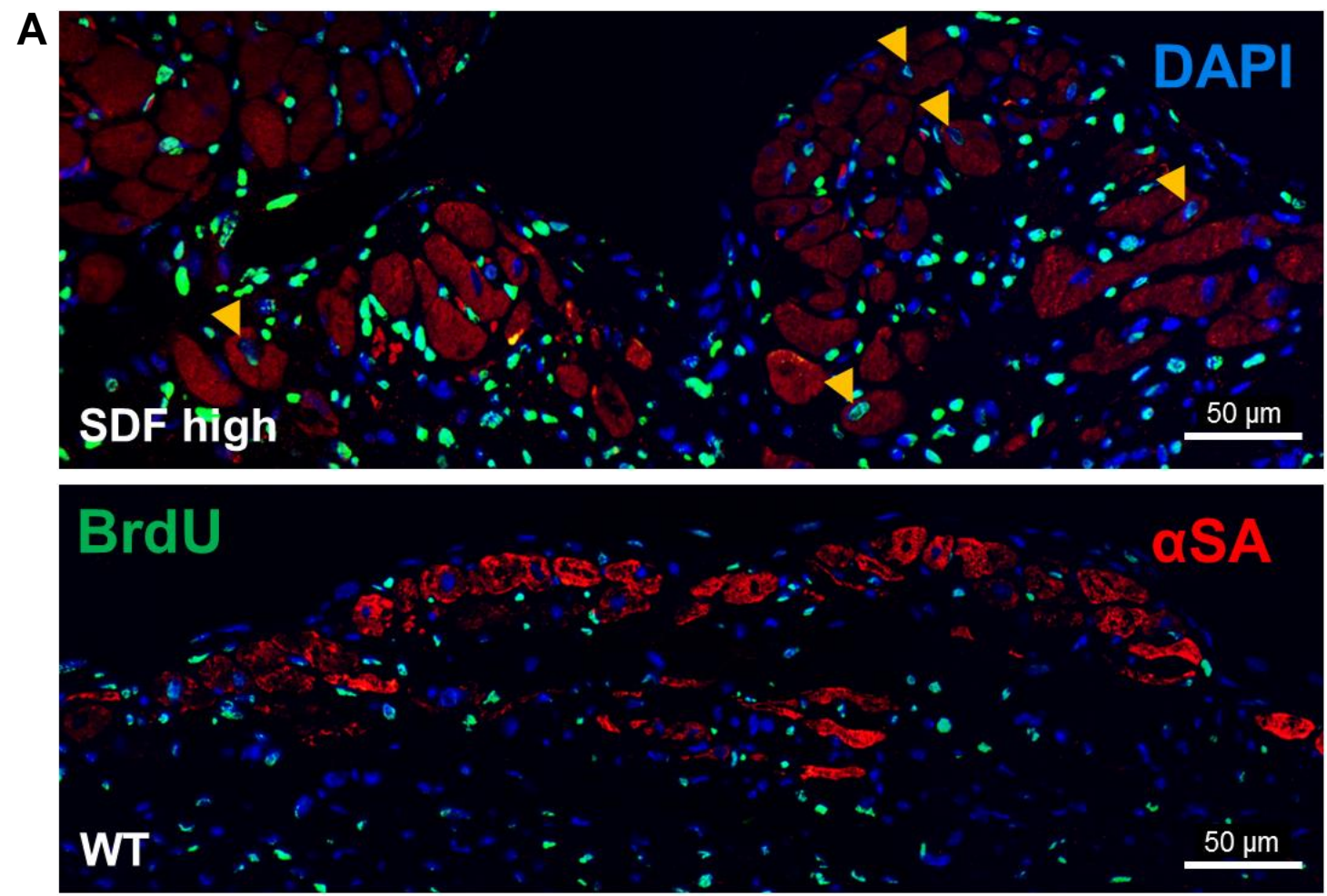

B

C
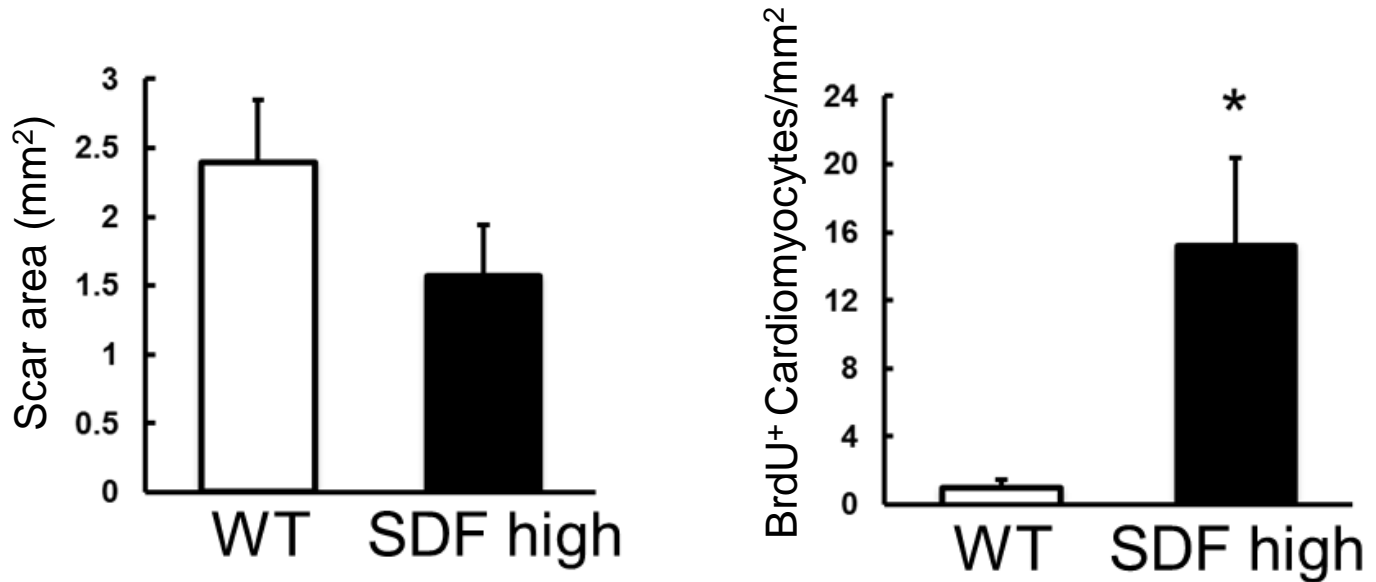

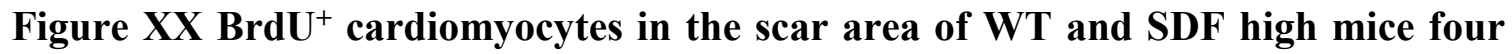
weeks after infarction

A: representative cross-section of BrdU (green), DAPI (blue) and $\alpha$-sarcomeric actin (red) stained sections SDF high mice (A, top panel, SDF high) and WT (A, lower panel) mice. B: Infarct size. C: Number of dividing, $\mathrm{BrdU}^{+}$cardiomyocytes in the scar area $(\mathrm{N}=6$, $\left.{ }^{*} \mathrm{p}<0.05\right)$. 


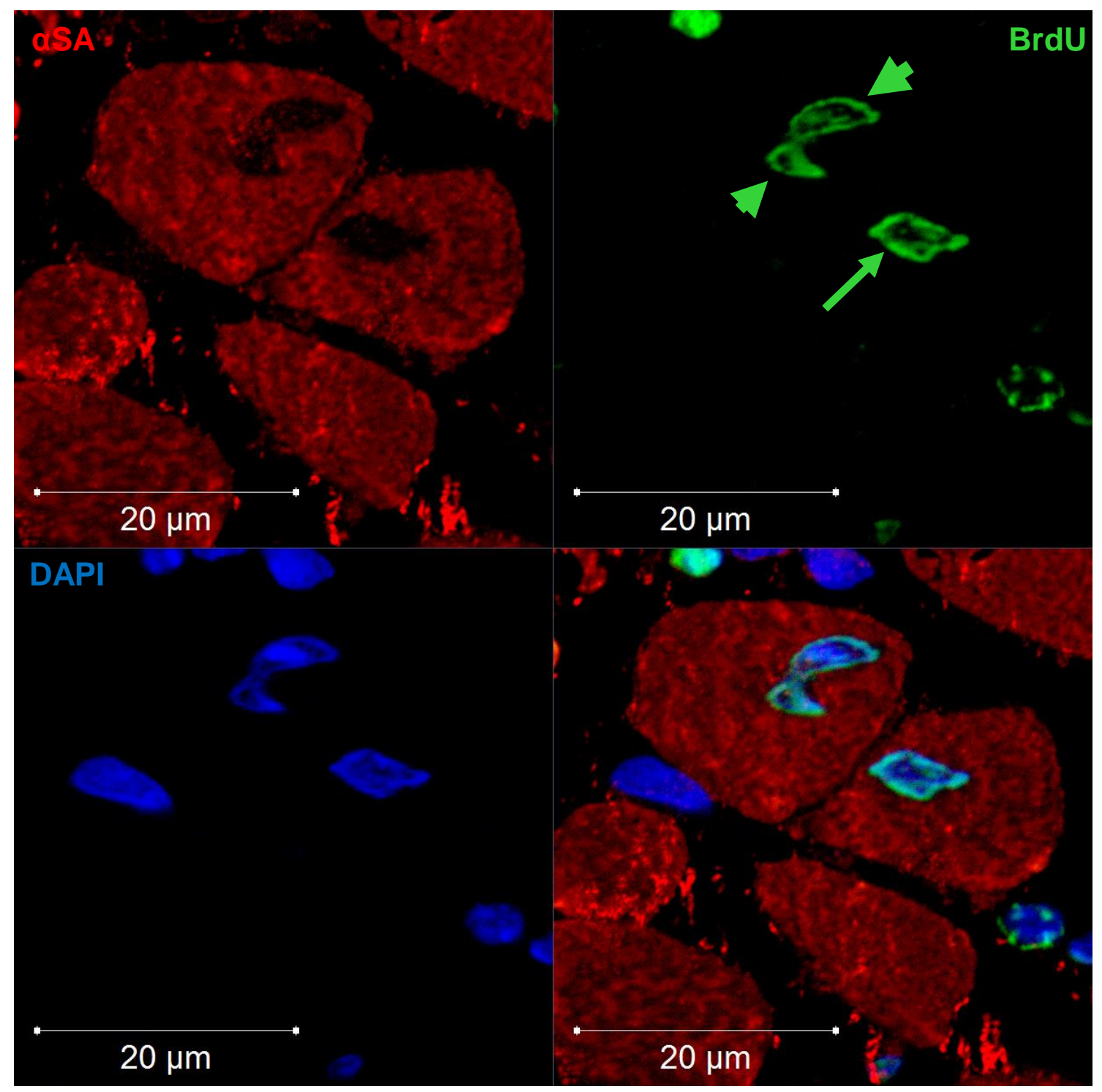

Figure XXI Dividing cardiomyocyte in the border zone of a SDF high overexpressing mouse

Arrow heads indicate nucleus undergo karyokinesis, while arrow indicate the nucleus of a daughter cell after cytokinesis. 


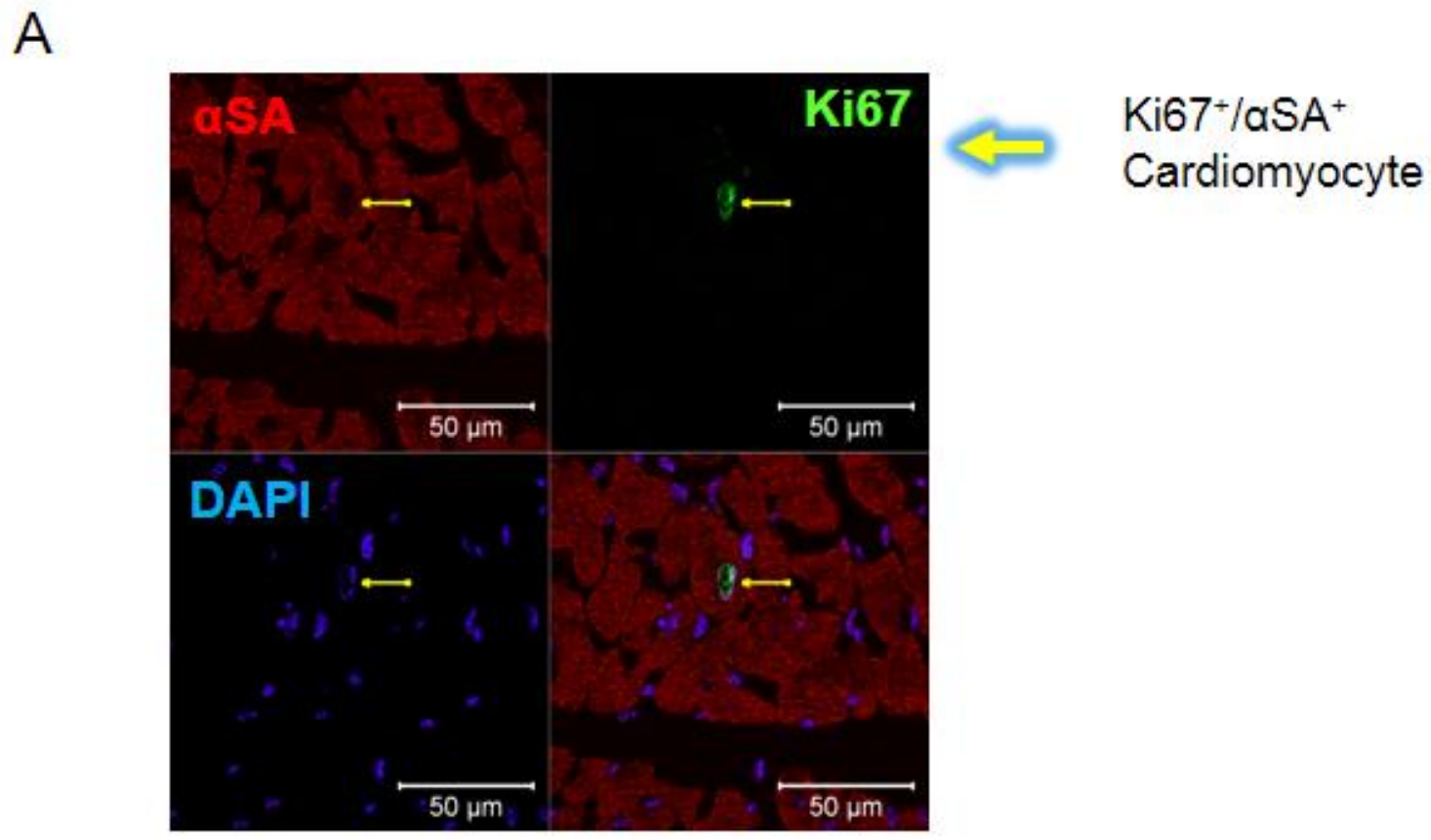

B

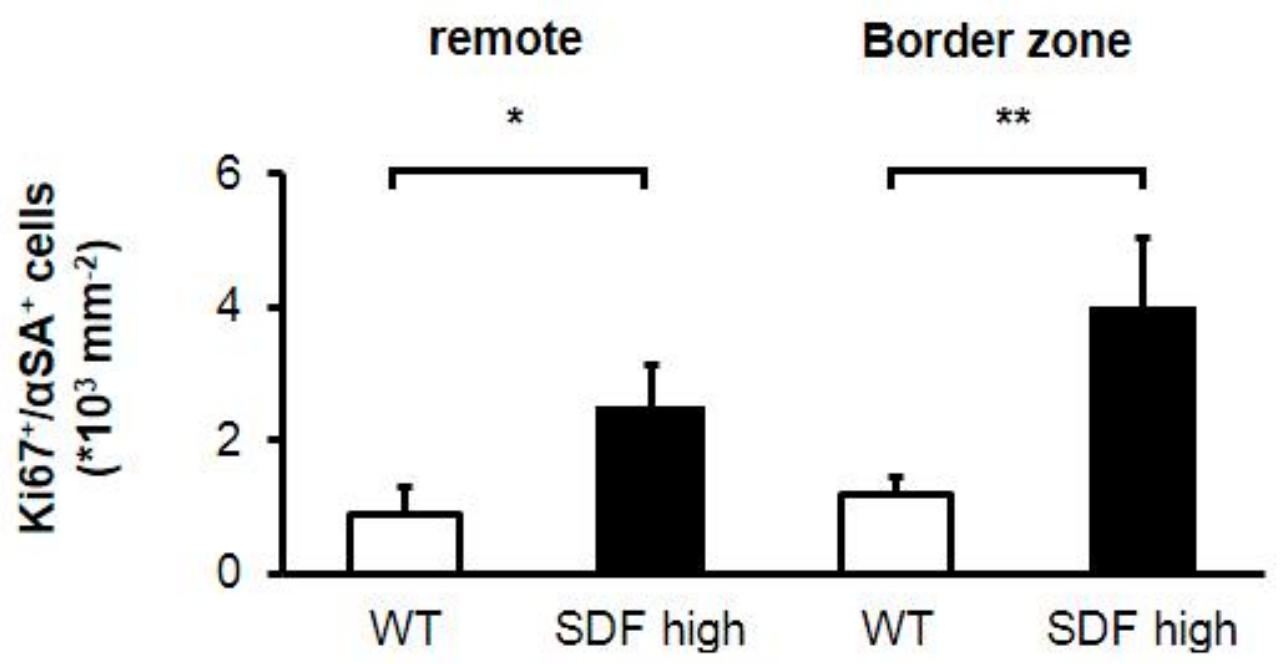

Figure XXII Ki67 $7^{+}$cardiomyocytes in the remote and border zone of WT and SDF high mice four weeks after infarction

A: representative example of an area at the border zone of a SDF high mouse, showing a dividing cardiomyocyte. B: Number of Ki67 / $\alpha$-sarcomeric actin ${ }^{+}$in the border and remote zone of WT and SDF high mice $\left(\mathrm{N}=7-9,{ }^{*}, \mathrm{p}<0.05,{ }^{* *}, \mathrm{p}<0.01\right.$, unpaired student's t-test). 


\section{A Sham operated}
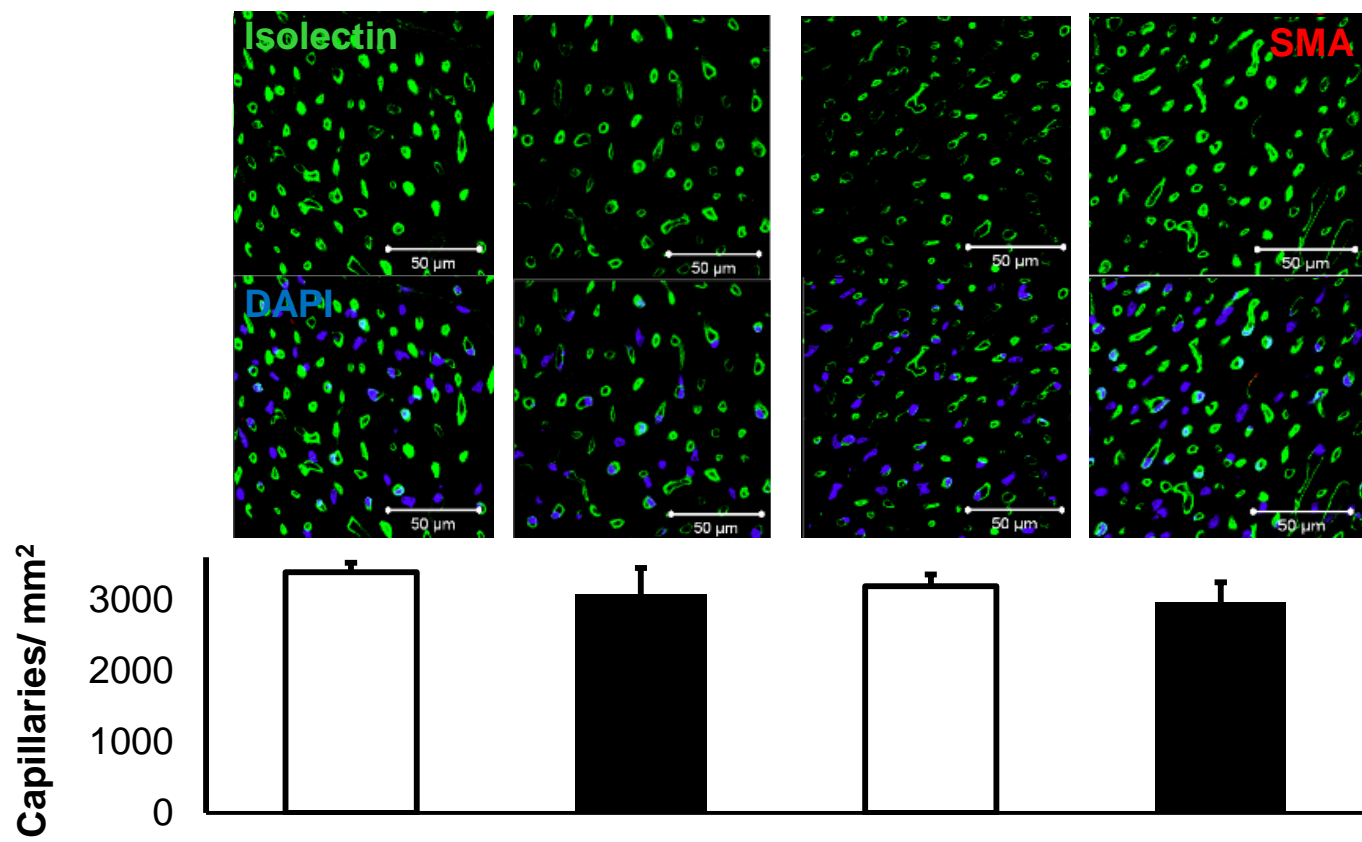

B 4 weeks after myocardial infarction
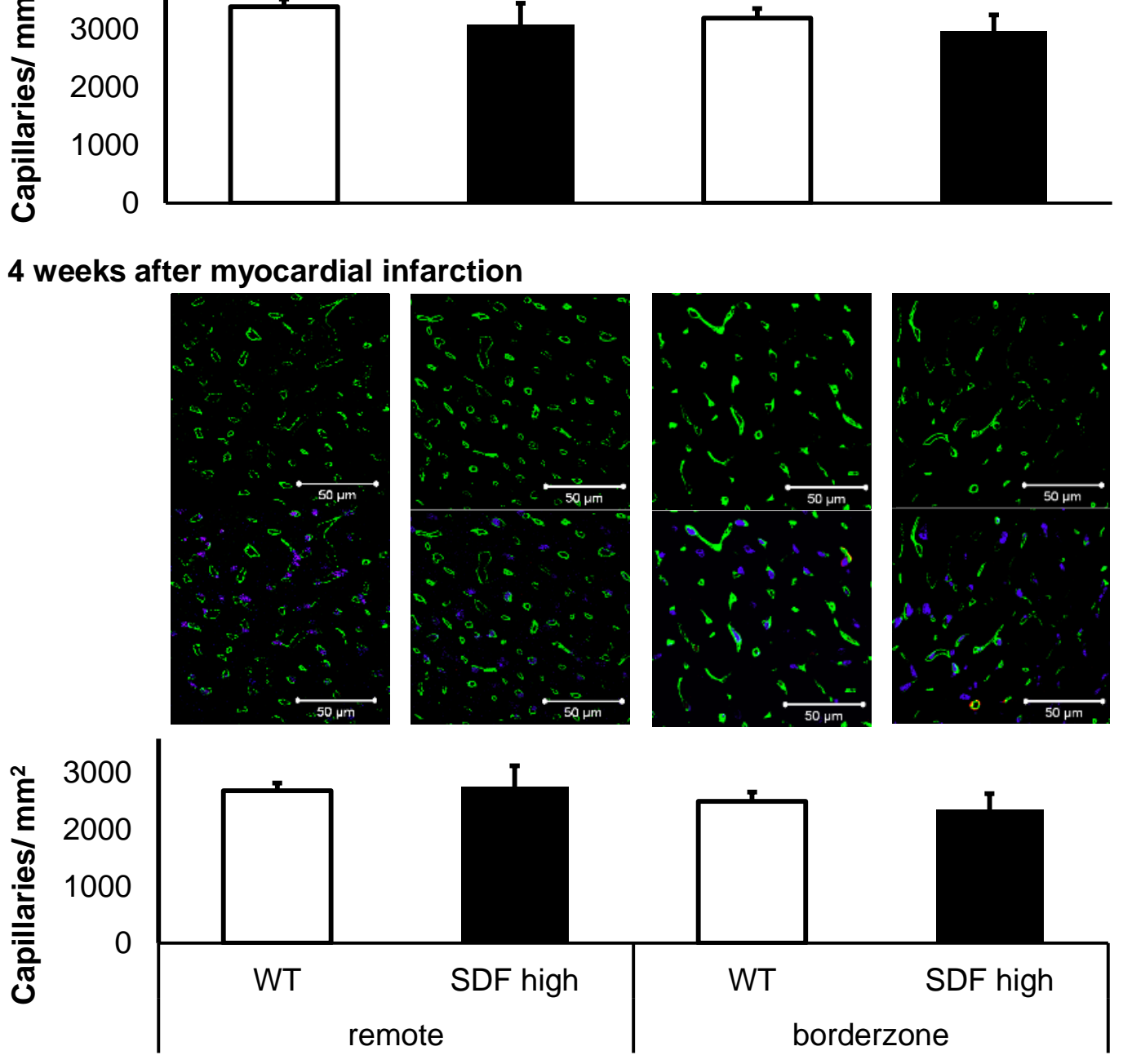

Figure XXIII Capillary density in WT and SDF high mice after sham operation and four weeks permanent ligation in the remote and border zone

A: Capillary density in sham operated animals. B: Capillary density in mice underwent permanent coronary ligation ( $\mathrm{N}=12-14)$. 


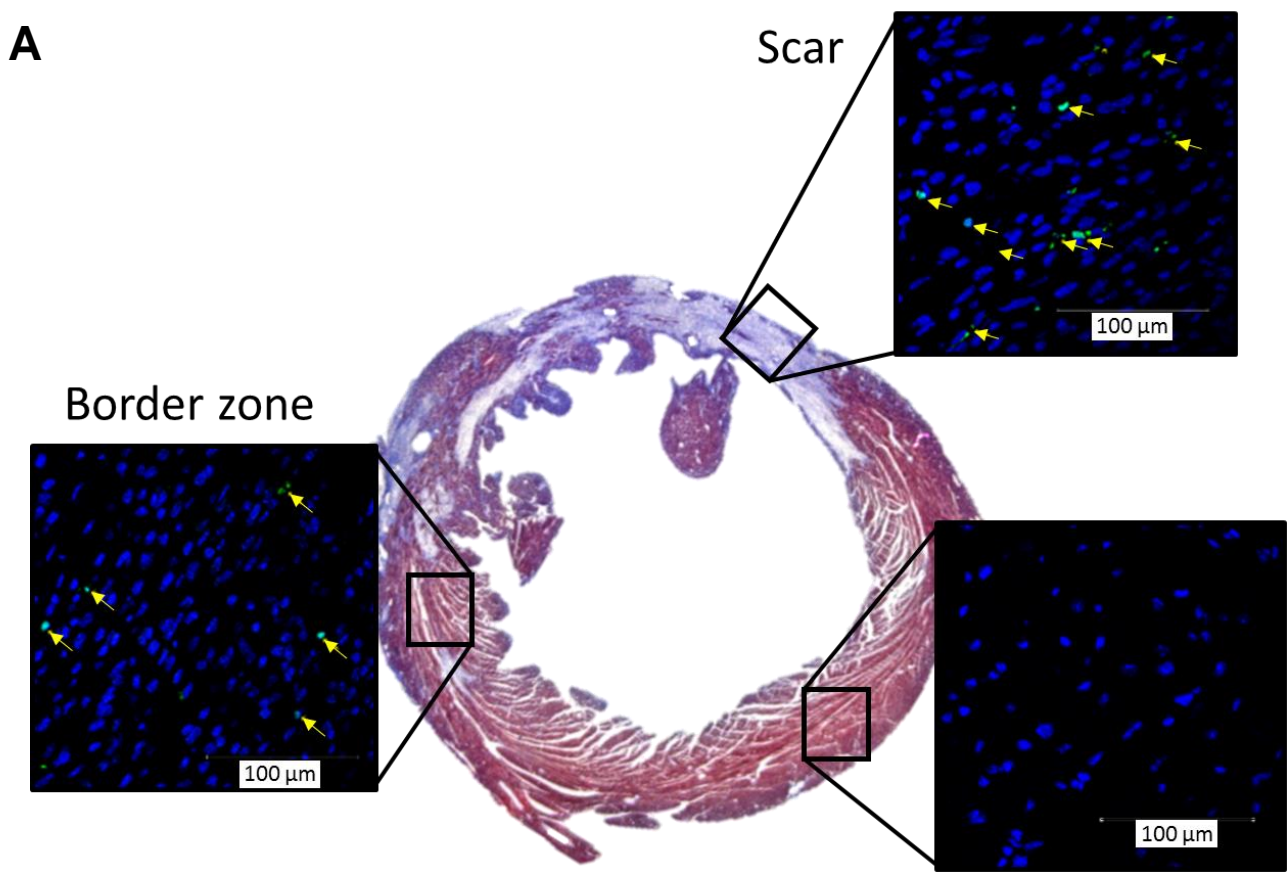

\section{B}

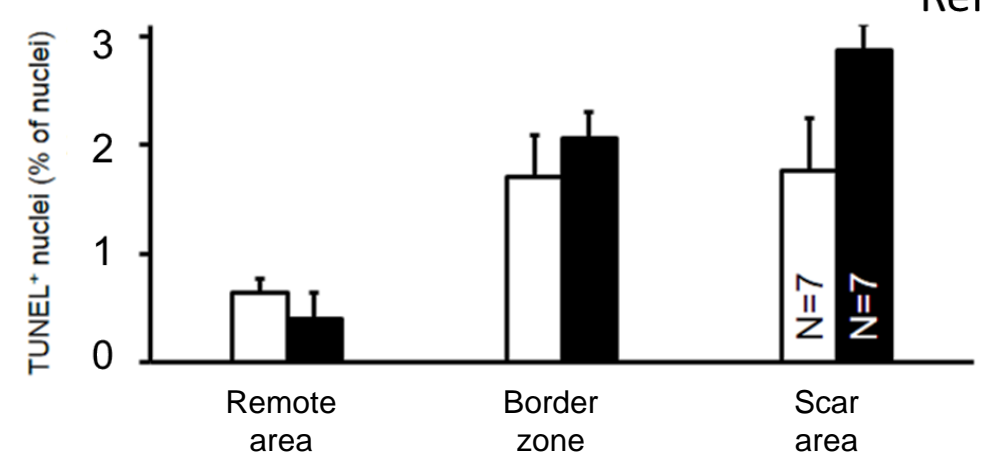

C

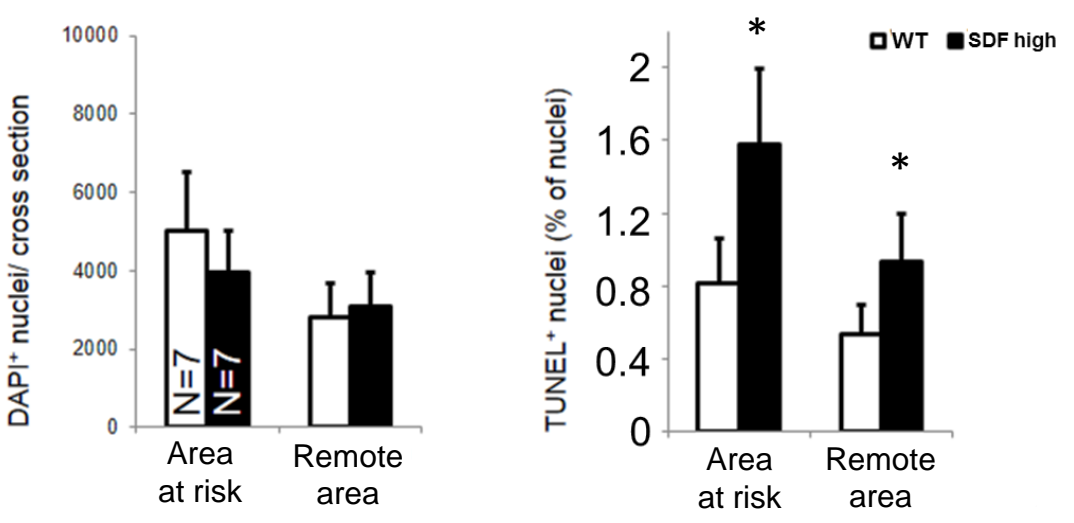

Figure XXIV TUNEL ${ }^{+}$nuclei one and four weeks after permanent ligation

A: Representative cross section through a SDF high heart with images of $\mathrm{TUNEL}^{+}$section in scar, border, and remote zone one week after permanent ligation. B, C: Quantitative analysis of TUNEL ${ }^{+}$nuclei (yellow arrows) in WT and SDF high mice in each area one (B) and four (C, right) weeks after infarct. * $\mathrm{p}<0.05$, unpaired student's t-test. 
Remote area
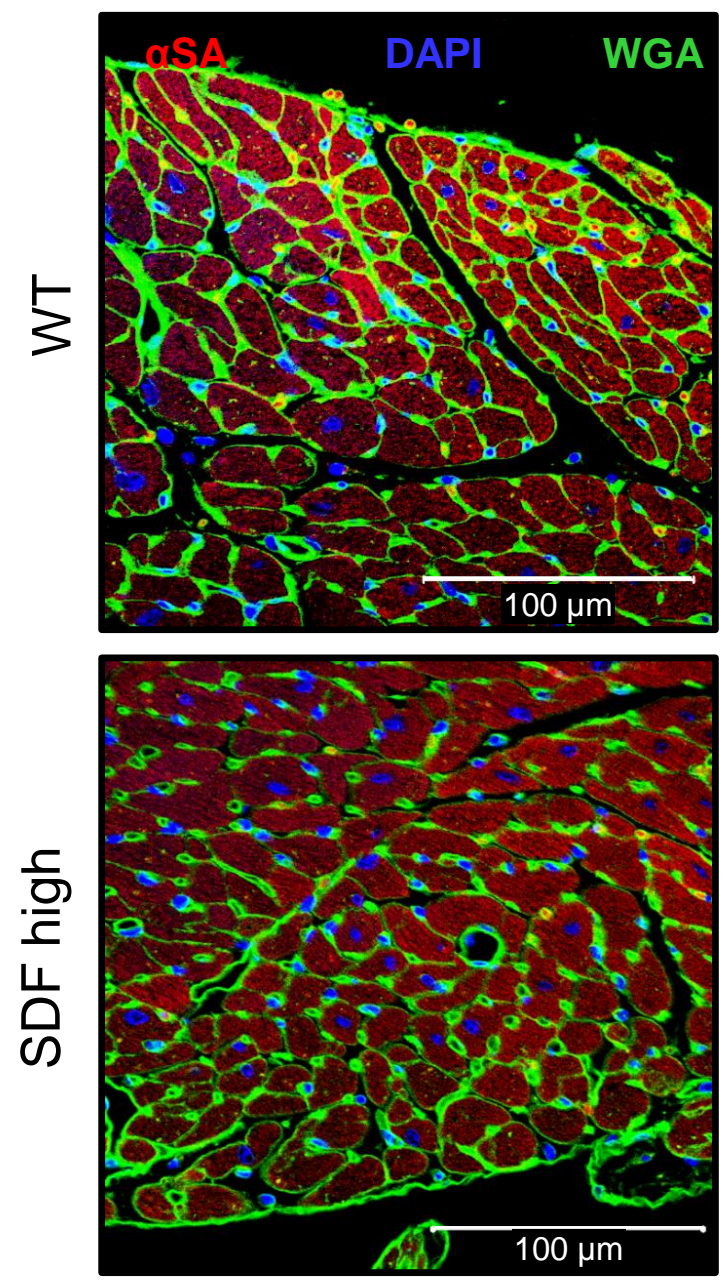

Border zone
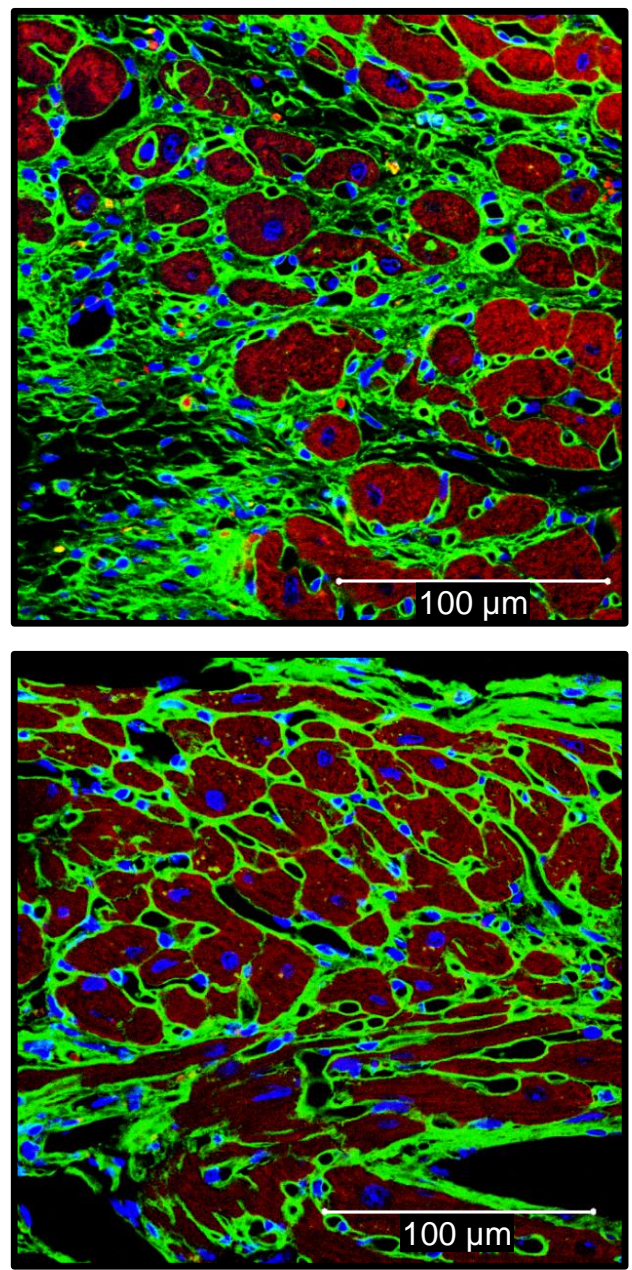

Figure XXV Wheat-germ agglutinin staining for measurement of myocytes crosssectional area

Wheat-germ agglutinin staining of representative areas of remote (left) and border-zone (right) in WT and SDF high mice. 
Cardiomyocyte cross-sectional area $\left(\mu \mathrm{m}^{2}\right)$

\section{Figure XXVI Histogram of cardiomyocyte cross-sectional area}

Upper panel shows the number of myocytes of each specific size (logarithmic scale) in the border (left side) and the frequency distribution (right side, median [range]) in the border zone. The lower panel shows the corresponding results in the remote zone. There was a slight difference between WT and SDF high mice showing smaller myocytes in the border zone. Total number of myocytes analyzed in the border zone (WT: 925, SDF high: 974) and in the remote zone (WT: 851, SDF high: 1148). ${ }^{*}, \mathrm{p}<0.05$, Mann-Whitney test. 


\section{CONCLUSION}

In conclusion, our data clearly indicate that in a permanent coronary artery ligation model, SDF overexpression fails to protect against ischemic injury. The key feature of a permanent coronary artery ligation model is the absolute lack of oxygen and nutrition support to the ischemic area. As the myocardium of mice lacks significant collateral circulation compared to other species (i.e. canine, human) ${ }^{85}$ the survival of myocardium due to collateralization in this model is very unlikely. Importantly, we found increased myocardial regeneration already within four weeks after the injury, as indicated by BrdU and Ki67 staining. Surprisingly, regeneration was accompanied by increased apoptosis. Cardiomyocytes stained positive for BrdU were detectable as early as one week after myocardial infarction, partially featuring already an adult cardiomyocyte phenotype (Figure 27).

Different possible mechanisms might be responsible for this impressive regeneration potential: Previous work suggested that even adult cardiomyocytes have the potential to undergo cell division initiated by either inhibition of p38 MAP kinase ${ }^{86}$ or GSK-3 $\beta$ inhibition. ${ }^{87}$ Furthermore, circulating as well as resident c-kit ${ }^{+}$progenitor cells might be differentiated towards a cardiomyocyte phenotype. Interestingly, we detected a significant increase in apoptosis in SDF overexpressing mice one and four weeks after myocardial infarction. These data contrast published work in myeloid progenitor cells $\mathrm{s}^{64,88}$ in which apoptosis was inhibited in the presence of SDF.

The overexpression of SDF prevents a decline of global and regional LV function after myocardial infarction. About $20 \%$ of all cardiomyocyte nuclei were $\mathrm{BrdU}^{+}$, representing about $4 \%$ of all cardiomyocytes regenerated in the border zone. The volume 
of newly generated cells appears to be too small to cause a significant increase in LV function, suggesting that secreted SDF also acted as a paracrine factor increasing myocardial contractility. ${ }^{89}$ However, neither short-term (five weeks) nor long-term (more than 30 weeks) SDF overexpression affected the myocardial function in sham-operated,

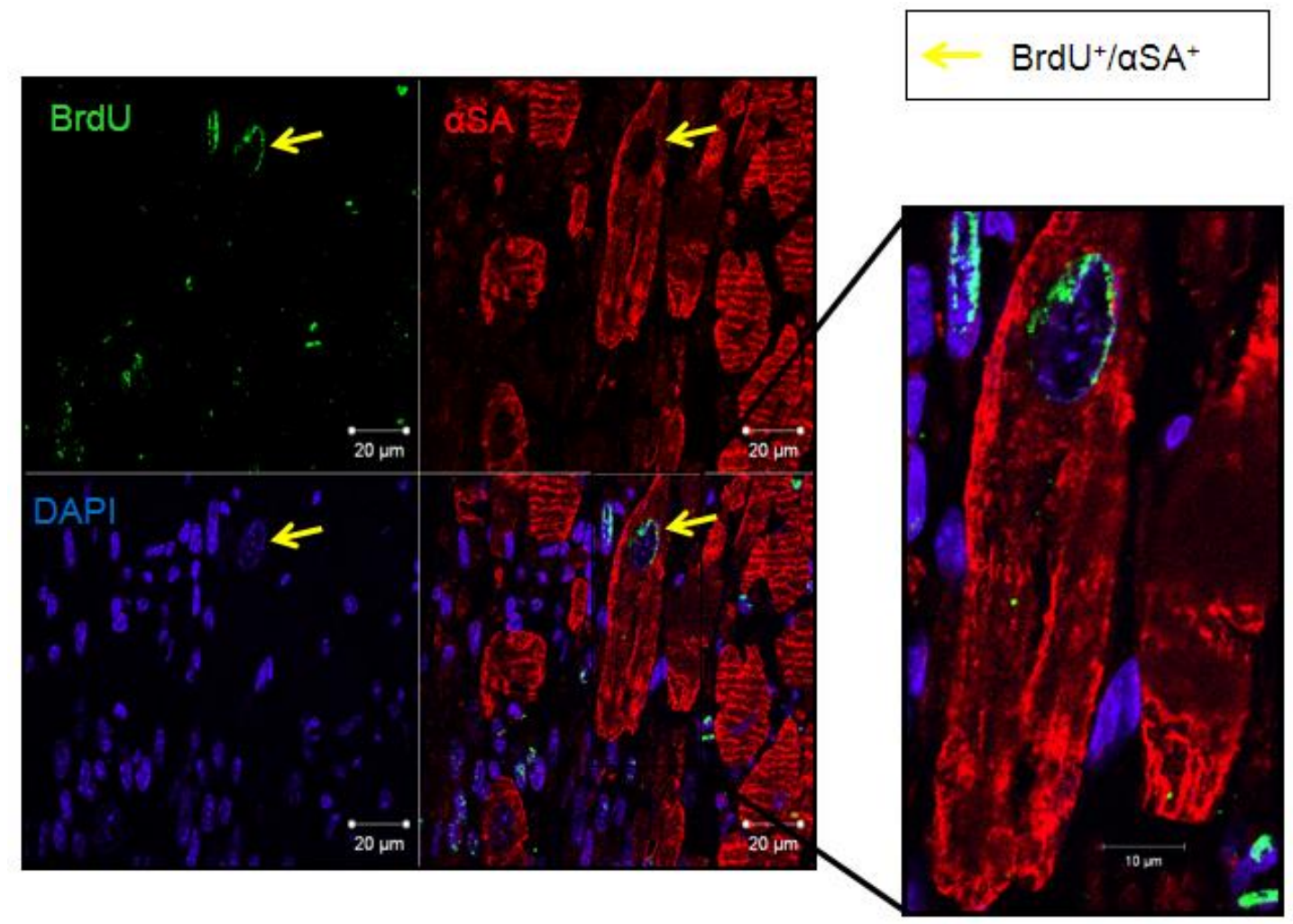

Figure XXVII Adult phenotype of new generated myocyte one week after infarction

non-infarcted, mice. This might suggest that cardiomyocytes changed their sensitivity towards SDF after myocardial infarction by accelerating cardio-protective signaling pathways.

SDF / CXCR4 was identified as a key factor in the recruitment of stem cells to areas of tissue injury in multiple organ systems. 
Interestingly, our data did not confirm the overall finding that SDF / CXCR4 acts as a molecular hub modulating neo-angiogenesis. ${ }^{90}$ SDF not only promotes revascularization by engaging with $\mathrm{CXCR} 4$ expressed on the vascular cells but also supports mobilization of pro-angiogentic $\mathrm{CXCR} 4^{+} \mathrm{VEGFR} 1^{+}$hematopoietic cells, thereby accelerating revascularization of ischemic organs. Shahin Rafii introduced the concept that, by modulating plasma SDF levels, the CXCR4 antagonist AMD3100 acutely promotes, while chronic AMD3100 treatment inhibits, mobilization of pro-angiogenic cells.

In contrast to most of the previous studies suggesting neovascularization after SDF treatment, in our model SDF was only overexpressed in cardiomyocytes and our intervention was not accompanied by simultaneous infusion of hematopoietic stem/ progenitor cells or their mobilization from the bone marrow (i.e. by administration of GCSF or AMD3100) as previous described. Therefore, our data suggested that cardiomyocytes-specific SDF overexpression might primarily act as a para- and / or intracrine factor causing cardiomyocyte proliferation. 


\section{CHAPTER 6}

\section{SUMMARY AND FUTURE RESEARCH DIRECTIONS}

Several different studies have been performed using SDF as chemokine to accelerate cardiac regeneration after myocardial infarction. However, less was known about the direct effect of chronic cardiomyocyte-specific expression of SDF cardiac regeneration and regulation of cell proliferation after myocardial infarction. Our results can be summarized as follows:

- This is the first study showing that cardiomyocyte-specific overexpression of SDF results in improved LV function, decreased myocardial infarction, and increased generation of new cardiomyocytes.

- We found no difference in myocardial infarct size and LV function directly after permanent ligation (i.e. three and seven days), which suggested the same initial injury between WT and SDF overexpressing mice.

- LV function remained unchanged despite cardiomyocyte-specific overexpression of SDF for five and 30 weeks, respectively.

- SDF overexpression resulted in a gene copy-number dependent increase of CK1 $\alpha$ and phosphorylation of AKT affect two important factors of cardiac regeneration: An increase in CSPC numbers within the heart of SDF high mice, and an increase of cardioprotective signaling. 
- However, BM function seems to be diminished as the number of leukocytes decreased after five and 30 weeks exposure to increased cardiac SDF levels, respectively. In contrast to previous published data, we did not see an increase in neo-vascularization after SDF overexpression but an increase apoptosis indicated by more $\mathrm{TUNEL}^{+}$cells.

As discussed above stem cell therapy currently appears to be the most attractive approach to generate new myocardium after an infarction. Nevertheless, some limitations apply as mentioned above, and therefore, alternatives are needed.

Here we used a model of cardiac-specific SDF overexpression and detected a marked increase in cardiac regeneration with a reduction in infarct size. Some special findings should be further annotated:

What is the origin of the new cardiomyocytes?

We detected a significant increase in cardiac regeneration including a marked increase in $\mathrm{BrdU}^{+}$or $\mathrm{Ki}^{+} 7^{+}$cardiomyocytes after permanent coronary ligation. The question becomes whether these are newly generated cardiomyocytes or a sort of differentiated, cardiac linage committed progenitor cells. Unfortunately, our study does not allow us to determine the origin of these newly formed cells. As extensively reviewed by Dr. Pierro Anversa's group ${ }^{91}$ and others, several explanations are possible:

a) Fate mapping studies using dilution of GFP labeling as indicator for newly formed cardiomyocyte, indicated $35 \%$ of the cardiomyocytes in the border zone and $28 \%$ in the remote-zone were newly generated, compared to $14 \%$ in sham operated mice. ${ }^{74}$ In contrast to Dr. Anversa's group, Richard Lee suggests that pre-existing cardiomyocytes are 
the primary source of cell replacement after injury. ${ }^{76}$ Using in vitro experiments, Keating and colleagues providing evidence that cardiomyocyte division occurs by either p38 MAP kinase inhibition ${ }^{86}$ or blockade of GSK $-3^{87}$ resulting in newly formed adult mammalian cardiomyocytes.

b) ${\mathrm{C}-\mathrm{kit}^{+}}^{+}$progenitor cells are considered as cardiac-specific stem cell source, giving rise to oligolineage progenitors, which after losing their self-renewal ability and withdrawal from cell-cycle, eventually become mature cardiomyocytes. ${ }^{92,93}$

c) Finally, reprogramming and trans-differentiation have been proposed as sources for new cardiomyocytes. Reprogramming of somatic cell (i.e. cardiac fibroblasts) towards cardiac lineage requires complex modulation using several transcription factors ${ }^{94,95}$ which appears unlikely in the model described in this thesis.

As chemoattractant, SDF has the potential ability to recruit hematopoietic stem cells to the infarct area, where those cells de-differentiate to myocytes or vascular cells. Although we cannot rule out this possibility, the absence of EPC mobilization after myocardial infarction in SDF Tg mice suggests that circulating cells most likely are not responsible for the improved function and generation of new cardiomyocytes seen in our experiments.

Cell cycle control by SDF appears to be different between cardiomyocytes and CSPCS.

Previous published data suggest that SDF mediates CSPC quiescence through a CK $1 \alpha$ dependent mechanism, as administration of CK1 $\alpha$ resulted in decreased CSPC proliferation. The western blot analysis from SDF overexpressing hearts in this study revealed a gene-copy number dependent increase in CK1 $1 \alpha$, which was accompanied by an 
increased number of CSPC in sham-operated animals. However, the number of $\mathrm{BrdU}^{+} / \mathrm{c}-$ $\mathrm{kit}^{+}$cells within the heart was similar to the WT controls, indicating decreased CSPC proliferation and confirming our previous in vitro work. ${ }^{46}$ Interestingly, besides the marked increase of $\mathrm{BrdU}^{+} / \alpha$-sarcomeric actin ${ }^{+}$cardiomyocyte numbers in the border zone after myocardial infarction, we also detected in the non-ischemic region accelerated proliferation of cardiomyocytes. Assuming that CK1 $\alpha$ expression in this region of the heart is similar to sham-operated animals, the data would suggest that cardiomyocyte proliferation is subject to a different regulatory pathway, which might or might not include CK1 $\alpha$.

Besides the increase in $\mathrm{BrdU}^{+}$and $\mathrm{Ki}^{+} 7^{+}$cardiomyocytes one and four weeks after myocardial infarction, we detected a significant increase in $\mathrm{TUNEL}^{+}$nuclei, indicating increased apoptosis and cardiac remodeling:

Increased apoptosis

In contrast to previously published work suggesting anti-apoptotic properties of SDF, these findings came as a surprise, but might be explained by the prolonged exposure of circulating cells towards SDF in weeks prior to myocardial ischemia. Different authors suggested that circulating $\mathrm{CD} 8{ }^{+},{ }^{96} \mathrm{CD} 4+,{ }^{+}{ }^{9}$ and specific tumor cells, ${ }^{98,99}$ undergo apoptosis after prolonged exposure to SDF. Interestingly, even concentrations as low as $10 \mathrm{ng} / 1$ might induce apoptosis dependent on the duration circulating cells are exposed to the chemokine. ${ }^{97}$ The molecular mechanism triggering the cell death is not quite understood, but Herbein ${ }^{96}$ detects after a relative high concentration of SDF (i.e. $1 \mu \mathrm{g} / 1$ ) a progressive increase of CD95 antigen expression on the cell surface as well as CD95L within the cell. 
Others describe up-regulation of TNF $\alpha$ or TNF-R which led to cell death after secondary exposure to SDF.

Finally, we did not find any difference in capillary density between WT and SDF overexpressing mice:

\section{SDF overexpression did not promote neovascularization}

SDF is identified to directly participate in new blood vessel formation in vitro by preventing EPC apoptosis ${ }^{100,101}$ and in vivo by inducing vasculogenesis. Mobilization of pro-angiogenic hematopoietic cells can be increased by either elevating SDF levels or by blocking CXCR4 by AMD3100. ${ }^{102,103}$ However, dynamics of mobilization between both methods are quite different as injection of AMD3100 rapidly mobilized hematopoietic stem cells, pro-angiogenic cells, and EPCs, while SDF mediated mobilization requires several days. Petit and colleagues suggest a "niche-dependent mobilization model", in which different "geographical microenvironments" are stimulated by both methods: ${ }^{90}$ The easy accessible perivascular niche, readily available to release hematopoietic stem cells, will respond quickly to an CXCR4 inhibition. In contrast, SDF mediated release of hematopoietic stem cells from the stromal or osteoblastic niches within the BM require a cascade of events and therefore requires several days to release hematopoietic stem cells into the circulation. ${ }^{104}$

Although we did not reach the significance level, the number of EPCs was reduced in the BM sample and the peripheral blood, respectively, which would suggest a diminished pool of EPCs in the Tg mice, reflected by the absence of EPC mobilization 72 hours after permanent ligation. 
Furthermore, it has been reported that knockdown of CK1 $1 \alpha \mathrm{LS}$ inhibits vascular cell proliferation in various isolated vessels (i.e. human umbilical vein endothelial cells, human coronary artery smooth muscle cells, and human coronary artery endothelial cells). ${ }^{105}$ As $\mathrm{CK} 1 \alpha \mathrm{LS}$ is thought to function antagonistically to its related cytosolic splice forms CK1 $\alpha$ and $\mathrm{CK} 1 \alpha \mathrm{S}$, which are known to negatively regulate pro-proliferative pathways, ${ }^{106,107} \mathrm{SDF}$ mediated overexpression of $\mathrm{CK} 1 \alpha$ might also be responsible for diminished revascularization after myocardial infarction.

\section{LIMITATIONS}

The conclusion that SDF overexpression facilitates increased regeneration after myocardial infarction resulting in improved function was based on the fact that we found an increase in $\mathrm{BrdU}^{+}$cardiomyocytes in the border-zone and in the scar area four weeks after myocardial infarction. As with many methods, BrdU incorporation as marker of cell division is recently challenged by the fact that theoretically, the replacement of thymidine with BrdU during DNA repair might also result in positive stained nuclei which could falsely interpreted as a cell undergo karyokinesis. In a recent study Richard Lee demonstrates that ${ }^{15} \mathrm{H}$ thymidine incorporation is two magnitudes higher in cells undergoing cell division than after $\mathrm{H}_{2} \mathrm{O}_{2}$ induced DNA damage and DNA synthesis. ${ }^{76}$

Our results might reflect SDF mediated increase in DNA synthesis after hypoxia induced cell injury without increased cell proliferation. However, Masson's trichrome analysis after one week indicated that $30 \%$ of the LV were scar tissue, similar between WT and SDF high mice. While the amount of scar tissue was significantly diminished in SDF 
high mice $(13 \%)$ the scar size remained the same in WT mice four weeks, suggesting the generation of new, viable myocardium in the SDF Tg hearts.

The combination of both observations (i.e. higher magnitude of BrdU incorporation in myocytes undergo karyokinesis and a significant reduction in infarct size) lead to our conclusion that cardiomyocyte specific overexpression of SDF facilitates regeneration of myocardium after permanent coronary ligation.

\section{FUTURE DIRECTIONS}

For the first time, our experiments provide evidence that the regeneration profile of the heart is facilitated after permanent coronary ligation by overexpressing SDF in the cardiomyocytes, which resulted in newly generated myocytes, increased LV function, and reduced myocardial infarct size. Further studies are needed to determine the role of CK1 $\alpha$ in cardiomyocyte and stem cell proliferation to determine whether it is suitable for gene therapy directly targeting myocytes renewal. The effect of chronic myocyte-specific SDF overexpression on $\mathrm{BM}$ homeostasis needs to be further evaluated as a depression of the BM would limit SDF overexpression as therapeutic options in the future. 


\section{REFERENCES}

1. Anversa, P.\& Kajstura, J. Ventricular myocytes are not terminally differentiated in the adult mammalian heart. Circulation research 83, 1-14 (1998). [PMID: $9670913]$

2. Beltrami, A.P., Urbanek, K., Kajstura, J., Yan, S.M., Finato, N., Bussani, R., NadalGinard, B., Silvestri, F., Leri, A., Beltrami, C.A. \& Anversa, P. Evidence that human cardiac myocytes divide after myocardial infarction. The New England journal of medicine 344, 1750-1757 (2001). [PMID: 11396441]

3. Tang, X.L., Rokosh, G., Sanganalmath, S.K., Yuan, F., Sato, H., Mu, J., Dai, S., Li, C., Chen, N., Peng, Y., Dawn, B., Hunt, G., Leri, A., Kajstura, J., Tiwari, S., Shirk, G., Anversa, P. \& Bolli, R. Intracoronary administration of cardiac progenitor cells alleviates left ventricular dysfunction in rats with a 30-day-old infarction. Circulation 121, 293-305 (2010). [PMID: 20048209]

4. Zuba-Surma, E.K., Guo, Y., Taher, H., Sanganalmath, S.K., Hunt, G., Vincent, R.J., Kucia, M., Abdel-Latif, A., Tang, X.L., Ratajczak, M.Z., Dawn, B. \& Bolli, R. Transplantation of expanded bone marrow-derived very small embryonic-like stem cells (VSEL-SCs) improves left ventricular function and remodelling after myocardial infarction. J Cell Mol Med 15, 1319-1328 (2011). [PMID: 20629987]

5. Bolli, R., Chugh, A.R., D'Amario, D., Loughran, J.H., Stoddard, M.F., Ikram, S., Beache, G.M., Wagner, S.G., Leri, A., Hosoda, T., Sanada, F., Elmore, J.B., Goichberg, P., Cappetta, D., Solankhi, N.K., Fahsah, I., Rokosh, D.G., Slaughter, 
M.S., Kajstura, J. \& Anversa, P. Cardiac stem cells in patients with ischaemic cardiomyopathy (SCIPIO): initial results of a randomised phase 1 trial. Lancet 378, 1847-1857 (2011). [PMID: 22088800]

6. Assmus, B., Schachinger, V., Teupe, C., Britten, M., Lehmann, R., Dobert, N., Grunwald, F., Aicher, A., Urbich, C., Martin, H., Hoelzer, D., Dimmeler, S. \& Zeiher, A.M. Transplantation of Progenitor Cells and Regeneration Enhancement in Acute Myocardial Infarction (TOPCARE-AMI). Circulation 106, 3009-3017 (2002). [PMID: 12473544]

7. Dawn, B., Abdel-Latif, A., Sanganalmath, S.K., Flaherty, M.P. \& Zuba-Surma, E.K. Cardiac repair with adult bone marrow-derived cells: the clinical evidence. Antioxidants \& redox signaling 11, 1865-1882 (2009). [PMID: 19203221]

8. Jeevanantham, V., Butler, M., Saad, A., Abdel-Latif, A., Zuba-Surma, E.K. \& Dawn, B. Adult bone marrow cell therapy improves survival and induces long-term improvement in cardiac parameters: a systematic review and meta-analysis. Circulation 126, 551-568 (2012). [PMID: 22730444]

9. Hu, X., Dai, S., Wu, W.J., Tan, W., Zhu, X., Mu, J., Guo, Y., Bolli, R. \& Rokosh, G. Stromal cell derived factor-1 alpha confers protection against myocardial ischemia/reperfusion injury: role of the cardiac stromal cell derived factor-1 alpha CXCR4 axis. Circulation 116, 654-663 (2007). [PMID: 17646584]

10. Dai, S., Yuan, F., Mu, J., Li, C., Chen, N., Guo, S., Kingery, J., Prabhu, S.D., Bolli, R. \& Rokosh, G. Chronic AMD3100 antagonism of SDF-1alpha-CXCR4 exacerbates cardiac dysfunction and remodeling after myocardial infarction. Journal of molecular and cellular cardiology 49, 587-597 (2010). [PMID: 20655922] 
11. Pillarisetti, K. \& Gupta, S.K. Cloning and relative expression analysis of rat stromal cell derived factor-1 (SDF-1)1: SDF-1 alpha mRNA is selectively induced in rat model of myocardial infarction. Inflammation 25, 293-300 (2001). [PMID: $11820456]$

12. Askari, A.T. \& Penn, M.S. Stromal cell-derived factor-1 mediates stem cell homing and tissue regeneration. Discovery medicine 3, 46-47 (2003). [PMID: 20704864]

13. Abbott, J.D., Huang, Y., Liu, D., Hickey, R., Krause, D.S. \& Giordano, F.J. Stromal cell-derived factor-1 alpha plays a critical role in stem cell recruitment to the heart after myocardial infarction but is not sufficient to induce homing in the absence of injury. Circulation 110, 3300-3305 (2004). [PMID: 15533866]

14. Yamani, M.H., Ratliff, N.B., Cook, D.J., Tuzcu, E.M., Yu, Y., Hobbs, R., Rincon, G., Bott-Silverman, C., Young, J.B., Smedira, N. \& Starling, R.C. Peritransplant ischemic injury is associated with up-regulation of stromal cell-derived factor-1. $J$ Am Coll Cardiol 46, 1029-1035 (2005). [PMID: 16168287]

15. Leone, A.M., Rutella, S., Bonanno, G., Contemi, A.M., de Ritis, D.G., Giannico, M.B., Rebuzzi, A.G., Leone, G. \& Crea, F. Endogenous G-CSF and CD34+ cell mobilization after acute myocardial infarction. International journal of cardiology 111, 202-208 (2006). [PMID: 16051386]

16. Ceradini, D.J., Kulkarni, A.R., Callaghan, M.J., Tepper, O.M., Bastidas, N., Kleinman, M.E., Capla, J.M., Galiano, R.D., Levine, J.P. \& Gurtner, G.C. Progenitor cell trafficking is regulated by hypoxic gradients through HIF-1 induction of SDF-1. Nature medicine 10, 858-864 (2004). [PMID: 15235597]

17. Tang, Y.L., Zhu, W., Cheng, M., Chen, L., Zhang, J., Sun, T., Kishore, R., Phillips, M.I., Losordo, D.W. \& Qin, G. Hypoxic preconditioning enhances the benefit of 
cardiac progenitor cell therapy for treatment of myocardial infarction by inducing CXCR4 expression. Circulation research 104, 1209-1216 (2009). [PMID: 19407239]

18. Kajstura, J., Leri, A., Finato, N., Di Loreto, C., Beltrami, C.A. \& Anversa, P. Myocyte proliferation in end-stage cardiac failure in humans. Proceedings of the National Academy of Sciences of the United States of America 95, 8801-8805 (1998). [PMID: 9671759]

19. Quaini, F., Cigola, E., Lagrasta, C., Saccani, G., Quaini, E., Rossi, C., Olivetti, G. $\&$ Anversa, P. End-stage cardiac failure in humans is coupled with the induction of proliferating cell nuclear antigen and nuclear mitotic division in ventricular myocytes. Circulation research 75, 1050-1063 (1994). [PMID: 7955143]

20. Bergmann, O., Bhardwaj, R.D., Bernard, S., Zdunek, S., Barnabe-Heider, F., Walsh, S., Zupicich, J., Alkass, K., Buchholz, B.A., Druid, H., Jovinge, S. \& Frisen, J. Evidence for cardiomyocyte renewal in humans. Science 324, 98-102 (2009). [PMID: 19342590]

21. Kajstura, J., Bai, Y., Cappetta, D., Kim, J., Arranto, C., Sanada, F., D'Amario, D., Matsuda, A., Bardelli, S., Ferreira-Martins, J., Hosoda, T., Leri, A., Rota, M., Loscalzo, J. \& Anversa, P. Tracking chromatid segregation to identify human cardiac stem cells that regenerate extensively the infarcted myocardium. Circulation research 111, 894-906 (2012). [PMID: 22851539]

22. Kucia, M., Jankowski, K., Reca, R., Wysoczynski, M., Bandura, L., Allendorf, D.J., Zhang, J., Ratajczak, J. \& Ratajczak, M.Z. CXCR4-SDF-1 signalling, locomotion, chemotaxis and adhesion. J Mol Histol 35, 233-245 (2004). [PMID: 15339043] 
23. Lapidot, T. \& Kollet, O. The essential roles of the chemokine SDF-1 and its receptor CXCR4 in human stem cell homing and repopulation of transplanted immune-deficient NOD/SCID and NOD/SCID/B2m(null) mice. Leukemia 16, 1992-2003 (2002). [PMID: 12357350]

24. Kucia, M., Dawn, B., Hunt, G., Guo, Y., Wysoczynski, M., Majka, M., Ratajczak, J., Rezzoug, F., Ildstad, S.T., Bolli, R. \& Ratajczak, M.Z. Cells expressing early cardiac markers reside in the bone marrow and are mobilized into the peripheral blood after myocardial infarction. Circulation research 95, 1191-1199 (2004). [PMID: 15550692]

25. Pituch-Noworolska, A., Majka, M., Janowska-Wieczorek, A., Baj-Krzyworzeka, M., Urbanowicz, B., Malec, E. \& Ratajczak, M.Z. Circulating CXCR4-positive stem/progenitor cells compete for SDF-1-positive niches in bone marrow, muscle and neural tissues: an alternative hypothesis to stem cell plasticity. Folia Histochem Cytobiol 41, 13-21 (2003). [PMID: 12705474]

26. Ratajczak, M.Z., Majka, M., Kucia, M., Drukala, J., Pietrzkowski, Z., Peiper, S. \& Janowska-Wieczorek, A. Expression of functional CXCR4 by muscle satellite cells and secretion of SDF-1 by muscle-derived fibroblasts is associated with the presence of both muscle progenitors in bone marrow and hematopoietic stem/progenitor cells in muscles. Stem cells 21, 363-371 (2003). [PMID: $12743331]$

27. Damas, J.K., Eiken, H.G., Oie, E., Bjerkeli, V., Yndestad, A., Ueland, T., Tonnessen, T., Geiran, O.R., Aass, H., Simonsen, S., Christensen, G., Froland, S.S., Attramadal, H., Gullestad, L. \& Aukrust, P. Myocardial expression of CC- and $\mathrm{CXC}$-chemokines and their receptors in human end-stage heart failure. Cardiovasc Res 47, 778-787 (2000). [PMID: 10974226$]$ 
28. Hatch, H.M., Zheng, D., Jorgensen, M.L. \& Petersen, B.E. SDF-1alpha/CXCR4: a mechanism for hepatic oval cell activation and bone marrow stem cell recruitment to the injured liver of rats. Cloning and stem cells 4, 339-351 (2002). [PMID: $12626097]$

29. Togel, F., Isaac, J., Hu, Z., Weiss, K. \& Westenfelder, C. Renal SDF-1 signals mobilization and homing of CXCR4-positive cells to the kidney after ischemic injury. Kidney international 67, 1772-1784 (2005). [PMID: 15840024]

30. Sierro, F., Biben, C., Martinez-Munoz, L., Mellado, M., Ransohoff, R.M., Li, M., Woehl, B., Leung, H., Groom, J., Batten, M., Harvey, R.P., Martinez, A.C., Mackay, C.R. \& Mackay, F. Disrupted cardiac development but normal hematopoiesis in mice deficient in the second CXCL12/SDF-1 receptor, CXCR7. Proceedings of the National Academy of Sciences of the United States of America 104, 14759-14764 (2007). [PMID: 17804806]

31. McGrath, K.E., Koniski, A.D., Maltby, K.M., McGann, J.K. \& Palis, J. Embryonic expression and function of the chemokine SDF-1 and its receptor, CXCR4. Developmental biology 213, 442-456 (1999). [PMID: 10479460]

32. Chiriac, A., Nelson, T.J., Faustino, R.S., Behfar, A. \& Terzic, A. Cardiogenic induction of pluripotent stem cells streamlined through a conserved SDF1/VEGF/BMP2 integrated network. PloS one 5, e9943 (2010). [PMID: 20376342]

33. Tachibana, K., Hirota, S., Iizasa, H., Yoshida, H., Kawabata, K., Kataoka, Y., Kitamura, Y., Matsushima, K., Yoshida, N., Nishikawa, S., Kishimoto, T. \& Nagasawa, T. The chemokine receptor CXCR4 is essential for vascularization of the gastrointestinal tract. Nature 393, 591-594 (1998). [PMID: 9634237$]$ 
34. Zou, Y.R., Kottmann, A.H., Kuroda, M., Taniuchi, I. \& Littman, D.R. Function of the chemokine receptor CXCR4 in haematopoiesis and in cerebellar development. Nature 393, 595-599 (1998). [PMID: 9634238$]$

35. Lazarini, F., Tham, T.N., Casanova, P., Arenzana-Seisdedos, F. \& Dubois-Dalcq, M. Role of the alpha-chemokine stromal cell-derived factor (SDF-1) in the developing and mature central nervous system. Glia 42, 139-148 (2003). [PMID: $12655598]$

36. Ghadge, S.K., Mühlstedt, S., Özcelik, C. \& Bader, M. SDF-1 $\alpha$ as a therapeutic stem cell homing factor in myocardial infarction. Pharmacology \& therapeutics 129, 97 108 (2011). [PMID: 20965212]

37. Elmadbouh, I., Haider, H., Jiang, S., Idris, N.M., Lu, G. \& Ashraf, M. Ex vivo delivered stromal cell-derived factor-1alpha promotes stem cell homing and induces angiomyogenesis in the infarcted myocardium. Journal of molecular and cellular cardiology 42, 792-803 (2007). [PMID: 17350033]

38. Huang, C., Gu, H., Zhang, W., Manukyan, M.C., Shou, W. \& Wang, M. SDF1/CXCR4 mediates acute protection of cardiac function through myocardial STAT3 signaling following global ischemia/reperfusion injury. American journal of physiology. Heart and circulatory physiology 301, H1496-1505 (2011). [PMID: $21821779]$

39. Saxena, A., Fish, J.E., White, M.D., Yu, S., Smyth, J.W., Shaw, R.M., DiMaio, J.M. \& Srivastava, D. Stromal cell-derived factor-1alpha is cardioprotective after myocardial infarction. Circulation 117, 2224-2231 (2008). [PMID: 18427137$]$

40. Schuh, A., Liehn, E.A., Sasse, A., Hristov, M., Sobota, R., Kelm, M., Merx, M.W. \& Weber, C. Transplantation of endothelial progenitor cells improves 
neovascularization and left ventricular function after myocardial infarction in a rat model. Basic Res Cardiol 103, 69-77 (2008). [PMID: 17999028]

41. Zhang, M., Mal, N., Kiedrowski, M., Chacko, M., Askari, A.T., Popovic, Z.B., Koc, O.N. \& Penn, M.S. SDF-1 expression by mesenchymal stem cells results in trophic support of cardiac myocytes after myocardial infarction. The FASEB Journal 21, 3197-3207 (2007). [PMID:

42. Zhao, T., Zhang, D., Millard, R.W., Ashraf, M. \& Wang, Y. Stem cell homing and angiomyogenesis in transplanted hearts are enhanced by combined intramyocardial SDF-1alpha delivery and endogenous cytokine signaling. American journal of physiology. Heart and circulatory physiology 296, H976-986 (2009). [PMID: $19181961]$

43. Segers, V.F., Tokunou, T., Higgins, L.J., MacGillivray, C., Gannon, J. \& Lee, R.T. Local delivery of protease-resistant stromal cell derived factor-1 for stem cell recruitment after myocardial infarction. Circulation 116, 1683-1692 (2007). [PMID: 17875967]

44. Zaruba, M.M., Theiss, H.D., Vallaster, M., Mehl, U., Brunner, S., David, R., Fischer, R., Krieg, L., Hirsch, E., Huber, B., Nathan, P., Israel, L., Imhof, A., Herbach, N., Assmann, G., Wanke, R., Mueller-Hoecker, J., Steinbeck, G. \& Franz, W.M. Synergy between CD26/DPP-IV inhibition and G-CSF improves cardiac function after acute myocardial infarction. Cell Stem Cell 4, 313-323 (2009). [PMID: 19341621]

45. Cheng, Z., Ou, L., Zhou, X., Li, F., Jia, X., Zhang, Y., Liu, X., Li, Y., Ward, C.A., Melo, L.G. \& Kong, D. Targeted migration of mesenchymal stem cells modified with CXCR4 gene to infarcted myocardium improves cardiac performance. 
Molecular therapy : the journal of the American Society of Gene Therapy 16, 571579 (2008). [PMID: 18253156]

46. Dimova, N., Wysoczynski, M. \& Rokosh, G. Stromal Cell Derived Factor-1alpha Promotes C-Kit(+) Cardiac Stem/Progenitor Cell Quiescence Through Casein Kinase 1alpha and GSK3beta. Stem cells 32, 487-499 (2014). [PMID: 24038789]

47. Gross, S.D., Hoffman, D.P., Fisette, P.L., Baas, P. \& Anderson, R.A. A phosphatidylinositol 4,5-bisphosphate-sensitive casein kinase I alpha associates with synaptic vesicles and phosphorylates a subset of vesicle proteins. J Cell Biol 130, 711-724 (1995). [PMID: 7622570$]$

48. Fish, K.J., Cegielska, A., Getman, M.E., Landes, G.M. \& Virshup, D.M. Isolation and characterization of human casein kinase I epsilon (CKI), a novel member of the CKI gene family. The Journal of biological chemistry 270, 14875-14883 (1995). [PMID: 7797465]

49. Graves, P.R. \& Roach, P.J. Role of COOH-terminal phosphorylation in the regulation of casein kinase I delta. The Journal of biological chemistry 270, 2168921694 (1995). [PMID: 7665585$]$

50. Rowles, J., Slaughter, C., Moomaw, C., Hsu, J. \& Cobb, M.H. Purification of casein kinase I and isolation of cDNAs encoding multiple casein kinase I-like enzymes. Proceedings of the National Academy of Sciences of the United States of America 88, 9548-9552 (1991). [PMID: 1946367]

51. Wang, X., Hoekstra, M.F., DeMaggio, A.J., Dhillon, N., Vancura, A., Kuret, J., Johnston, G.C. \& Singer, R.A. Prenylated isoforms of yeast casein kinase I, including the novel Yck3p, suppress the gcs1 blockage of cell proliferation from stationary phase. Mol Cell Biol 16, 5375-5385 (1996). [PMID: 8816449] 
52. Zhai, L., Graves, P.R., Robinson, L.C., Italiano, M., Culbertson, M.R., Rowles, J., Cobb, M.H., DePaoli-Roach, A.A. \& Roach, P.J. Casein kinase I gamma subfamily. Molecular cloning, expression, and characterization of three mammalian isoforms and complementation of defects in the Saccharomyces cerevisiae YCK genes. The Journal of biological chemistry 270, 12717-12724 (1995). [PMID: 7759525]

53. Knippschild, U., Gocht, A., Wolff, S., Huber, N., Lohler, J. \& Stoter, M. The casein kinase 1 family: participation in multiple cellular processes in eukaryotes. Cell Signal 17, 675-689 (2005). [PMID: 15722192]

54. Knippschild, U., Wolff, S., Giamas, G., Brockschmidt, C., Wittau, M., Wurl, P.U., Eismann, T. \& Stoter, M. The role of the casein kinase 1 (CK1) family in different signaling pathways linked to cancer development. Onkologie 28, 508-514 (2005). [PMID: 16186692]

55. Cruciat, C.M., Dolde, C., de Groot, R.E., Ohkawara, B., Reinhard, C., Korswagen, H.C. \& Niehrs, C. RNA helicase DDX3 is a regulatory subunit of casein kinase 1 in Wnt-beta-catenin signaling. Science 339, 1436-1441 (2013). [PMID: 23413191$]$

56. Gietzen, K.F. \& Virshup, D.M. Identification of inhibitory autophosphorylation sites in casein kinase I epsilon. The Journal of biological chemistry 274, 3206332070 (1999). [PMID: 10542239]

57. Sanbe, A., Gulick, J., Hanks, M.C., Liang, Q., Osinska, H. \& Robbins, J. Reengineering inducible cardiac-specific transgenesis with an attenuated myosin heavy chain promoter. Circulation research 92, 609-616 (2003). [PMID: $12623879]$ 
58. Baron, U., Gossen, M. \& Bujard, H. Tetracycline-controlled transcription in eukaryotes: novel transactivators with graded transactivation potential. Nucleic acids research 25, 2723-2729 (1997). [PMID: 9207017]

59. Lima e Silva, R., Shen, J., Hackett, S.F., Kachi, S., Akiyama, H., Kiuchi, K., Yokoi, K., Hatara, M.C., Lauer, T., Aslam, S., Gong, Y.Y., Xiao, W.-H., Khu, N.H., Thut, C. \& Campochiaro, P.A. The SDF-1/CXCR4 ligand/receptor pair is an important contributor to several types of ocular neovascularization. The FASEB Journal 21, 3219-3230 (2007). [PMID: 17522382]

60. Xu, X., Zhu, F., Zhang, M., Zeng, D., Luo, D., Liu, G., Cui, W., Wang, S., Guo, W., Xing, W., Liang, H., Li, L., Fu, X., Jiang, J. \& Huang, H. Stromal cell-derived factor-1 enhances wound healing through recruiting bone marrow-derived mesenchymal stem cells to the wound area and promoting neovascularization. Cells, tissues, organs 197, 103-113 (2013). [PMID: 23207453]

61. Broxmeyer, H.E., Hangoc, G., Cooper, S., Campbell, T., Ito, S. \& Mantel, C. AMD3100 and CD26 modulate mobilization, engraftment, and survival of hematopoietic stem and progenitor cells mediated by the SDF-1/CXCL12-CXCR4 axis. Annals of the New York Academy of Sciences 1106, 1-19 (2007). [PMID: 17360804]

62. Christopherson, K.W., 2nd, Hangoc, G. \& Broxmeyer, H.E. Cell surface peptidase CD26/dipeptidylpeptidase IV regulates CXCL12/stromal cell-derived factor-1 alpha-mediated chemotaxis of human cord blood CD34+ progenitor cells. Journal of immunology 169, 7000-7008 (2002). [PMID: 12471135]

63. De La Luz Sierra, M., Yang, F., Narazaki, M., Salvucci, O., Davis, D., Yarchoan, R., Zhang, H.H., Fales, H. \& Tosato, G. Differential processing of stromal-derived 
factor-1 alpha and stromal-derived factor-1beta explains functional diversity. Blood 103, 2452-2459 (2004). [PMID: 14525775]

64. Broxmeyer, H.E., Cooper, S., Kohli, L., Hangoc, G., Lee, Y., Mantel, C., Clapp, D.W. \& Kim, C.H. Transgenic expression of stromal cell-derived factor-1/CXC chemokine ligand 12 enhances myeloid progenitor cell survival/antiapoptosis in vitro in response to growth factor withdrawal and enhances myelopoiesis in vivo. Journal of immunology 170, 421-429 (2003). [PMID: 12496427]

65. Rollins, B.J. Chemokines. Blood 90, 909-928 (1997). [PMID: 9242519]

66. Kijowski, J., Baj-Krzyworzeka, M., Majka, M., Reca, R., Marquez, L.A., Christofidou-Solomidou, M., Janowska-Wieczorek, A. \& Ratajczak, M.Z. The SDF-1-CXCR4 axis stimulates VEGF secretion and activates integrins but does not affect proliferation and survival in lymphohematopoietic cells. Stem cells 19, 453466 (2001). [PMID: 11553854]

67. Hodohara, K., Fujii, N., Yamamoto, N. \& Kaushansky, K. Stromal cell-derived factor-1 (SDF-1) acts together with thrombopoietin to enhance the development of megakaryocytic progenitor cells (CFU-MK). Blood 95, 769-775 (2000). [PMID: $10648384]$

68. Lataillade, J.J., Clay, D., Dupuy, C., Rigal, S., Jasmin, C., Bourin, P. \& Le BousseKerdilès, M.C. Chemokine SDF-1 enhances circulating CD34(+) cell proliferation in synergy with cytokines: possible role in progenitor survival. Blood $\mathbf{9 5}, 756-768$ (2000). [PMID: 10648383]

69. Kanki, S., Segers, V.F., Wu, W., Kakkar, R., Gannon, J., Sys, S.U., Sandrasagra, A. \& Lee, R.T. Stromal cell-derived factor-1 retention and cardioprotection for 
ischemic myocardium. Circulation. Heart failure 4, 509-518 (2011). [PMID: $21606214]$

70. Vivaldi, M.T., Kloner, R.A. \& Schoen, F.J. Triphenyltetrazolium staining of irreversible ischemic injury following coronary artery occlusion in rats. The American journal of pathology 121, 522-530 (1985). [PMID: 2416222]

71. Gomori, G. A rapid one-step trichrome stain. American journal of clinical pathology 20, 661-664 (1950). [PMID: 15432364]

72. Hochman, J.S. \& Choo, H. Limitation of myocardial infarct expansion by reperfusion independent of myocardial salvage. Circulation 75, 299-306 (1987). [PMID: 3791612]

73. Kee, N., Sivalingam, S., Boonstra, R. \& Wojtowicz, J.M. The utility of Ki-67 and BrdU as proliferative markers of adult neurogenesis. Journal of neuroscience methods 115, 97-105 (2002). [PMID: 11897369]

74. Hsieh, P.C., Segers, V.F., Davis, M.E., MacGillivray, C., Gannon, J., Molkentin, J.D., Robbins, J. \& Lee, R.T. Evidence from a genetic fate-mapping study that stem cells refresh adult mammalian cardiomyocytes after injury. Nature medicine 13, 970-974 (2007). [PMID: 17660827]

75. Li, F., Wang, X., Capasso, J.M. \& Gerdes, A.M. Rapid transition of cardiac myocytes from hyperplasia to hypertrophy during postnatal development. Journal of molecular and cellular cardiology 28, 1737-1746 (1996). [PMID: 8877783]

76. Senyo, S.E., Steinhauser, M.L., Pizzimenti, C.L., Yang, V.K., Cai, L., Wang, M., Wu, T.D., Guerquin-Kern, J.L., Lechene, C.P. \& Lee, R.T. Mammalian heart 
renewal by pre-existing cardiomyocytes. Nature 493, 433-436 (2013). [PMID: $23222518]$

77. Scholzen, T. \& Gerdes, J. The Ki-67 protein: from the known and the unknown. Journal of cellular physiology 182, 311-322 (2000). [PMID: 10653597]

78. Hall, P.A., McKee, P.H., Menage, H.D., Dover, R. \& Lane, D.P. High levels of p53 protein in UV-irradiated normal human skin. Oncogene 8, 203-207 (1993). [PMID: 8093810]

79. Anversa, P., Cheng, W., Liu, Y., Leri, A., Redaelli, G. \& Kajstura, J. Apoptosis and myocardial infarction. Basic Res Cardiol 93 Suppl 3, 8-12 (1998). [PMID: 9879436]

80. Tang, J., Wang, J., Yang, J. \& Kong, X. Adenovirus-mediated stromal cell-derivedfactor-1alpha gene transfer induces cardiac preservation after infarction via angiogenesis of $\mathrm{CD} 133+$ stem cells and anti-apoptosis. Interactive cardiovascular and thoracic surgery 7, 767-770 (2008). [PMID: 18577527]

81. Bauer, M., Cheng, S., Jain, M., Ngoy, S., Theodoropoulos, C., Trujillo, A., Lin, F.C. \& Liao, R. Echocardiographic speckle-tracking based strain imaging for rapid cardiovascular phenotyping in mice. Circulation research 108, 908-916 (2011). [PMID: 21372284]

82. Heimdal, A., Stoylen, A., Torp, H. \& Skjaerpe, T. Real-time strain rate imaging of the left ventricle by ultrasound. Journal of the American Society of Echocardiography : official publication of the American Society of Echocardiography 11, 1013-1019 (1998). [PMID: 9812093] 
83. Collins, K.A., Korcarz, C.E., Shroff, S.G., Bednarz, J.E., Fentzke, R.C., Lin, H., Leiden, J.M. \& Lang, R.M. Accuracy of echocardiographic estimates of left ventricular mass in mice. American journal of physiology. Heart and circulatory physiology 280, H1954-1962 (2001). [PMID: 11299194]

84. Houser, S.R., Margulies, K.B., Murphy, A.M., Spinale, F.G., Francis, G.S., Prabhu, S.D., Rockman, H.A., Kass, D.A., Molkentin, J.D., Sussman, M.A., Koch, W.J., American Heart Association Council on Basic Cardiovascular Sciences, C.o.C.C., Council on Functional, G. \& Translational, B. Animal models of heart failure: a scientific statement from the American Heart Association. Circulation research 111, 131-150 (2012). [PMID: 22595296]

85. Maxwell, M.P., Hearse, D.J. \& Yellon, D.M. Species variation in the coronary collateral circulation during regional myocardial ischaemia: a critical determinant of the rate of evolution and extent of myocardial infarction. Cardiovasc Res 21, 737-746 (1987). [PMID: 3440266]

86. Engel, F.B., Schebesta, M., Duong, M.T., Lu, G., Ren, S., Madwed, J.B., Jiang, H., Wang, Y.\& Keating, M.T. p38 MAP kinase inhibition enables proliferation of adult mammalian cardiomyocytes. Genes \& development 19, 1175-1187 (2005). [PMID: $15870258]$

87. Tseng, A.-S., Engel, F.B. \& Keating, M.T. The GSK-3 inhibitor BIO promotes proliferation in mammalian cardiomyocytes. Chemistry \& biology 13, 957-963 (2006). [PMID: 16984885]

88. Broxmeyer, H.E., Kohli, L., Kim, C.H., Lee, Y., Mantel, C., Cooper, S., Hangoc, G., Shaheen, M., Li, X. \& Clapp, D.W. Stromal cell-derived factor-1/CXCL12 directly enhances survival/antiapoptosis of myeloid progenitor cells through CXCR4 and G(alpha)i proteins and enhances engraftment of competitive, 
repopulating stem cells. Journal of leukocyte biology 73, 630-638 (2003). [PMID: $12714578]$

89. Pyo, R.T., Sui, J., Dhume, A., Palomeque, J., Blaxall, B.C., Diaz, G., Tunstead, J., Logothetis, D.E., Hajjar, R.J. \& Schecter, A.D. CXCR4 modulates contractility in adult cardiac myocytes. Journal of molecular and cellular cardiology 41, 834-844 (2006). [PMID: 17010372]

90. Petit, I., Jin, D. \& Rafii, S. The SDF-1-CXCR4 signaling pathway: a molecular hub modulating neo-angiogenesis. Trends in immunology 28, 299-307 (2007). [PMID: 17560169]

91. Leri, A., Kajstura, J. \& Anversa, P. Mechanisms of myocardial regeneration. Trends Cardiovasc Med 21, 52-58 (2011). [PMID: 22578241]

92. Hosoda, T., D'Amario, D., Cabral-Da-Silva, M.C., Zheng, H., Padin-Iruegas, M.E., Ogorek, B., Ferreira-Martins, J., Yasuzawa-Amano, S., Amano, K., Ide-Iwata, N., Cheng, W., Rota, M., Urbanek, K., Kajstura, J., Anversa, P. \& Leri, A. Clonality of mouse and human cardiomyogenesis in vivo. Proceedings of the National Academy of Sciences of the United States of America 106, 17169-17174 (2009). [PMID: 19805158]

93. Ellison, G.M., Vicinanza, C., Smith, A.J., Aquila, I., Leone, A., Waring, C.D., Henning, B.J., Stirparo, G.G., Papait, R., Scarfò, M., Agosti, V., Viglietto, G., Condorelli, G., Indolfi, C., Ottolenghi, S., Torella, D. \& Nadal-Ginard, B. Adult ckitpos Cardiac Stem Cells Are Necessary and Sufficient for Functional Cardiac Regeneration and Repair. Cell 154, 827-842 (2013). [PMID: 23953114]

94. Wada, R., Muraoka, N., Inagawa, K., Yamakawa, H., Miyamoto, K., Sadahiro, T., Umei, T., Kaneda, R., Suzuki, T., Kamiya, K., Tohyama, S., Yuasa, S., Kokaji, K., 
Aeba, R., Yozu, R., Yamagishi, H., Kitamura, T., Fukuda, K. \& Ieda, M. Induction of human cardiomyocyte-like cells from fibroblasts by defined factors. Proceedings of the National Academy of Sciences of the United States of America 110, 1266712672 (2013). [PMID: 23861494]

95. Fu, J.D., Stone, N.R., Liu, L., Spencer, C.I., Qian, L., Hayashi, Y., Delgado-Olguin, P., Ding, S., Bruneau, B.G. \& Srivastava, D. Direct Reprogramming of Human Fibroblasts toward a Cardiomyocyte-like State. Stem cell reports 1, 235-247 (2013). [PMID: 24319660]

96. Herbein, G., Mahlknecht, U., Batliwalla, F., Gregersen, P., Pappas, T., Butler, J., O'Brien, W.A. \& Verdin, E. Apoptosis of CD8+ T cells is mediated by macrophages through interaction of HIV gp120 with chemokine receptor CXCR4. Nature 395, 189-194 (1998). [PMID: 9744279$]$

97. Colamussi, M.L., Secchiero, P., Gonelli, A., Marchisio, M., Zauli, G. \& Capitani, S. Stromal derived factor-1 alpha (SDF-1 alpha) induces CD4+ T cell apoptosis via the functional up-regulation of the Fas (CD95)/Fas ligand (CD95L) pathway. Journal of leukocyte biology 69, 263-270 (2001). [PMID: 11272277]

98. Wendt, M.K., Drury, L.J., Vongsa, R.A. \& Dwinell, M.B. Constitutive CXCL12 expression induces anoikis in colorectal carcinoma cells. Gastroenterology 135, 508-517 (2008). [PMID: 18558091$]$

99. Kremer, K.N., Peterson, K.L., Schneider, P.A., Meng, X.W., Dai, H., Hess, A.D., Smith, B.D., Rodriguez-Ramirez, C., Karp, J.E., Kaufmann, S.H. \& Hedin, K.E. CXCR4 chemokine receptor signaling induces apoptosis in acute myeloid leukemia cells via regulation of the Bcl-2 family members Bcl-XL, Noxa, and Bak. The Journal of biological chemistry 288, 22899-22914 (2013). [PMID: 23798675] 
100. Hiasa, K., Ishibashi, M., Ohtani, K., Inoue, S., Zhao, Q., Kitamoto, S., Sata, M., Ichiki, T., Takeshita, A. \& Egashira, K. Gene transfer of stromal cell-derived factor1alpha enhances ischemic vasculogenesis and angiogenesis via vascular endothelial growth factor/endothelial nitric oxide synthase-related pathway: next-generation chemokine therapy for therapeutic neovascularization. Circulation 109, 2454-2461 (2004). [PMID: 15148275]

101. Salvucci, O., Yao, L., Villalba, S., Sajewicz, A., Pittaluga, S. \& Tosato, G. Regulation of endothelial cell branching morphogenesis by endogenous chemokine stromal-derived factor-1. Blood 99, 2703-2711 (2002). [PMID: 11929756]

102. Shepherd, R.M., Capoccia, B.J., Devine, S.M., Dipersio, J., Trinkaus, K.M., Ingram, D. \& Link, D.C. Angiogenic cells can be rapidly mobilized and efficiently harvested from the blood following treatment with AMD3100. Blood 108, 36623667 (2006). [PMID: 16912220$]$

103. Capoccia, B.J., Shepherd, R.M. \& Link, D.C. G-CSF and AMD3100 mobilize monocytes into the blood that stimulate angiogenesis in vivo through a paracrine mechanism. Blood 108, 2438-2445 (2006). [PMID: 16735597]

104. Zhong, R., Law, P., Wong, D., Merzouk, A., Salari, H. \& Ball, E.D. Small peptide analogs to stromal derived factor-1 enhance chemotactic migration of human and mouse hematopoietic cells. Experimental hematology 32, 470-475 (2004). [PMID: $15145215]$

105. Panchenko, M.P., Siddiquee, Z., Dombkowski, D.M., Alekseyev, Y.O., Lenburg, M.E., Walker, J.D., Macgillivray, T.E., Preffer, F.I. \& Stone, J.R. Protein kinase CK1alphaLS promotes vascular cell proliferation and intimal hyperplasia. The American journal of pathology 177, 1562-1572 (2010). [PMID: 20696773] 
106. Price, M.A. CKI, there's more than one: casein kinase I family members in Wnt and Hedgehog signaling. Genes Dev 20, 399-410 (2006). [PMID: 16481469]

107. Zhu, J., Shibasaki, F., Price, R., Guillemot, J.C., Yano, T., Dotsch, V., Wagner, G., Ferrara, P. \& McKeon, F. Intramolecular masking of nuclear import signal on NFAT4 by casein kinase I and MEKK1. Cell 93, 851-861 (1998). [PMID: 9630228$]$ 


\title{
CURRICULUM VITAE
}

\section{Detlef Obal, M.S., M.D., D.E.S.A.}

\author{
Assistant Professor \\ Department of Anesthesiology and Perioperative Medicine \\ Institute of Molecular Cardiology \\ School of Medicine \\ University of Louisville \\ Louisville, Kentucky, 40202 USA \\ Office Address: \\ Department of Anesthesiology and Perioperative Medicine \\ University of Louisville, School of Medicine \\ 530 South Jackson Street, Room C2A03 \\ Louisville, Kentucky, 40202 USA \\ Phone: $\quad(+1) \quad 502-852-5851$ \\ Fax: $\quad(+1) \quad 502-852-6065$ \\ e-mail: d.obal@louisville.edu; dobal@me.com \\ www: http:/ louisville.edu/ medschool/ anesthesiology/ faculty-1/ detlef-obal-m-d.html \\ Home Address: \\ 3140 Sunfield Circle \\ Louisville, Kentucky, 40241 USA \\ Phone: (+1) 502-407-2865
}

\section{Laboratory Address:}

Institute of Molecular Cardiology

University of Louisville,

School of Medicine

530 South Preston Street, Baxter II Research

Building Room 304A, 307-309

Louisville, Kentucky, 40202 USA 


\section{EDUCATION:}

\section{Medical:}

1992-1999 Medical School Heinrich-Heine-University of Düsseldorf, Germany

\section{Graduate:}

04/ 2014 Doctor of Philosophy (Department of Physiology \& Biophysics, University of Louisville, KY, USA)

08/ 2010 Master of Science (Department of Physiology \& Biophysics, University of Louisville, KY, USA)

2008-2014 Ph.D. program at the Department of Physiology \& Biophysics, University of Louisville, KY, USA (Mentor: Gregg Rokosh, Ph.D., Chair: Roberto Bolli, M.D., Institute of Molecular Cardiology)

\section{Residency}

1999-2004 Residency, Department of Anesthesiology, University Hospital Düsseldorf, Germany, Chair of the Department: J. Tarnow, Professor of Anesthesiology, FRCA; since 2007: Chair: B. Pannen, Professor of Anesthesiology

\section{Fellowships}

Transesophageal Echocardiography course, Hamburg, Germany

2001

Training visit at the Department of Physiology, University of Regensburg, Germany (Chair: A. Kurtz, Professor of Physiology); Education in preparation of isolated rat kidneys and measurement of renal renin regulation

1998 Four months internal medicine rotation at the General Hospital of Ashtonunder-Lyne (teaching hospital of the University of Manchester, Great Britain)

1997 Department of Pediatrics, University of Pretoria, South Africa \& Department of Cardiology, University of Pretoria, South Africa

1996 Department of Anesthesiology and surgical intensive care medicine, urban hospital, Düsseldorf (Städt. Krankenhaus Gerresheim, Düsseldorf, Germany). 
Department of vascular surgery and renal replacement (Chair: W. Sandmann, Professor of vascular surgery) at the University Hospital of Düsseldorf \& Clerkship in internal medicine at an urban hospital, Düsseldorf (St. Martinus - Krankenhaus, Düsseldorf, Germany).

\section{Medical Activities during medical school}

1992-1999 Paramedic in an urban EMS service in the city of Neuss, Germany

1992-1998 Nursing on SICU (surgical intensive care unit, University Hospital, Düsseldorf, Germany)

\section{ACADEMIC APPOINTMENTS:}

2006-present Assistant Professor Department of Anesthesiology and Perioperative Medicine, University of Louisville, KY, USA

05/ 2005 Diplomat of the European Society of Anesthesiology (D.E.S.A.)

1999 M.D. Thesis: "Effect of acidotic reperfusion on myocardial reperfusion injury in dogs in vivo" (Magna cum laude)

\section{OTHER POSITIONS AND EMPOLYMENT}

2004-2006 Anesthesiologist at the Department of Anesthesiology and Perioperative Medicine, University of Düsseldorf, Germany

BOARD CERTIFICATION, LICENSURE, REGISTRATION:

GREAT BRITAIN: Specialist Register British General Medical Council (03/ 006)

KENTUCKY: $\quad$ FL018 (12/005)

GERMANY: $\quad$ Licensure to practice medicine (7/999)

2013 Refreshed ACLS training - valid until 12/ 015

2005 Certified Leading Emergency/ Rescue Physician

2004 Board certified for Anesthesiology (Germany)

$2000 \quad$ Specialist for Emergency/ Rescue medicine (EMS Physician)

$1992 \quad$ State-certified Paramedic (EMS) 


\section{PROFESSIONAL MEMBERSHIPS AND ACTIVITIES:}

Memberships

Since 2006 American Heart Association (AHA)

Since 2006 International Anesthesia Research Society (IARS)

Since 2006 American Society of Anesthesiology (ASA)

Since 2006 British Medical Council

2006-2007 American Medical Association (AMA)

2003-2010 National Society of Rescue Medicine, Nordrhein-Westfalen

2001-2010 European Society of Anesthesiology (ESA)

Since 2000 German Society of Anesthesiology (DGAI)

Activities Clinical Research

Since 06/010 Principle investigator of retrospective data-analysis "Effect of storage time of packed red blood cells on outcome after massive blood transfusion." Retrospective collection of 500 patient data files between 2005-2012.

2008-2012 Member of the NIH funded (P20 RR024489-01A1) COBRE grant (Center of Excellence in Diabetes and Obesity Research, PI: Aruni Bhatnagar, Ph.D.), 15\% time effort

2007-2013 Local principal investigator of the multicenter study ENIGMA II in Louisville, KY, USA (7500 patients, 36 centers), actually $\sim 170$ patients in Louisville enrolled ( $\sim 5 \%$ of total enrolled patients)

Since 2006 Member of the Outcomes Research Consortium ${ }^{\mathrm{TM}}$ (Head: D. Sessler, M.D.) and conductance of multiple studies evaluating the effect of anesthetics on the depth of sedation in volunteers. 
$\underline{\text { Activities Basic Research }}$

08/2006 Invited scholar of the Baltic Summer School: "Stem cell biology -Future perspectives and possible treatment options." 20.08.-01.09.2006 Kiel, Germany

Since 2006 Training in molecular biology at the Institute of Molecular Cardiology (Chair: R. Bolli, M.D.), Mentor: Gregg Rokosh, Ph.D.

2002-2004 Establishment of a chronic renal ischemia-reperfusion model in the rat in vivo (Measurement of renal function variables); Establishment of histology quantification of renal cell damage (Immune-histology, H\&E sections in cooperation with the Departments of Anatomy II and Pathology, University of Düsseldorf, Germany)

2001 Establishment of an acute model of lung injury after acidic aspiration in the rat in vivo (Continuous measurement of blood gases with the Paratrend ${ }^{\circledR}$ monitor device, cooperation with S. Loer, M.D, outside lecturer of anesthesiology, Düsseldorf, Germany)

2000-2001 Establishment of an acute model of renal ischemia/ eperfusion experiments in the rat in vivo (Continuous measurement of renal blood flow, side divided urinary outflow, histological determination of cell damage)

Since 2000 Working in a ratio of $60 / 0$ in the operation theatre and as scientific assistant in the Section of Experimental Anesthesiology, University of Düsseldorf, Germany (Chair: J.Tarnow, Professor of Anesthesiology, FRCA)

1999 Establishment of an acute model of ischemia-reperfusion situations in the rat heart in vivo (Continuous measurement of left ventricular pressure, cardiac output)

1995 Course of laboratory animal care and handling, Central Animal Research Institute, University of Düsseldorf, Germany (Chair: A. Treiber, veterinary doctor)

1995 Course for scientific statistical analysis using Windows SPSS computer software 
HONORS AND AWARDS:

First Price - Best abstract prize competition at the annual Euroanesthesia congress, Glasgow, Scotland:

Obal D, Müllenheim J, Favoccia C, Kratz M, Dettwiler S, Preckel B, Schlack W: Anaesthetic preconditioning and reduction of reperfusion injury by sevoflurane offered additive myocardial protection mediated by opening of KATP channels. Eur J Anaesthesiol 2003; 20 (Suppl. 30), A5.

\section{COMMITTEE ASSIGNMENTS AND ADMINISTRATIVE:}

Since 2008 Departmental Research Board (Overview of financial, academic and organizational aspects of departmental research activities, guidance to clinical research fellows)

2007-2013 University of Louisville Medical Center Blood Transfusion Committee (quarterly meetings)

Since 2007 University of Louisville Medical Trauma Quality Conference (monthly meetings)

\section{PEER REVIEWER OF MANUSCRIPTS:}

Since 2013 Review editor "Frontiers in Physiology, Oxidant Physiology"

Since 2011 Annual abstract reviewer for the AHA scientific sessions, basic science abstracts “Ischemia Reperfusion Injury” section

2014 Ad hock Reviewer:

* BMC Anesthesiology

* TAAP - Toxicology and Applied Pharmacology

2013 Ad hoc Reviewer:

* American Journal of Cardiology

* TAAP - Toxicology and Applied Pharmacology 
$2011 \quad$ Ad hoc Reviewer:

* American Journal of Cardiology

* Cardiovascular Diabetology

$2010 \quad$ Journal of Cellular and Molecular Neurobiology

2007 British Journal of Anaesthesiology

BOARD MEMBERSHIPS:

Since 2013 Editorial Board of Frontiers in Oxidant Physiology - Review Editor

Since 2013 Editorial Board BioMed Research International - Anesthesiology

\section{TEACHING:}

Since 2006 Scheduled Classes for Medical Students and Residents

2012 ACLS lecturer for Anesthesia Residents

2012 Course Director, Initiator, Program presenter, $1^{\text {st }}$ Louisville Airway Day, May $24^{\text {th }} 2012$, Louisville, KY, USA (CME accredited program)

2010 ASA Instructor of Difficult Airway Management (ASA annual meeting, San Diego, CA, USA)

Since 2009 Lectures for medical students and Ph.D. graduates in the Department of Pharmacology at the University of Louisville, KY, USA (4 hours/ year)

Since 2008 Lectures for medical students in the Department of Physiology and Biophysics at the School of Medicine, University of Louisville, KY, USA (8 hours/ semester)

Since 2006 Regular lectures for residents of the Department of Anesthesiology and Perioperative Medicine, University of Louisville, Louisville, KY, USA

2004-2005 Lecture for final year medical students in Anesthesiology, Department of Anesthesiology, University Hospital Düsseldorf, Germany

1999-2001 Clinical tutor for medical students in emergency medicine, Department of Anesthesiology, University Hospital Düsseldorf, Germany

1995-1997 Medical student tutor for cardiac and respiratory physiology, Department of Physiology, University of Düsseldorf 
Predoctoral Students supervised and mentored:

Since 1999 Laboratory tutor for medical students during their work for the thesis to doctorate

$\begin{array}{lllll}\text { H. Scharbatke } & - & 2004-2007 & - & \text { magna cum laude } \\ \text { F. Hoetterkes } & - & 2005-2008 & - & \text { magna cum laude } \\ \text { S. Dettwiler } & - & 2007-2009 & - & \text { magna cum laude } \\ \text { C. Favoccia } & - & 2007 & - & \text { pending } \\ \text { W. Brown (M.S.) } & - & \text { since } 2009 & & \\ \text { F. Memon (M.S.) } & - & 2010-2011 & \\ \text { T.B. Wright (M.S.) } & - & 2010-2013 & & \end{array}$

Mentor and Advisor of clinical research fellows

Ragu Govinda (2006-2008)

Anton Grankin $\quad$ (2008-2010)

Alexander Bautista $\quad$ (2009-2010)

Sunitha Kanchikandadai $\quad$ (2010-2011)

Sahil Chabra (2011-2013)

\section{ABSTRACTS AND PRESENTATIONS:}

\section{Oral Presentations: National/ International Meetings}

1. Obal D: Perioperative Administration of ondansetron or dolasetron does not lengthen QT interval. Outcomes Research Meeting at the American Society of Anesthesiology Annual Meeting, Washington, DC. 10/ 7/ 012

2. Obal D: Fiberoptic Intubation, $1^{\text {st }}$ Difficult Airway Course, Paris Simulation Center, University of Louisville, KY, May $12^{\text {th }}, 2012$

3. Obal D: Perioperative Use of Statins, Annual Kentucky Society of Anesthesia Spring Meeting, Marriott Cincinnati at Rivercenter, Covington, KY, March $24^{\text {th }}$, 2012 
4. Obal D: Effect of Storage Time on Outcome after Massive Blood Transfusion. Outcomes Research Meeting at the American Society of Anesthesiology Annual Meeting, San Diego. 10/7/ 010

5. Obal D, Schlack W: Intraoperative myocardial ischemia - what should I do ?; TED session at the annual meeting of the German society of Anesthesiology 04/ 7/ 005

6. Obal D: Organprotection by anesthetic preconditioning. Scientific meeting of the outcome research department, University of Louisville, KY, USA 02/ 1/ 005

7. Obal D: Prevention and treatment of perioperative myocardial ischemia

8. What the anesthesiologist should know. Didactic lecture for the residencies of the Department of Anesthesiology, University of Louisville, KY, USA. 02/ 7/ 005

9. Obal D: Perioperatives Nierenversagen; Didactic lecture 04/ 004 Department of Anesthesiology, University Hospital Düsseldorf, Germany

10. Obal D, Fräßdorf J, Müllenheim J, Preckel B, Schlack W: Rolle der Opiatrezeptoren bei der Morphin - induzierten späten Präkonditionierung. Anästhesiologie \& Intensivmedizin 2003; 44 FV 109.6.

11. Obal D, Müllenheim J, Preckel B, Thämer V, Schlack W: How do administration time and concentration affect the cardioprotection by sevoflurane against reperfusion injury? Anesthesiology 2001; 95, A682.

12. Obal D, Müllenheim J, Scharbatke H, Thämer V, Schlack W: Two minutes of sevoflurane administration are enough to protect the heart against reperfusion injury. Eur J Anaesthesiol 2001;18:A162.

13. Obal D, Preckel B, Müllenheim J, Thämer V, Schlack W: Einfluss der Konzentration und Applikationsdauer von Sevofluran auf die Ausdehnung des Reperfusionsschadens des Herzens. Anästhesiologie \& Intensivmedizin $2001 ; 42: 877$.

14. Obal D, Preckel B, Hoff J, Thämer V, Schlack W: Einfluß einer Stellatumblockade auf die Ventrikelfunktion - Studie an wachen Hunden. Anästhesiol Intensivmed Notfallmed Schmerzther 1998 


\section{Oral Presentations: Local/ Regional Meetings}

Grand Round presentations at the University of Louisville, Department of Anesthesiology:

- Obal D: Grand round, Department of Anesthesiology \& Perioperative Medicine: Perioperative Lung Function; August 22 ${ }^{\text {nd }}, 2013$

- Obal D: Grand round, Department of Anesthesiology \& Perioperative Medicine: Nitrous oxide - ENIGMA trial and other mysteries; July $7^{\text {th }}, 2013$

- Obal D: Grand round, Department of Anesthesiology \& Perioperative Medicine: QTc interval - neglected by anesthesiologists; August $3^{\text {rd }}, 2012$

- Vessel E, Obal D: Grand round, Department of Anesthesiology \& Perioperative Medicine: Repeat Operation on a Traumatic Hemorrhage; April 27 $7^{\text {th }}, 2012$

- Obal D : Grand round Department of Anesthesiology \& Perioperative Medicine: "Introduction to ROTEM" June 2011

- Obal D : Grand round Department of Anesthesiology \& Perioperative Medicine: "Introduction to TEG" February 2011

- Bo Hargett, Obal D. M\&M Conference: "Why so hypotensive?" December, $13^{\text {th }} 2010$

- Obal D. The perioperative ischemic evaluation-2 (POISE-2) trial or "What's new in the protection against perioperative infarction in patients undergoing non-cardiac surgery?" November, $8^{\text {th }} 2010$

- Obal D. "Blood transfusion - do we need to change our current practice?" July $6^{\text {th }} 2009$

- Obal D. M\&M Conference: Rush in the morning - the 5.30 am case. March $2^{\text {nd }}, 2009$

- Obal D, Lenhardt R, Turan A, Akca O. Research at the Department of Anesthesiology and Perioperative Medicine. May $18^{\text {th }}, 2008$

- Lenhardt R, Obal D. Hemorrhagic Shock \& Massive Transfusion - Standard Procedure at the UofL Hospital, March 10 ${ }^{\text {th }}, 2008$

- Obal D. Anesthesia and coagulation disorders. What the Anesthesia Provider Should Know ! April 14 ${ }^{\text {th }}, 2008$ 
- Obal D. The ENIGMA II Trail. "Nitrous Oxide Anesthesia and Cardiac Morbidity after Major Surgery". May $17^{\text {th }}, 2007$

- Obal D, Henson L. Perioperative and Anesthetic Care for Trauma Patients, October $9^{\text {th }}, 2006$

- Obal D. Anesthesia for emergency triplet A surgery. July $13^{\text {th }}, 2006$

\section{Poster Presentations: National/ International Meetings}

1. Obal D, Yang D, Sessler DI: Perioperative administration of ondansetron or dolasetron is not associated with QTc prolongation. ASA Annual meeting Abstract 2012, 12-A-3862-ASAHQ

2. Obal D, Dai S, Keith R, Dimova N, Kingery J, Zheng Y-T, Zweier J, Velayutham J, Prabhu S, Li Q, Conklin D, Bhatnagar A, Bolli R, Rokosh G: Overexpression of cardiomyocyte-specific extracellular superoxide dismutase increases nitric oxide bioavailability and reduces infarct size after ischemia/ reperfusion. Circulation 2010 AHA Annual meeting, Chicago

3. Bautista A, Brown B, Sessler D, Wadhwa A, Obal D: Effect of storage time of blood transfusion products on outcome in massive transfusion situations. Anesthesiology 2010, A1515

4. Kasuya Y, Govinda R, Obal D, Turan A, Sessler DI: Effect of Aminophylline on Loss of Consciousness, BIS, and Propofol Requirement in Human Volunteers. Anesthesiology 2007; 107: A521

5. Obal D, Favoccia C, Dettwiler S, Preckel B, Schlack W: Desflurane Postconditioning Reduces Renal Reperfusion Injury Anesthesiology 2005; 103: A337

6. Fräßdorf J, Weber NC, Toma O, Obal D, Kojda G, Preckel B, Schlack W: Opioide receptors are mediators of late cardioprotection - involvement of the nuclear transcription factor $\kappa \mathrm{B}$ Cardio-Visionen - Symposium der NordrheinWestfälischen Akademie der Wissenschaften, 2004, 1: 149

7. Dettwiler S, Obal D, Favoccia C, Preckel B, Schlack W: Preconditioning induced by the volatile anaesthetic sevoflurane did not improve renal function after 
ischaemia and reperfusion. Pflügers Arch Eur J Physiol 2004, Deutscher Physiologen Kongress

8. Toma O, Weber NC, Wolter JI, Obal D, Preckel B, Schlack W: Die Desfluraninduzierte Präkonditionierung wird über eine zeitabhängige Aktivierung der PKC$\varepsilon$ und ERK-2 vermittelt. Anästhesiologie \& Intensivmedizin 2004, 45: 691-718

9. Pakulla MA, Obal D, Seidel D, Loer SA: Salzsäure-induzierte Lungenschädigung - Effekte einer frühen partiellen Flüssigkeitsbeatmung auf den Gasaustausch und das Überleben von Ratten. Anästhesiologie \& Intensivmedizin 2004, 45: 691-718

10. Weber NC, Toma O, Wolter JI, Obal D, Schlack W, Preckel B: Xenon induziert eine pharmakologische Präkonditionierung des Rattenherzens in vivo über eine Induktion der PKC- $\varepsilon$ und p38 MAPK. Anästhesiologie \& Intensivmedizin 2004, 45: $691-718$

11. Toma O, Obal D, Weber NC, Dettwiler S, Preckel B, Schlack W: Zeitlicher Verlauf von PKC- $\varepsilon$ und ERK-2 bei der Desfluran-induzierten Präkonditionierung am Rattenherz in vivo. Anästhesiol Intensivmed Notfallmed Schmerzther 2004; DAK: PO-1-3.3.

12. Ley S, Obal D, Dettwiler S, Preckel B, Schlack W: Effekt von Sevolfluraninduzierter Präkonditionierung auf den Ischämie-Reperfusionsschaden der Niere. Anästhesiol Intensivmed Notfallmed Schmerzther 2004; DAK: PO-1-3.2.

13. Obal D, Dettwiler S, Ley S, Preckel B, Schlack W: Sevoflurane induced preconditioning did not improve renal function after ischaemia/ eperfusion. Eur $\mathrm{J}$ Anaesthesiol 2004; ESA annual meeting

14. Obal D, Dettwiler S, Weber NC, Preckel B, Schlack W: Myocardial protection by preconditioning through protein kinase $\mathrm{C}$ activation depends on isoflurane concentration. Anesthesiology 2004; 101: A701

15. Obal D, Dettwiler S, Favoccia C, Preckel B, Schlack W: Renal function did not improve after Sevoflurane induced preconditioning. Anesthesiology 2004; 101: A724

16. Obal D, Müllenheim J, Dettwiler S, Schlack W: Effect of protein kinase c inhibition by staurosporin on isoflurane preconditioning in the rat heart in vivo. Anesthesiology 2003; 99, A1550. 
17. Toma O, Weber NC, Obal D, Preckel B, Schlack W: Xenon induces myocardial protection by preconditioning. Involvement of protein kinase $\mathrm{C}$ (PKC). Anesthesiology 2003; 99, A1540

18. Fräßdorf J, Obal D, Malpohl A, Preckel B, Müllenheim J, Schlack W: Morphine and LPS induced late preconditioning: Are opioidreceptors trigger, mediator or both ? Eur J Anaesthesiol 2003; 20 (Suppl. 30), A231.

19. Pakulla MA, Obal D, Seidel D, Loer SA: Partial liquid ventilation in acid-induced lung injury - effects of immediate and delayed initiation. Intensive Care Med 2003; 29 (9 Suppl.), 559

20. Pakulla MA, Obal D, Loer SA: Intraarterielles Blutgasmonitoring bei Ratten. Anästhesiologie \& Intensivmedizin 2003; 44, PD 404.7

21. Fräßdorf J, Obal D, Preckel B, Müllenheim J, Schlack W: Rolle der Opiatrezeptoren bei der Morphin- und Lipopolysaccharid-induzierten späten Präkonditionierung. Anästhesiol Intensivmed Notfallmed Schmerzther 2003.

22. Obal D, Kratz M, Dettwiler S, Favoccia C, Preckel B, Müllenheim J, Schlack W: Die Gabe von Sevofluran während der Reperfusion verstärkt die Wirkung der Anästhetika induzierten Präkonditionierung. Anästhesiologie \& Intensivmedizin 2003; 44, FV109.4.

23. Pakulla MA, Obal D, Loer SA: Continuous intra-arterial blood gas monitoring in rats. Eur J Anaesthesiol 2003; 20 (Suppl. 30), A113

24. Obal D, Scharbatke H, Müllenheim J, Preckel B, Schlack W: Myocardial Protection by Preconditioning with Sevoflurane Is Further Enhanced by Sevoflurane Administration during Reperfusion. Anesthesiology 2002; 96, A607

25. Preckel B, Müllenheim J, Hoff J, Obal D, Thämer V, Schlack W: Inotropic effects of inhalational anesthetics in dogs with severe heart failure. Anesth Analg. 2002;94:S-283.

26. Pakulla MA, Obal D, Loer SA: Kontinuierliche intraarterielle Blutgas-Messung bei Ratten. Intensivmedizin und Notfallmedizin 2002; 39 (Suppl. 1), I/ 6

27. Obal D, Preckel B, Scharbatke H, Thämer V, Schlack W: Is the protective effect of sevoflurane against myocardial reperfusion injury concentration dependent? Eur J Anaesthesiol. 2001;18:A161 
28. Scharbatke H, Obal D, Müllenheim J, Preckel B, Thämer V, Schlack W: Bereits eine zweiminütige Gabe von Sevofluran schützt das Herz vor dem Reperfusionsschaden in vivo. Studie an Ratten. Anästhesiologie \& Intensivmedizin $2001 ; 472$.

29. Preckel B, Obal D, Scharbatke H, Müllenheim J, Thämer V, Schlack W: Two minutes of sevoflurane administration are enough to protect against myocardial reperfusion injury. Minerva Anestesiol 2001;67:139.

30. Preckel B, Obal D, Scharbatke H, Müllenheim J, Thämer V, Schlack W: The protective effect of sevoflurane against myocardial reperfusion injury is concentration dependent. Minerva Anestesiol 2001;67:138.

31. Heiderhoff M, Obal D, Hoff J, Preckel B, Schlack W, Thämer V: Effect of volantile anaesthetics of frequence-dependency of myocardial contraction velocity in chronically instrumented dogs. Pflügers Arch Eur J Physiol 1999;437:P28-12.

32. Heiderhoff M, Obal D, Preckel B, Thämer V, Schlack W: Effect of a left stellate ganglion block on left ventricular function in chronically instrumented dogs. Br J Anaesth 1999;82:A.203.

33. Obal D, Heiderhoff M, Preckel B, Thämer V, Schlack W: Effect of volatile anaesthetics on frequence-dependency of myocardial contractility in chronically instrumented dogs. Eur J Anaesthesiol 1999

34. Preckel B, Schlack W, Gonzáles M, Obal D, Barthel H, Thämer V: Influences of Angiotensin II $\mathrm{AT}_{1}$ receptor antagonism on ischaemia / reperfusion injury of the dog heart in vivo. Pflügers Arch Eur J Physiol 1998;435.

35. Gonzáles M, Preckel B, Schlack W, Obal D, Barthel H, Thämer V: Einfluß einer Angiotensin II $\mathrm{AT}_{1}$ Rezeptorblockade auf den myokardialen Ischämie / Reperfusionsschaden am Hundeherzen in vivo. Z Kardiol 1998;87:FV 980.

36. Preckel B, Schlack W, Obal D, Heiderhoff M, Hoff J, Thämer V: Effect of a left stellate ganglion blockade on left ventricular function in conscious dogs. Pflügers Arch Eur J Physiol 1998;435.

37. Obal D, Preckel B, Barthel H, Ebel D, Grunert S, Schlack W, Thämer V: Effekt einer intrakoronaren $\mathrm{pH}$ Senkung nach Koronarokklusion auf die Infarktgrösse in vivo. Z Kardiol 1997;86:335. 
38. Preckel B, Schlack W, Comfère T, Obal D, Thämer V: Holothan reduziert den Reperfusionsschaden nach regionaler Koronarokklusion in vivo. Anästhesiol Intensivmed Notfallmed Schmerzther 1997;32:FV17.1.

39. Preckel B, Schlack W, Obal D, Gonzáles M, Thämer V: Wirkung verschiedener Inhalationsanästhetika auf den myokardialen Reperfusionsschaden in vivo. $\mathrm{Z}$ Kardiol 1997;86:90

40. Preckel B, Schlack W, Obal D, Thämer V: Different effects of Enflurane, Isoflurane, Sevoflurane, Desflurane on myocardial reperfusion injury in vivo. Br J Anaesth 1997;78 (Suppl. 1): A.149

41. Barthel H, Preckel B, Kojda G, Schlack W, Obal D, Kottenberg K, Noack E, Thämer V: Effekte verschiedener NO Donatoren auf die myokardiale Funktion am Hundeherzen in vivo. Anästhesiol Intensivmed Notfallmed Schmerzther 1997; 32 (Suppl. 1):S153.

42. Preckel B, Kojda G, Schlack W, Barthel H, Ebel D, Obal D, Grunert S, Kottenberg $\mathrm{K}$, Noack E, Thämer V: Inotropic effects of different NO-donors in the dog heart in vivo. Pflügers Arch Eur J Physiol 1997; 433 (Suppl. 6):R 22.

43. Preckel B, Schlack W, Ebel D, Barthel H, Obal D, Grunert S, Meyer O, Halilovic $\mathrm{S}$, Thämer V: Reperfusion with acidotic blood after coronary artery occlusion does not reduce infarct size in dogs. Pflügers Arch 1996; 431, Suppl.6:R146.

44. Preckel B, Kojda G, Schlack W, Ebel D, Barthel H, Obal D, Kottenberg K, Thämer $\mathrm{V}$ : Influence of spontaneous NO-donors and organic nitrates on regional myocardial inotropy in the dog heart in vivo. Eur J Anaesthesiol 1996

\section{Poster Presentations: Local/ Regional Meetings}

- Obal D, Hu X, Dimova N, Brittian K, Book M, Guo Y, Bhatnagar A, Bolli R, Rokosh G: Inducible, cardiomyocyte-specific transgenic stromal cell derived factor 1 expression facilitates cardiac regeneration after permanent coronary ligation in mice. The cardiovascular forum for promoting centers of excellence and young investigators. International Academy of Cardiovascular Science annual meeting, Louisville August 15-17, 2013 


\section{PATENTS:}

$\mathrm{N} / \mathrm{A}$

\section{RESEARCH FUNDING:}

PEER Reviewed:

NIH COBRE Grant A. Bhatnagar, Ph.D. (PI) 04/ 1/9-present

Center of excellence in diabetes and obesity research (Collaborator: 15\% time support)

The specific objective of the Center is to develop a basic and clinical understanding of the molecular mechanisms of diabetes and obesity and how they contribute to the burden of cardiovascular disease. In this focus I am studying the impact of hyperglycemia on cardiac reparative potential by mesenchymal and cardiac specific stem cells and whether modulation of cardiac environment increases regeneration tendency in diabetes.

\section{CLINICAL SERVICE:}

I provide general anesthesia services in the main operating room at the University of Louisville Hospital, covering general surgery, vascular surgery, neurosurgery, endovascular procedures, oncology surgery, liver surgery, ENT surgery, OB/YN surgery and procedures, cardiovascular and thoracic surgery, trauma surgery. The University of Louisville is a level one-trauma center; therefore, orthopedic surgery and trauma surgery procedures are a major focus of our work, including regional anesthesia procedures as well as emergency procedures (rescue surgery after major trauma). The anesthesia service covers all cardiovascular resuscitations and difficult endotracheal intubations 24/ at the University Hospital. My call schedule includes six to eight 12 hour call shifts including two night/weekend calls/month. These call shifts require physician's in-house presence. 


\section{PUBLICATIONS, BOOK CHAPTERS, TEXTBOOK}

\section{Peer reviewed paper:}

1. Houser P, Miller J, Obal D: A case of critical intra-operative tracheal stenosis complicated by tension pneumothorax and postobstructive pulmonary edema. Clin Anesthesia 2014; xy: xx-xy (submitted for publication)

2. Obal D, Yang D, Sessler DI: Perioperative doses of ondansetron or dolasetron do not lengthen the QT interval. Mayo Clin Proc 2014; 89 (1): 69-80

3. Luo J, Obal D, Dimova N, Tang XL, Rokosh G: Cardiac myocyte-specific transgenic ecSOD targets mitochondria to protect against $\mathrm{Ca}(2+)$ induced permeability transition. Front Physiol. 2013 Oct 29;4:295. doi: 10.3389/ phys.2013.00295.

4. Obal D, Dai S, Keith R, Dimova N, Kingery J, Zheng Y-T, Zweier J, Velayutham J, Prabhu S, Li Q, Conklin D, Bhatnagar A, Bolli R, Rokosh G: Overexpression of Cardiomyocyte-specific Extracellular Superoxide Dismutase Increases NO Bioavailability and Reduces Infarct size after Ischemia Reperfusion. Basic Res Cardiol 2012;107(6):305. doi: 10.1007/ 00395-012-0305-1. Epub 2012 Oct 262

5. Wadhwa A, Kandadai SK, Tongpresert S, Obal D, Gebhard RE: Ultrasound guidance for deep peripheral nerve blocks: a brief review. Anesthesiol Res Pract. 2011; 2011:262070. Epub 2011 Jul 27.

6. Turan A, Kasuya Y, Govinda R, Orhan-Sungur M, Obal D, Rauch S, Dalton J, Akça O, Sessler DI: The effect of aminophylline on loss of consciousness, bispectral index, propofol requirement, and minimum alveolar concentration of desflurane in volunteers. Anesth Analg. 2010 Feb 1;110(2):449-54

7. West MB, Rokosh G, Obal D, Velayutham M, Xuan YT, Hill BG, Keith RJ, Schrader J, Guo Y, Conklin DJ, Prabhu SD, Zweier JL, Bolli R, Bhatnagar A: Cardiac myocyte-specific expression of inducible nitric oxide synthase protects against ischemia/ eperfusion injury by preventing mitochondrial permeability transition. Circulation. 2008 Nov 4;118(19):1970-8.

8. Preckel B, Obal D, Müllenheim J, Hennes J, Heiderhoff M, Thämer V, Schlack W: Effects of halothane, sevoflurane and desflurane on the force-frequency relation in the dog heart in vivo. Can J Anaesth. 2006 Nov;53(11):1118-25. 
9. Obal D, Rascher K, Favoccia C, Dettwiler S, Schlack W: Post-conditioning by a short administration of desflurane reduced renal reperfusion injury after differing of ischaemia times in rats. Br J Anaesth. 2006 Dec;97(6):783-91.

10. Obal D, Dettwiler S, Favoccia C, Rascher K, Preckel B, Schlack W: Effect of sevoflurane preconditioning on ischaemia/ reperfusion injury in the rat kidney in vivo. Eur J Anaesthesiol. 2006 Apr;23(4):319-26.

11. Weber NC, Toma O, Wolter JI, Obal D, Müllenheim J, Preckel B, Schlack W: The noble gas xenon induces pharmacological preconditioning in the rat heart in vivo via induction of PKC-epsilon and p38 MAPK Br J Pharmacol 2005, 144(1):12332.

12. Obal D, Dettwiler S, Favoccia C, Scharbatke H, Preckel B, Schlack W: The influence of mitochondrial $\mathrm{K}_{\mathrm{ATP}}$-channels in the cardioprotection of preconditioning and postconditioning by sevoflurane in the rat in vivo. Anesth Analg. 2005 Nov;101(5):1252-60

13. Fräßdorf J, Weber NC, Obal D, Toma O, Müllenheim J, Kojda G, Preckel B, Schlack W: Morphine induces late cardioprotection in rat hearts in vivo: the involvement of opioid receptors and nuclear transcription factor kappaB. Anesth Analg. 2005 Oct;101(4):934-41

14. Obal D, Weber NC, Zacharowski K, Toma O, Dettwiler S, Wolter JI, Kratz M,

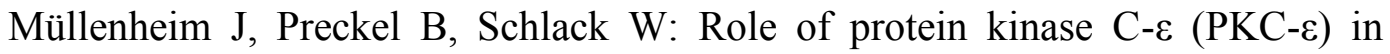
isoflurane induced cardioprotection. Low, but not high concentrations of isoflurane activate PKC-E. B J Anaesth 2005; 94(2):166-73

15. Schober P, Seidel D, Kalb R, Obal D, Pakulla MA, Loer SA: Partial liquid ventilation in acute salt water-induced lung injury. Eur J Anaesthesiol. 2005 Jul;22(7):536-40.

16. Obal D, Kindgen-Milles D, Schoebel F, Schlack W: Coronary artery angioplasty for treatment of perioperative myocardial ischaemia. Anaesthesia 2005; 60(2):1947

17. Toma O, Weber NC, Wolter JC, Obal D, Preckel B, Schlack W: Desflurane preconditioning induces time-dependent activation of protein kinase $\mathrm{C}$ epsilon and 
extracellular regulated kinase 1 and 2 in the rat heart in vivo. Anesthesiology 2004, $101 ; 6: 1372-1380$

18. Preckel B, Müllenheim J, Hoff J, Obal D, Thämer V, Schlack W: Haemodynamic changes during halothane, sevoflurane and desflurane anaesthesia in dogs before and after the induction of severe heart failure. Eur J Anaesth 2004; 21(10):797-806

19. Pakulla MA, Obal D, Loer SA: Continuous intra-arterial blood gas monitoring in rats. Lab Anim Sci 2004;38:133-137

20. Barthel H, Ebel D, Müllenheim J, Obal D, Preckel B, Schlack W: Effect of lidocaine on ischemic preconditioning in the isolated rat heart. $\mathrm{Br} \mathrm{J}$ Anaesth 2004;87:905-911

21. Pakulla MA, Seidel D, Obal D, Loer SA: Hydrochloric acid-induced lung injury: effects of early partial liquid ventilation on survival rate, gas exchange, and pulmonary neutrophil accumulation. Intensive Care Med 2004;30:2110-2119

22. Obal D, Scharbatke H, Barthel H, Preckel B, Müllenheim J, Schlack W: Cardioprotection against reperfusion injury is maximal with only 2 minutes of sevoflurane administration in rats. Can J Anaesth 2003; 50:940-945

23. Obal D, Preckel B, Scharbatke H, Müllenheim J, Höterkes F, Thämer V, Schlack W: One MAC of sevoflurane provides protection against reperfusion injury in the rat heart in vivo. Br J Anaesth 2001;87:905-911

24. Preckel B, Schlack W, Gonzalez M, Obal D, Barthel H, Thämer V: Influence of the angiotensin II AT1 receptor antagonist irbesartan on ischemia/ eperfusion injury in the dog heart. Basic Res Cardiol 2000;95:404-412.

25. Müllenheim J, Preckel B, Obal D, Heiderhoff M, Hoff J, Thämer V, Schlack W: Left stellate ganglion block has only small effects on left ventricular function in awake dogs before and after induction of heart failure. Anesth Analg 2000;91:787792.

26. Preckel B, Schlack W, Obal D, Barthel H, Ebel D, Grunert S, Thämer V: Effect of acidotic blood reperfusion on reperfusion injury after coronary artery occlusion in the dog heart. J Cardiovasc Pharmacol 1998;31:179-186.

27. Preckel B, Schlack W, Comfère T, Obal D, Barthel H, Thämer V: Effects of enflurane, isoflurane, sevoflurane and desflurane on reperfusion injury after 
regional myocardial ischaemia in the rabbit heart in vivo. $\mathrm{Br} \mathrm{J}$ Anaesth 1998;81:905-912

28. Schlack W, Preckel B, Barthel H, Obal D, Thämer V: Halothane reduces reperfusion injury after regional ischaemia in the rabbit heart in vivo. Br J Anaesth 1997;79:88-96.

Non-Peer reviewed paper:

1. Wadhwa A, Gebhard RE, Obal D: Single or multiple guidance methods for peripheral nerve blockade in modern-day practice of regional anesthesia. Advances in Anesthesia 2010; 28: 187-210 